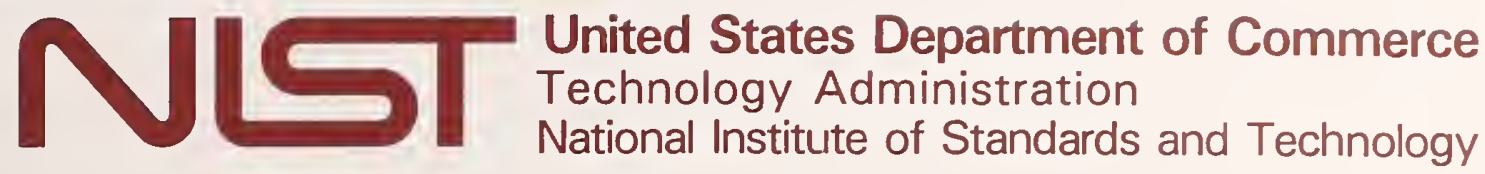

NIST Technical Note 1393

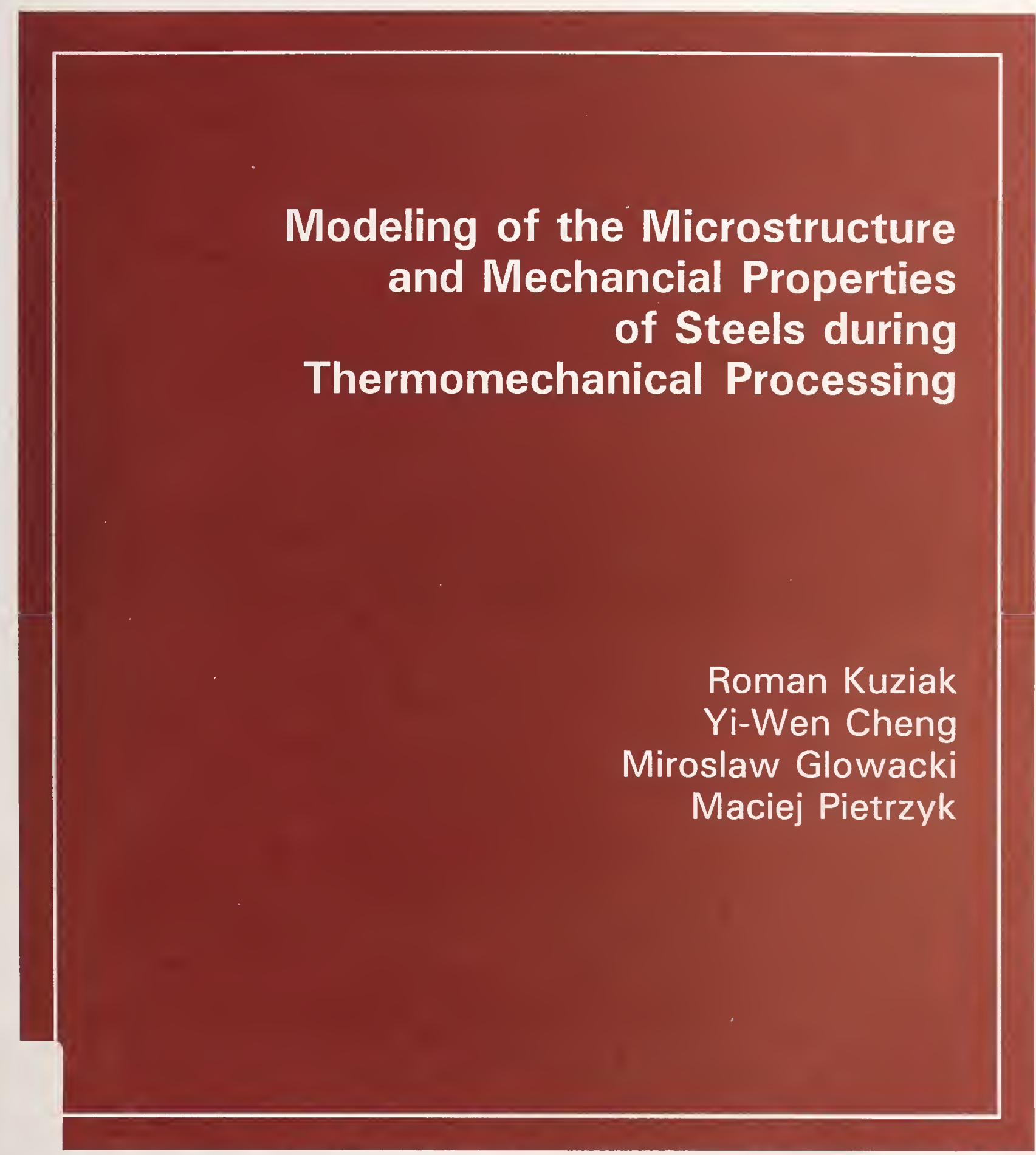

100

U5753

NO. 1393 



\section{Modeling of the Microstructure and Mechancial Properties of Steels during Thermomechanical Processing}

Roman Kuziak*

Yi-Wen Cheng

Miroslaw Glowacki**

Maciej Pietrzyk**

Materials Reliability Division

Materials Science Engineering Laboratory

National Institute of Standards and Technology

325 Broadway

Boulder, Colorado 80303-3328

* Materials Science Department Institute of Ferrous Metallurgy Gliwice, Poland

* * Materials Engineering Department Academy of Mining and Metallurgy Cracow, Poland

Supported by

The United States-Poland Maria Sklodowska-Curie Joint Fund II

November 1997

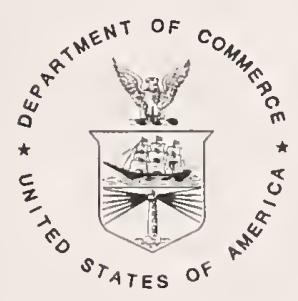

U.S. DEPARTMENT OF COMMERCE, William M. Daley, Secretary TECHNOLOGY ADMINISTRATION, Gary R. Bachula, Acting Under Secretary for Technology NATIONAL INSTITUTE OF STANDARDS AND TECHNOLOGY, Raymond G. Kammer, Director 
National Institute of Standards and Technology Technical Note

Natl. Inst. Stand. Technol., Tech. Note 1393, 80 pages (November 1997) CODEN:NTNOEF

\section{U.S. GOVERNMENT PRINTING OFFICE \\ WASHINGTON: 1997}

For sale by the Superintendent of Documents, U.S. Government Printing Office, Washington, DC 20402-9325 


\section{Contents}

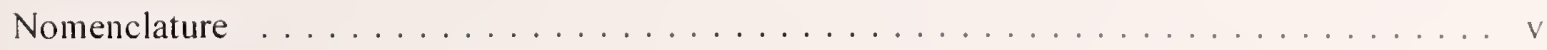

Foreword $\ldots \ldots \ldots \ldots \ldots \ldots \ldots \ldots \ldots \ldots \ldots \ldots \ldots \ldots \ldots \ldots \ldots \ldots$

Abstract ...............................

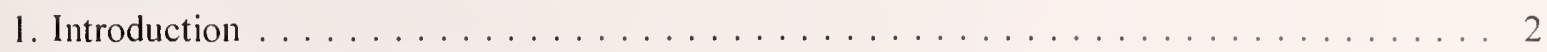

2. Structure of the Research Project . . . . . . . . . . . . . . . . . 4

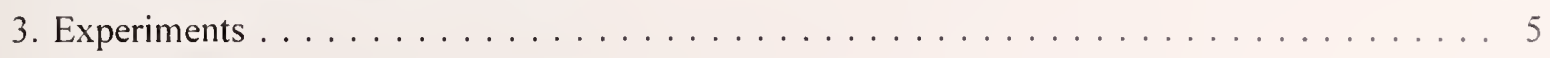

4. Microstructural Evolution Models ...................... 7

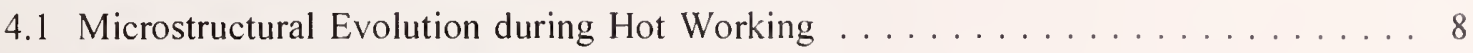

4.1 .1 Static Recrystallization Model . . . . . . . . . . . . . . . . 8

4.1 .2 Dynamic Recrystallization Model . . . . . . . . . . . . . . . . . 14

4.1.3 Metadynamic Recrystallization Model . . . . . . . . . . . . . . . . . . 17

4.1.4 Grain Growth of the Austenite after Recrystallization . . . . . . . . . . . . 19

4.2 Phase Transformations on Cooling after Hot Working . . . . . . . . . 20

4.2 .1 Ferrite-Pearlite Steels . . . . . . . . . . . . . . . . . . 20

4.2 .2 900A Eutectoid Steel . . . . . . . . . . . . . . . . . . . . . . 24

5. Microstructure-Mechanical-Property Relationships . . . . . . . . . . . . . . . 27

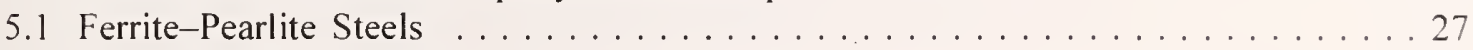

5.2900 A Eutectoid Steel . . . . . . . . . . . . . . . . . . 31

6. Laboratory Experimental Validation of the Microstructural Evolution Models . . . . . . 32

6.1 Laboratory Experiments and the Linkage to the Finite-Element Codes . . . . . . . 32

6.2 Press Compression of Carbon-Manganese Steel . . . . . . . . . . . . . . 35

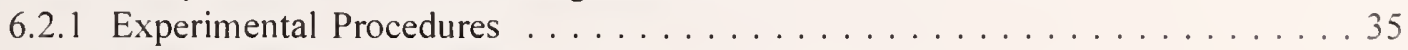

6.2 .2 Thermomechanical Behavior during Compression . . . . . . . . . . . 37

6.2.3 Effect of Processing Conditions on the Mechanical Properties . . . . . . . . 39

6.2.4 Effect of Processing Conditions on Microstructure . . . . . . . . . . . . 41

6.3 Forging of Vanadium-Treated Microalloyed Medium-Carbon Steel . . . . . . . . 46

6.3 .1 Experimental Procedures . . . . . . . . . . . . . . . . . . . 46

6.3.2 Mathematical Modeling . . . . . . . . . . . . . . . . . 47

6.4 Flat Rolling of 900 A Eutectoid Steel . . . . . . . . . . . . . . 51

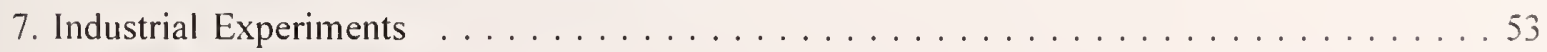

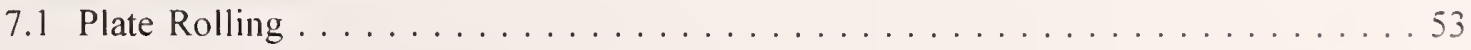

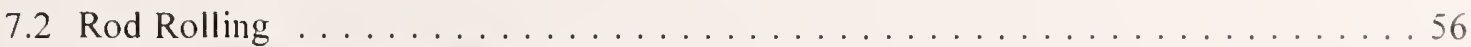

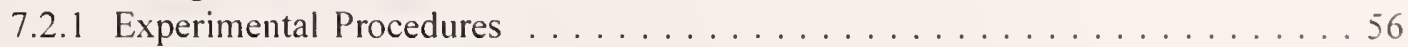

7.2 .2 Validation of the Model . . . . . . . . . . . . . . . . 57

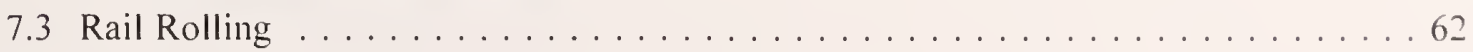

8. Summary ...............................68

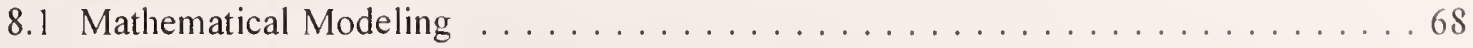

8.2 Industrial Experiments . . . . . . . . . . . . . . . . . . 69

8.2 .1 Plate Rolling . . . . . . . . . . . . . . . . . . . . . 69

8.2 .2 Rod Rolling . . . . . . . . . . . . . . . . . . . . . . . . 69

8.2 .3 Rail Rolling ......................... 70

9. Acknowledgments ............................. . . 70

10. References ............................. 70 



\section{Nomenclature}

\section{Abbreviations}

FDT finish deformation temperature

FEM finite-element method

FRT finish rolling temperature

$\mathrm{HV}_{5}$ Vickers microhardness (load $\left.=5 \mathrm{~N}\right)$

ITT impact transition temperature

tot total

VT vanadium treated

\section{Symbols}

$\varepsilon \quad$ strain

$\dot{\varepsilon} \quad$ strain rate

$\varepsilon_{a} \quad$ strain retained in the microstructure after cooling to ambient temperature

$\varepsilon_{c} \quad$ critical strain for dynamic recrystallization

$\varepsilon_{i} \quad$ total strain imposed on a specimen during the $i$ th deformation

$\varepsilon_{p} \quad$ strain to peak stress in the flow curve

$\varepsilon_{r}^{i} \quad$ retained strain

$\kappa$ thermal conductivity

$\lambda$ penalty coefficient

$\rho$ material density

$\rho_{0} \quad$ initial dislocation density

$\rho_{d}$ dislocation density

$\rho_{g} \quad$ forest-dislocation density

$\sigma_{0}$ saturation stress in the flow curve

$\sigma_{d}$ yield strength component due to dislocation

$\sigma_{i} \quad i$ th component of stress tensor

$\sigma_{f} \quad$ vector of boundary traction

$\sigma_{s} \quad$ structure-related yield strength

$\sigma_{\text {tot }}$ total yield strength

$\sigma_{u} \quad$ ultimate tensile strength

$\sigma_{y}$ yield strength

$\tau$ incubation time

$\tau_{f} \quad$ vector of boundary traction

$A_{r 3}$ austenite-to-ferrite transformation temperature

$b$ Burgers vector

$C_{P} \quad$ specific heat

$C_{r}$ cooling rate over the transformation temperature range 
$D_{0} \quad$ initial grain size

$D_{\alpha} \quad$ ferrite grain size

$D_{y}$ austenite grain size

$D_{c}$ pearlite colony size

$D_{\text {dyn }}$ dynamically recrystallized grain size

$D_{\text {md }}$ metadynamically recrystallized grain size

$D_{\text {rex }}$ statically recrystallized grain size

$D(t)$ effective grain size during static recrystallization

$f_{\text {eq }}$ volume fraction of ferrite after equilibrium transformation

$f_{\alpha}$ volume fraction of ferrite after nonequilibrium transformation

$f_{w}$ nonequiaxed ferrite volume fraction

$G$ shear modulus

$M$ mean distance for slip in pearlite ferrite

$N_{d}$ pearlite nodule diameter

$Q$ heat generated during deformation

$Q_{d}$ activation energy for deformation

$R$ gas constant

$S$ boundary surface

$S_{0} \quad$ mean true interlamellar spacing of cementite in pearlite

$t$ time

$t_{0.5}$ time for 50 percent of recrystallization

$t_{C} \quad$ carbide thickness

$T$ absolute temperature

$T_{0}$ equilibrium transformation temperature

$T_{\gamma}$ austenitization temperature

$T_{d}$ temperature of deformation

$T_{p}$ pearlite transformation temperature

$T_{R}$ reheating temperature

$|v|$ relative velocity at the tool-material interface

$V$ control volume

$W$ real velocity field

$X$ volume fraction

$X(t)$ total volume fraction of recrystallized material by all mechanisms

$X(t)_{\mathrm{d} y \mathrm{n}}$ volume fraction of dynamically recrystallized material

$X(t)$ md volume fraction of metadynamically recrystallized material

$X(t)_{s}$ volume fraction of statically recrystallized material

$X(t) p$ changes in pearlite volume fraction as a function of time

Z Zener-Hollomon parameter 


\section{Foreword}

The Materials Reliability Series of NIST Technical Notes are reports covering significant research accomplishments of the Materials Reliability Division. The division develops measurement technologies that enable the producers and users of materials to improve the quality and reliability of their products. Measurement technologies are developed for process control to improve the quality and consistency of materials, for nondestructive evaluation to ensure the quality of finished materials and products, and for materials evaluation to ensure reliable performance. Within these broad areas of measurement technology, the division has focused its resources on three research themes:

- Intelligent Processing of Materials: To develop on-line sensors for measuring the materials characteristics and/or processing conditions needed for real-time process control.

- Ultrasonic Characterization of Materials: To deveiop ultrasonic measurements for characterizing internal geometries of materials, such as defects, microstructures, and lattice distortions.

- Micrometer-Scale Measurements for Materials Evaluation: To develop measurement techniques for evaluating the mechanical, thermal, and magnetic behavior of thin films and coatings at the appropriate scale.

Research on microstructural evolution in steel is one of the projects in our research on Intelligent Processing of Materials. This report is a result of cooperative research between the Institute for Ferrous Metallurgy (IFM), Gliwice, Poland and NIST. The research was supported by the United States-Poland Maria Sklodowska-Curie Joint Fund II, and the research was conducted mainly at IFM. The research plan was formulated while the principal author. Dr. Roman Kuziak, was a guest researcher in the Materials Reliability Division during 1990 and 1991.

Harry I. McHenry

Chief

Materials Reliability Division 



\title{
Modeling of the \\ Microstructure and Mechanical Properties of Steels during Thermomechanical Processing
}

\author{
Roman Kuziak \\ Materials Science Department \\ Institute of Ferrous Metallurgy \\ Gliwice, Poland \\ Yi-Wen Cheng \\ Materials Reliability Division \\ National Institute of Standards and Technology \\ Boulder, Colorado, USA \\ Miroslaw Glowacki and Maciej Pietrzyk \\ Materials Engineering Department \\ Academy of Mining and Metallurgy \\ Cracow, Poland
}

Models have been developed for the microstructural changes in C-Mn, vanadiumtreated, and eutectoid steels during thermomechanical processing. They relate processing parameters, such as strain, strain rate, and temperature, to microstructural features, such as volume fraction of the recrystallized material and austenite grain size, with emphasis on the effect of microstructural changes on the mechanical properties of the final product. Model-predicted mechanical properties were compared with values measured in laboratory and industrial experiments. The models gave an accurate, quantitative characterization of the plates, rods, and rails subjected to rolling processes. The results of this study provide a basis for future optimization of the chemical composition and processing of steels.

Key words: C-Mn steel; computer modeling; eutectoid steel; finite-element method: mechanical properties; microstructure; thermomechanical processing: vanadium-treated steel. 


\section{Introduction}

Recent research in computer modeling of the microstructural evolution of steels during thermomechanical processing has increased our understanding of the austenite microstructural restoration processes occurring during and after plastic deformation. Computer modeling can accurately characterize the sequences and interactions of the mechanisms that change the austenite microstructure. Thus, we can predict the effects of chemical composition and processing parameters on the final microstructure and mechanical properties of a steel. Since modeling is an efficient tool for the development of new steel grades and for optimizing production technologies, it has great potential for improving the manufacturing processes and reducing the cost of steel products.

The ultimate goal of modeling industrial processes is to predict the mechanical properties of commercial products. Quantitative relationships between the microstructural parameters and the mechanical properties are frequently based upon a Hall-Petch type of relationship. To date, many relationships have been developed for the yield strength, ultimate tensile strength, and impact transition temperature in a variety of steels. One of the most successful approaches to the prediction of mechanical properties was developed by Gladman et al. [1]. However, our critical assessment of the equations deveoped by Gladman and coworkers has shown that their accuracy of prediction may be insufficient for a particular application. Therefore, we developed some new relationships for the steels investigated in this study.

The objectives of this research project were

1. to develop and validate models of microstructural evolution and mechanical properties for plain-carbon (C-Mn), vanadium-treated (VT), and eutectoid steels and

2. to couple these models with finite-element-method (FEM) calculations to predict the microstructures and mechanical properties of these steels following industrial rolling of plates, rods, and rails.

The microstructural evolution models developed in this study are composed of equations that relate parameters characterizing the state of austenite microstructure during and after plastic deformation at elevated temperatures to the deformation parameters, which include strain, strain rate, and temperature. To demonstrate the practical application of the models, the effects of microstructural changes on the mechanical properties of the final industrial products were also examined. Although models can predict the development of austenite microstructure during all stages of thermomechanical processing, their accuracy depends on precise knowledge of the deformation parameters of the workpiece. For simplicity, flat-rolling parameters are often assumed to be constant through the thickness direction. However, for bar- and rail-rolling processes and for more complete analysis of the flat-rolling process, these parameters must be obtained with numerical analyses, such as FEM.

Generally, two types of behavior occur during hot working of steels, and they are reflected in the shape of the flow curve (fig. 1). Dynamic recrystallization initiates easily in materials with low stacking-fault energy that are deformed at low and moderate strain rates at elevated temperatures (fig. la). Following initiation of dynamic recrystallization, the flow stress decreases continually until the entire material is recrystallized. Upon completion of dynamic recrystallization, steady flow is established in the deformed material. After deformation, postdynamic processes predominate in the deformed material: metadynamic recrystallization, static recrystallization, and static recovery. Low-temperature deformation employing high strain rates does not lead 

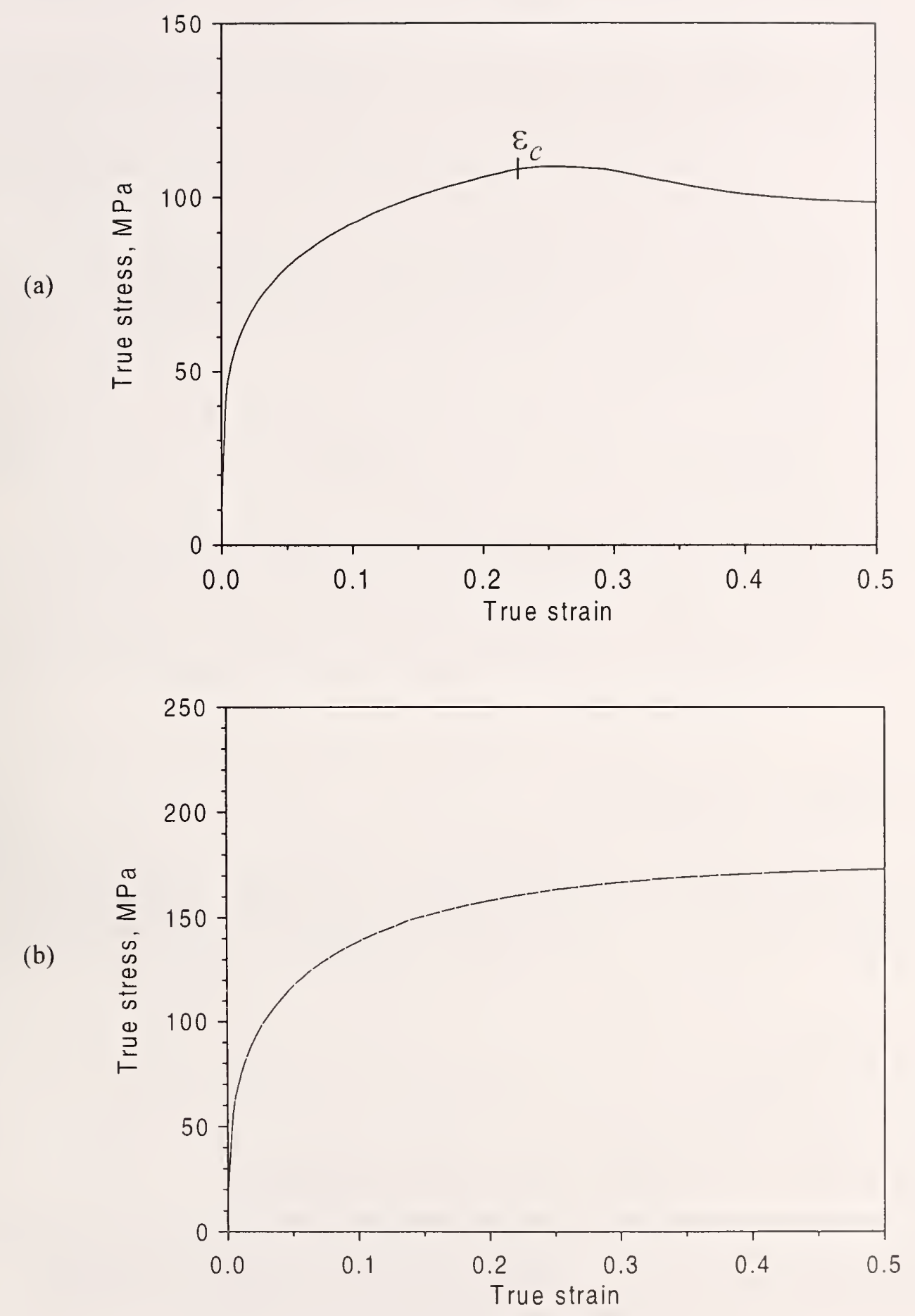

Figure 1. Flow curves of the VT steel deformed by compression in the dilatometer $\left(\dot{\varepsilon}=3 \mathrm{~s}^{-1} ; D_{0}=65 \mu \mathrm{m}\right)$. (a) Dynamic recrystallization initiates once the critical strain is reached $\left(T_{d}=1180^{\circ} \mathrm{C}\right)$. (b) Recovery offsets work hardening before the critical strain for dynamic recrystallization is reached $\left(T_{d}=950^{\circ} \mathrm{C}\right)$. 
to dynamic recrystallization; instead, the work hardening is counterbalanced by recovery that leads to the steady flow shown in the flow curve in figure $1 \mathrm{~b}$.

The conventional approach to microstructural evolution modeling is based upon the effects of strain, strain rate, temperature, and the austenite grain size before deformation. Some fundamental effects of these parameters on the plastic flow and resulting microstructural evolution are discussed by Sellars [2]. The major difficulty in the application of the conventional approach to computer modeling of industrial processes is that the models do not incorporate the inhomogeneity of plastic flow and temperature fields in the workpiece during processes such as shape rolling. To remedy the deficiency in the conventional approach, thermomechanical FEM computer codes developed at the Academy of Mining and Metallurgy in Cracow, Poland were used in the present investigation to calculate the deformation and temperature fields in the workpiece during the various industrial processes.

Computer simulations of the microstructural evolution of austenite during thermomechanical processing make it possible to calculate phase transformations (and thus the microstructure that develops in final products) after processing and cooling. This step is prerequisite for predicting the mechanical properties of steel products. The transformation models can be based upon sophisticated classical theories [3], but this approach is not very productive because the transformation models would require substantial adjustments to specific conditions prevailing in industrial practice. Therefore, in the present study, mostly empirical models were developed to quantitatively relate the microstructure of the final product to the parameters characterizing the state of the austenite microstructure before transformations, the processing parameters, and the cooling conditions after plastic deformation.

\section{Structure of the Research Project}

The primary objective of this research project was to develop models to characterize the microstructural evolution occurring during thermomechanical processing of C-Mn, VT mediumcarbon, and $900 \mathrm{~A}$ eutectoid steels. To complete this task, submodels for the following phenomena were developed:

- work hardening and dynamic recovery

- static recrystallization

- dynamic recrystallization

- metadynamic recrystallization

- grain growth following recrystallization

- phase transformations on cooling after thermomechanical processing

Finally, we developed relationships linking strength properties to the microstructural parameters and the chemical compositions of the experimental steels. After completing the development of the microstructural evolution models, we incorporated constitutive equations into the thermomechanical FEM codes for some industrial plate- and shape-rolling simulations. 


\section{Experiments}

The chemical compositions of the steels used in our model-development experiments are listed in table 1. The steels were produced in continuously cast industrial heats. We developed the predictive equations from averaged measurements of 30 to 40 specimens. Although the microstructural evolution models in the research program were developed essentially for the thermomechanical processing of these basic steels, some submodels were substantially extended to cover a wider range of steels.

The submodels were developed from experiments conducted with a dilatometer that is equipped with a hot-deformation attachment that conducts very precise simulations of thermomechanical processing. Specimen deformation in the dilatometer was imposed by compression. The two simulation schedules used in the development and validation of the microstructuralevolution models are shown in figures 2 and 3, respectively. All reheating, deformation, and cooling parameters were precisely controlled during the experiment. The models were validated further in laboratory press-forging and plate-rolling experiments; the details of these experiments are given below. The verified models were used to simulate industrial processes.

Typically, we used an optical microscope to study microstructural evolution in deformed specimens as a function of strain $\varepsilon$, strain rate $\dot{\varepsilon}$, temperature $T$, and time $t$ after deformation. Saturated picric acid was used to delineate austenite grain boundaries, and the mean-linearintercept method was adopted to measure the austenite grain size. To examine the microstructures in greater detail, we used a transmission electron microscope and a scanning electron microscope.

The major difficulty in relating the state of the austenite microstructure to hot-deformation conditions is the nonuniformity of the plastic flow during compression. To alleviate this problem, a commercial FEM program was used to calculate the deformation parameters in the deformed specimens [4]. An example of the calculation for specific deformation conditions is shown in figure 4 . The results demonstrate that the deformation parameters are relatively homogeneous in the central region of the specimen. In figure $4 \mathrm{c}$, the lower temperature at the top is due to heat loss to the anvil, and the higher temperature at the bottom (center of specimen) is due to heat generated by plastic deformation.

Table 1. Chemical composition (mass percent) of the experimental steels.

\begin{tabular}{ccccccccc}
\hline Steel & $\mathrm{C}$ & $\mathrm{Mn}$ & $\mathrm{Si}$ & $\mathrm{P}$ & $\mathrm{S}$ & $\mathrm{V}$ & $\mathrm{Al}$ tot & $\mathrm{N}$ \\
\hline $\mathrm{C}-\mathrm{Mn}$ & 0.18 & 1.40 & 0.23 & 0.024 & 0.021 & - & 0.002 & 0.007 \\
VT & 0.20 & 1.36 & 0.26 & 0.022 & 0.020 & 0.09 & 0.002 & 0.009 \\
eutectoid & 0.72 & 1.20 & 0.28 & 0.023 & 0.018 & - & 0.001 & 0.006 \\
\hline
\end{tabular}




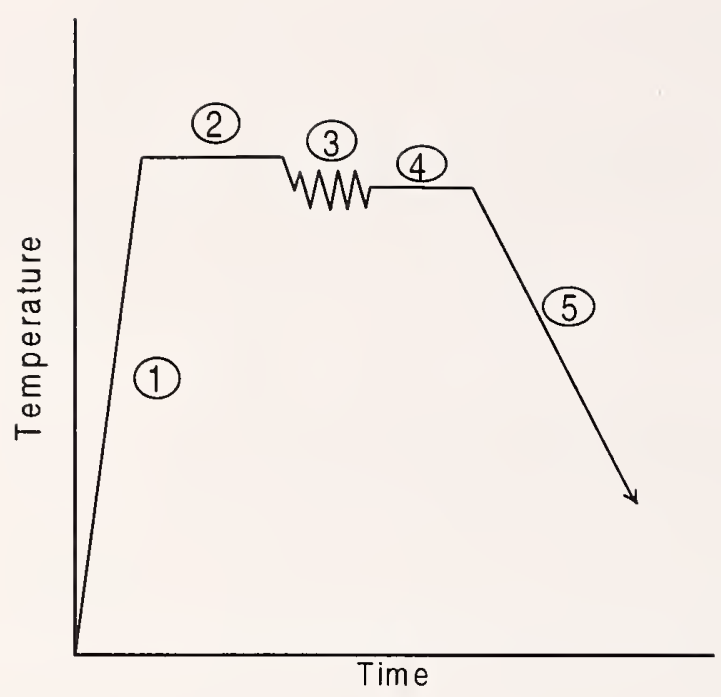

Figure 2. One-step deformation experiment conducted in the dilatometer to develop constitutive equations for the microstructural evolution models: (1) reheating at a constant rate; (2) soaking at a predefined temperature and duration; (3) cooling to the deformation temperature and deformation at predefined parameters; (4) holding for a specified time after deformation; (5) quenching.

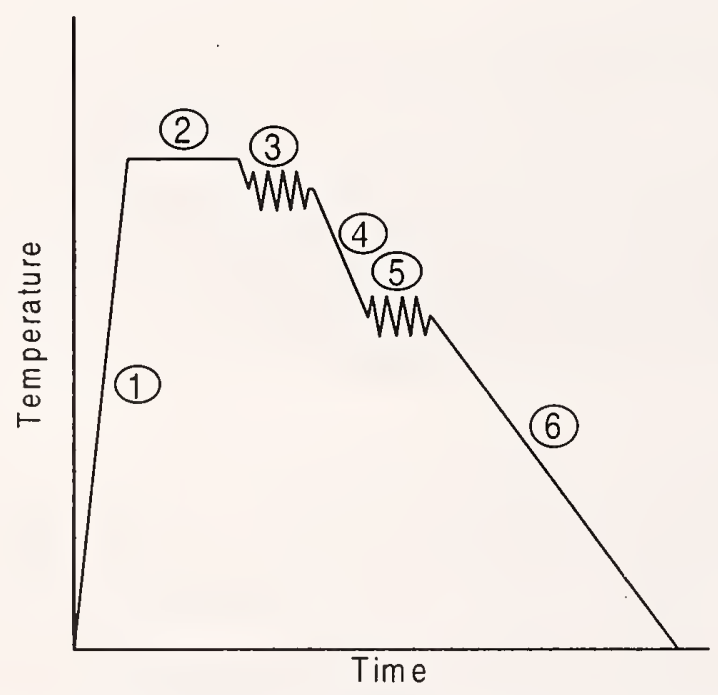

Figure 3. Two-step deformation experiment conducted in the dilatometer to validate microstructural evolution models: (1) reheating; (2) soaking; (3) first deformation; (4) cooling to second deformation temperature; (5) second deformation; (6) quenching. 
(a)

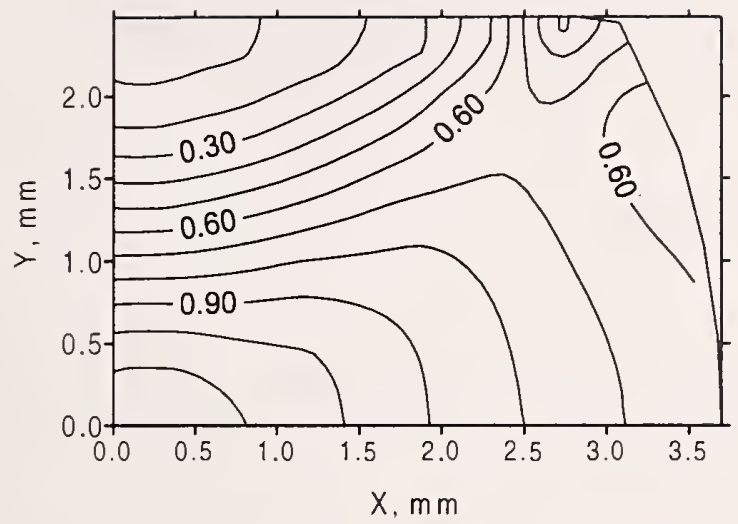

(b)

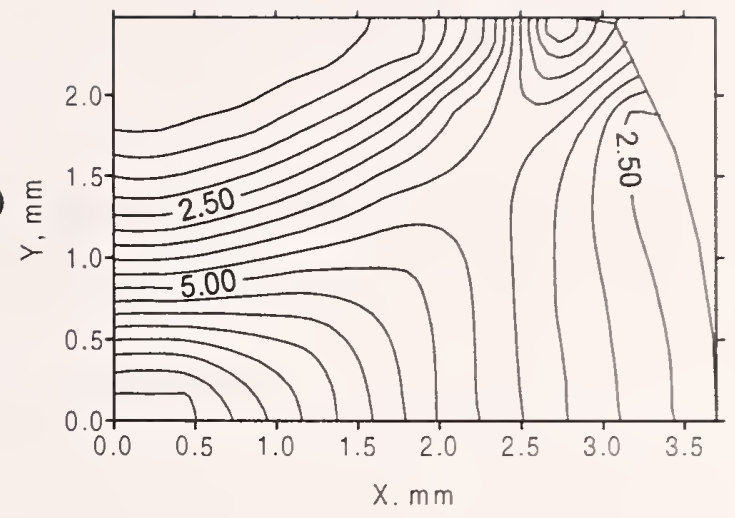

(c)

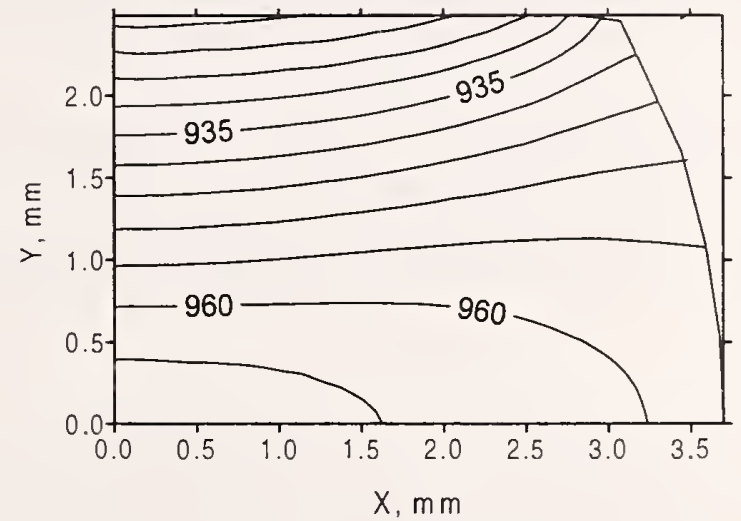

Figure 4. Results of an FEM calculation for the deformation $\left(T_{d}=950^{\circ} \mathrm{C}\right)$ of a cylindrical specimen $10 \mathrm{~mm}$ high and $8 \mathrm{~mm}$ in diameter: (a) strain field; (b) strain-rate field; (c) temperature field. The specimen was reduced from 10 to $4.9 \mathrm{~mm}$. Since the specimen was symmetrical with respect to its center, only one quarter of the specimen is shown in this figure.

\section{Microstructural Evolution Models}

Depending on the deformation conditions and the state of the austenite microstructure before deformation, different processes are involved in the restoration of the work-hardened microstructure. The most important are dynamic recovery and recrystallization, metadynamic recrystallization, static recovery and recrystallization, and grain growth after recrystallization. The conventional approach to the microstructural evolution modeling, adopted for this study, is based upon relating the state of the austenite microstructure during and after deformation to the state of the austenite microstructure before the deformation and to the deformation parameters. The set of consecutive equations of the microstructural evolution model can be used to develop a computational procedure for computer modeling of microstructural evolution during thermomechanical processing.

For deformation experiments conducted in the dilatometer, the general strategy was to select deformation conditions to simulate either one process or a sequence of consecutive 
processes. The austenite-microstructure restoration processes were identified by flow-curve analysis (fig. 1); they were characterized by measuring microstructural changes as a function of time.

\subsection{Microstructural Evolution during Hot Working}

\subsubsection{Static Recrystallization Model}

Typically, static recrystallization nuclei are formed throughout the deformed material when the deformation conditions during processing are not favorable for initiation of dynamic recrystallization and when the critical strain for static recrystallization initiation is exceeded. Most research on static recrystallization kinetics uses the fractional-softening method [5], but for our study, this method was not suitable because the plastic flow in the specimens deformed by compression in the dilatometer was not homogeneous.

Therefore, a new method based upon analysis of the average austenite grain-size changes during recrystallization was proposed. It employs an equation cited by Beynon and Sellars [6] relating effective grain size during static recrystallization $D(t)$ to the recrystallized grain size $D_{\text {rex }}$, initial grain size $D_{0}$, and volume fraction of recrystallized material $X(t)_{s}$ :

$$
D(t)=X(t)_{s}^{\frac{4}{3}} D_{\mathrm{rex}}+\left[1-X(t)_{s}\right] D_{0}^{2} .
$$

Equation (1) gives a good characterization of the average variation in austenite grain size during static recrystallization. By combining this relationship with the Avrami-type equation

$$
X(t)_{s}=1-\exp \left[-0.693\left(\frac{t}{t_{0.5}}\right)^{n}\right],
$$

commonly used for characterizing the kinetics of static recrystallization [6], we obtained $D_{\text {rex }}$, $n$, and $t_{0.5}$ (time for 50 percent of recrystallization). As an example, figure 5 presents a best-fit curve obtained from eqs (1) and (2) with respect to the measured average changes in austenite grain size during static recrystallization of the VT steel. By changing the deformation conditions and the austenite grain size before the deformation, we obtained general equations relating $D_{\text {rex }}$ and $t_{0.5}$ to $\varepsilon, \dot{\varepsilon}$, and $D_{0}$. Selected data related to static recrystallization in the experimental VT steel are listed in table 2 . The set of equations for the static recrystallization model for the VT steel developed from these data is given in table 3. A comparison of the model-predicted and measured dependences of the statically recrystallized grain size on strain in the VT steel is shown in figure 6. Based upon the results shown in figures 5 and 6 , we postulate that the equations of the static recrystallization model give a good characterization of this process in the experimental steel. The form of the equation for $t_{0.5}$ used for the VT steel is adopted from the model developed by Beynon and Sellars [6]. According to this model, the effect of $D_{0}$ on $t_{0.5}$ is expressed by the term $D_{0}^{2}$, which can be rationalized on the basis of the effect of the grain size on nucleation-site density.

The static recrystallization process in the experimental C-Mn steel can be adequately described by the equations of Roberts et al. [7] (see table 4). An example of their capability for predicting the austenite grain-size changes during static recrystallization in the experimcntal 


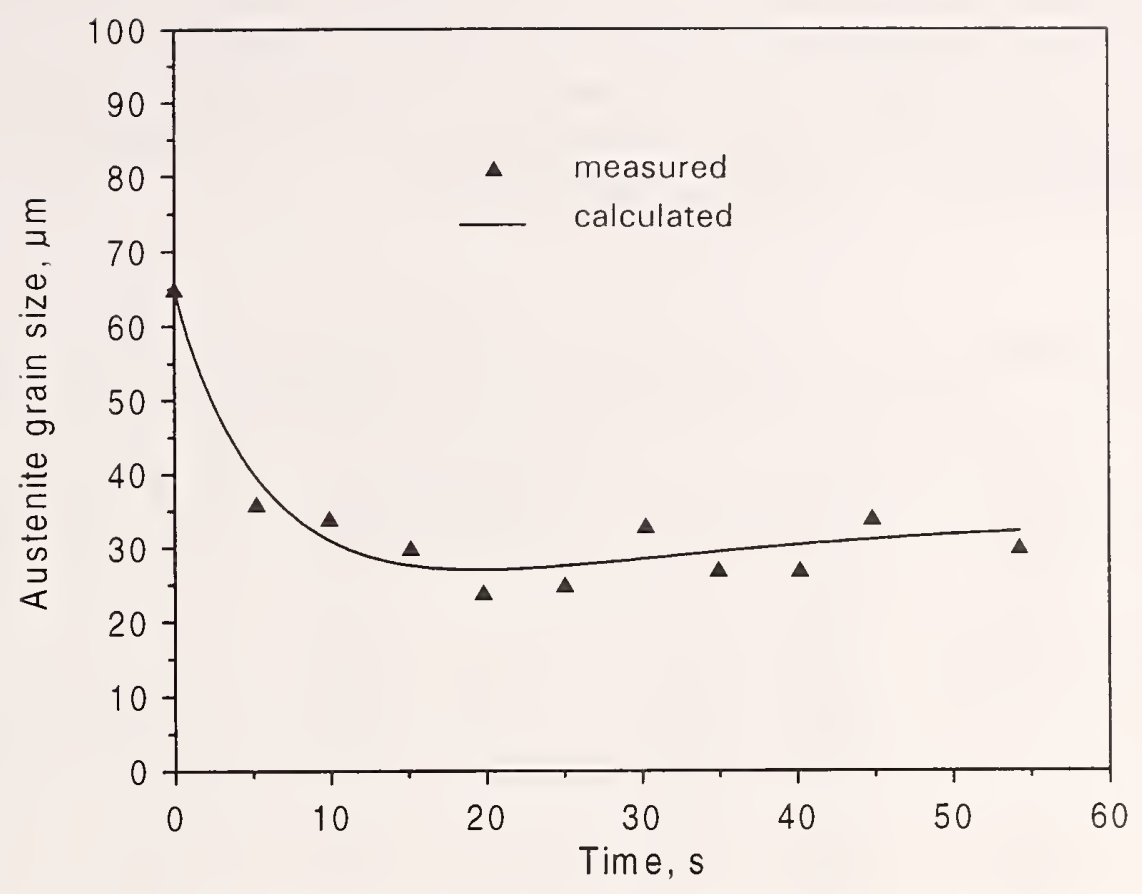

Figure 5. Average austenite grain size as a function of time during static recrystallization in the VT steel $\left(D_{0}=65 \mu \mathrm{m} ; T_{d}=950^{\circ} \mathrm{C} ; \varepsilon=0.22 ; \dot{\varepsilon}=3 \mathrm{~s}^{-1}\right)$. Calculations using eq (1) agree well with the experimental data.

C-Mn steel is shown in figure 7. These equations do not account for the effect of strain rate on the static recrystallization kinetics, which is relatively small in the case of plate rolling. In the rod-rolling process, however, the strain rate is very high (as high as $1000 \mathrm{~s}^{-1}$ ), and its effect should not be neglected in the calculation. Therefore, an equation (T-8) developed by Medina and Lopez [8] for $t_{0.5}$ was used for the rod-rolling process instead of eq (T-7) of Roberts and coworkers.

Results of another investigation by Kuziak [9] on microstructural evolution in eutectoid steels have shown that the equations developed by Beynon and Sellars [6] poorly substantiate the experimental results of static recrystallization in these steels. The best fit of the experimental results in this case is obtained by employing equations of Choquet et al. [10]. The set of constants of this model, adjusted to the behavior of the experimental $900 \mathrm{~A}$ steel, is given in table 5 . The effect of the austenite grain size on recrystallization kinetics in the model of Choquet and coworkers is much more complicated than that in the model of Sellars; it cannot be explained simply by rational assumptions. The capability of the model of Choquet and coworkers to predict effective austenite grain-size evolution during static recrystallization in the $900 \mathrm{~A}$ eutectoid steel is demonstrated in figure 8 .

The models described in this section adequately predict the influence of the processing parameters and austenite grain size on the kinetics of static recrystallization and the overall changes of the grain size during the recrystallization. By employing eq (1), some results obtained earlier by Kuziak and Cheng [11] were correlated quantitatively with the model. For 
example, they observed that the deformation of a fine-grain austenite in $\mathrm{Ti}-\mathrm{V}-\mathrm{N}$ steels at elevated temperatures led to extensive grain growth during static recrystallization. These characteristics of the recrystallization process were predicted by the model (see fig. 9); they can be associated with the vast mobility of small recrystallization nuclei at elevated temperatures. The result of this simulation shows that static recrystallization does not necessarily lead to austenite grain refinement at the high temperatures of hot working.

Table 2. Experimental data related to static recrystallization in the VT steel.

\begin{tabular}{crcccc}
\hline$D_{0}, \mu \mathrm{m}$ & $T,{ }^{\circ} \mathrm{C}$ & $\varepsilon$ & $\dot{\varepsilon}, \mathrm{s}^{-1}$ & $t_{0.5}, \mathrm{~s}$ & $D_{\mathrm{rex}}, \mu \mathrm{m}$ \\
\hline 163 & 930 & 0.15 & 2.2 & 480 & 80 \\
163 & 930 & 0.18 & 2.2 & 240 & 68 \\
163 & 930 & 0.22 & 2.2 & 100 & 60 \\
94 & 980 & 0.15 & 2.0 & 63 & 50 \\
94 & 980 & 0.18 & 2.0 & 40 & 57 \\
94 & 980 & 0.22 & 2.0 & 13 & 48 \\
122 & 950 & 0.22 & 4.0 & 43 & 54 \\
122 & 1000 & 0.22 & 3.0 & 14 & 56 \\
122 & 1050 & 0.22 & 2.5 & 9 & 60 \\
72 & 980 & 0.27 & 4.0 & 3.2 & 30 \\
72 & 1050 & 0.25 & 3.2 & 1.3 & 34 \\
72 & 1180 & 0.23 & 2.0 & - & 43 \\
72 & 950 & 0.16 & 1.8 & 48.0 & 48 \\
72 & 950 & 0.27 & 3.6 & 5.0 & 33 \\
72 & 950 & 0.38 & 3.8 & 1.2 & 29 \\
72 & 950 & 0.46 & 4.4 & - & 21 \\
53 & 930 & 0.31 & 3.0 & 3.2 & 28 \\
53 & 980 & 0.31 & 3.0 & - & 22 \\
53 & 1130 & 0.31 & 3.0 & - & 31 \\
\hline
\end{tabular}


Table 3. Equations in the static recrystallization model for the VT steel.

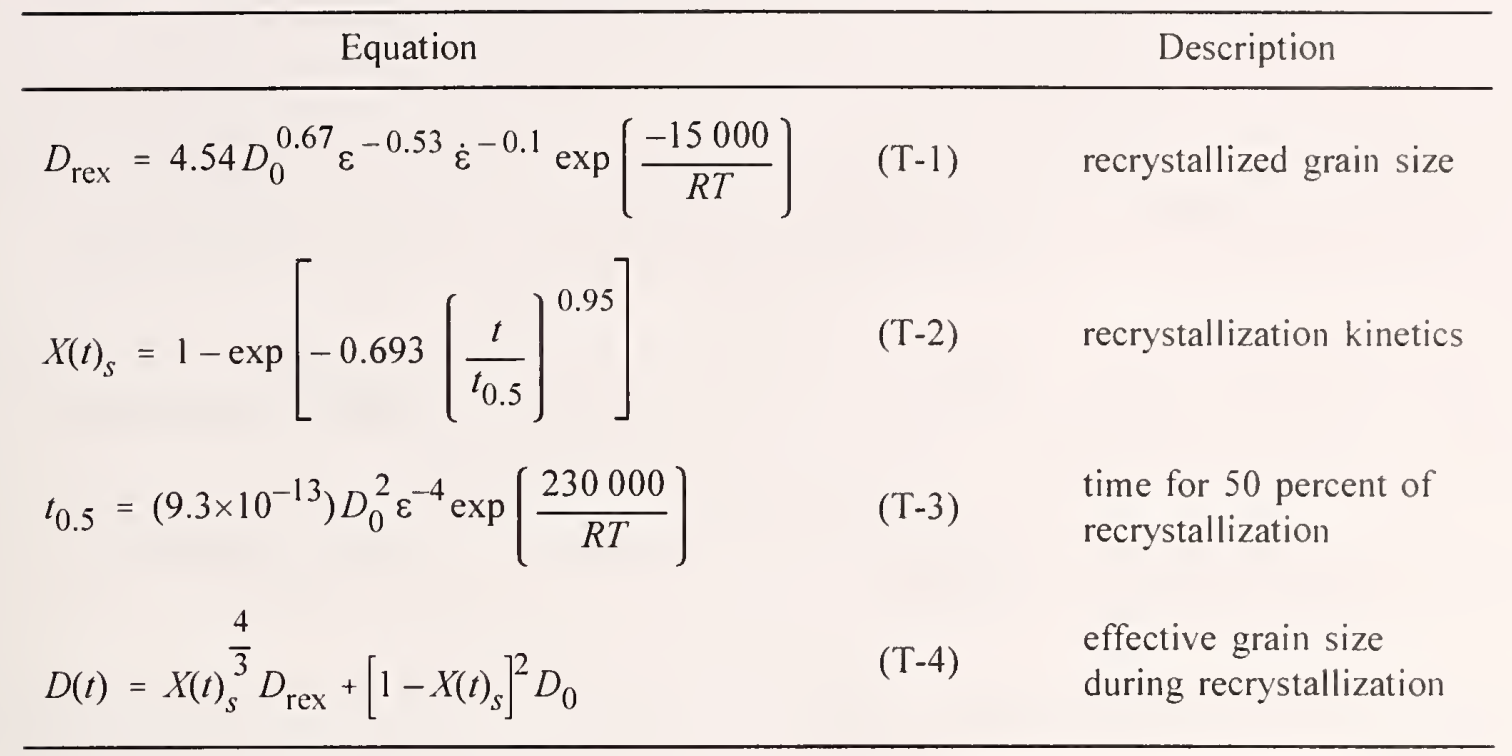

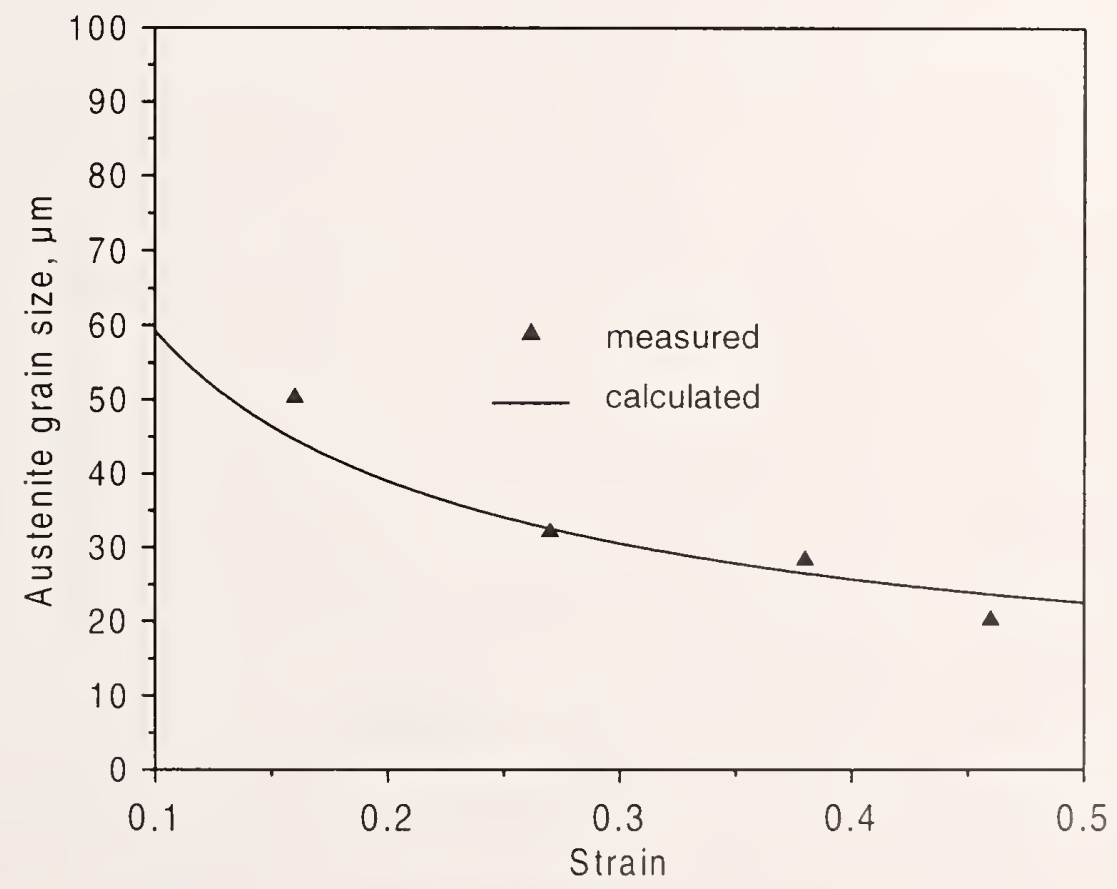

Figure 6. Statically recrystallized austenite grain size as a function of strain $\left(D_{0}=72 \mu \mathrm{m}\right.$ : $\left.T_{d}=950^{\circ} \mathrm{C}\right)$. Calculations using eq $(\mathrm{T}-1)$ agree well with experimental data. 
Table 4. Equations in the static-recrystallization model for the $\mathrm{C}-\mathrm{Mn}$ steel adopted from Roberts et al. [7] [eqs (T-5-T-7)] and Medina and Lopez [8] [eq (T-8)].

\begin{tabular}{cll}
\hline Equation & \multicolumn{1}{c}{ Description } \\
\hline$D_{\text {rex }}=6.2+55.7 D_{0}^{0.15} \varepsilon^{-0.65}\left[\exp \left[\frac{350000}{R T}\right]\right]^{-0.11}(\mathrm{~T}-5)$ & recrystallized grain size \\
$X(t)_{s}=1-\exp \left[-0.693\left[\frac{t}{t_{0.5}}\right]^{1.7}\right]$ & $(\mathrm{T}-6)$ & $\begin{array}{l}\text { recrystallization kinetics } \\
t_{0.5}=\left(5.1 \times 10^{-21}\right) D_{0}^{2} \varepsilon^{-4} \exp \left[\frac{330000}{R T}\right]\end{array}$ \\
$t_{0.5}=\left(1.03 \times 10^{-10}\right) \varepsilon^{-2.6} \dot{\varepsilon}^{-0.44} D_{0}\left[\frac{158000}{R T}\right]$ & $(\mathrm{T}-7)$ & $\begin{array}{l}\text { time for 50 percent of } \\
\text { recrystallization }\end{array}$ \\
\hline
\end{tabular}

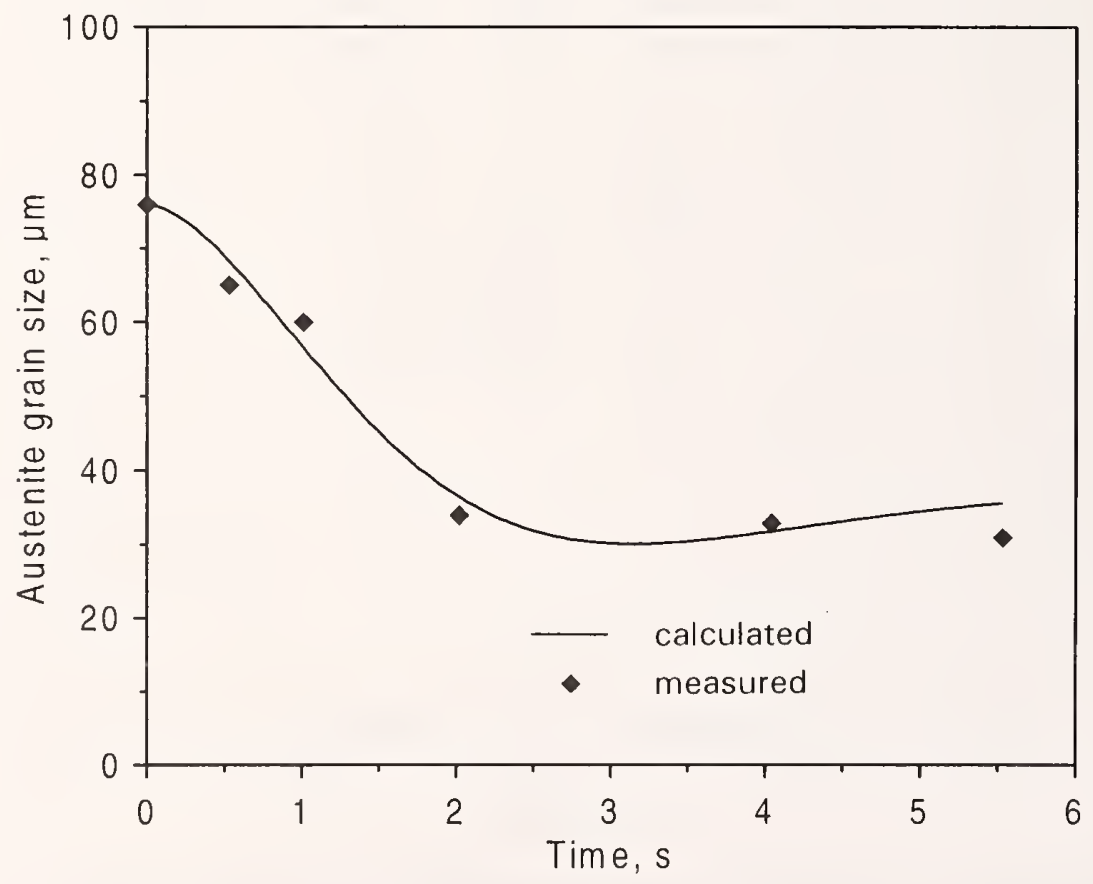

Figure 7. Average austenite grain-size changes during static recrystallization in the experimental C-Mn steel $\left(D_{0}=76 \mu \mathrm{m} ; T_{d}=950^{\circ} \mathrm{C} ; \varepsilon=0.2\right)$ compared with the model predictions of Roberts et al. [7] (table 4). 
Table 5. Equations in the static-recrystallization model for the eutectoid steel [10].

\begin{tabular}{|c|c|c|}
\hline Equation & & Description \\
\hline$D_{\text {rex }}=9.91 D_{0}^{0.54} \varepsilon^{-65} \dot{\varepsilon}^{-0.1} \exp \left(\frac{-17540}{R T}\right)$ & $(\mathrm{T}-9)$ & recrystallized grain size \\
\hline$X(t)_{s}=1-\exp \left[-0.693\left(\frac{t}{t_{0.5}}\right)^{0.95}\right]$ & $(\mathrm{T}-10)$ & recrystallization kinetics \\
\hline $\begin{array}{c}t_{0.5}=\left(2.403 \times 10^{-8}\right) \exp \left[\frac{160420}{R T}\right] \varepsilon^{p} \dot{\varepsilon}^{-0.29} D_{0}^{-0.2} \\
p=-1.006 D_{0}^{0.22}\end{array}$ & $(\mathrm{~T}-11)$ & $\begin{array}{l}\text { time for } 50 \text { percent of } \\
\text { recrystallization }\end{array}$ \\
\hline
\end{tabular}

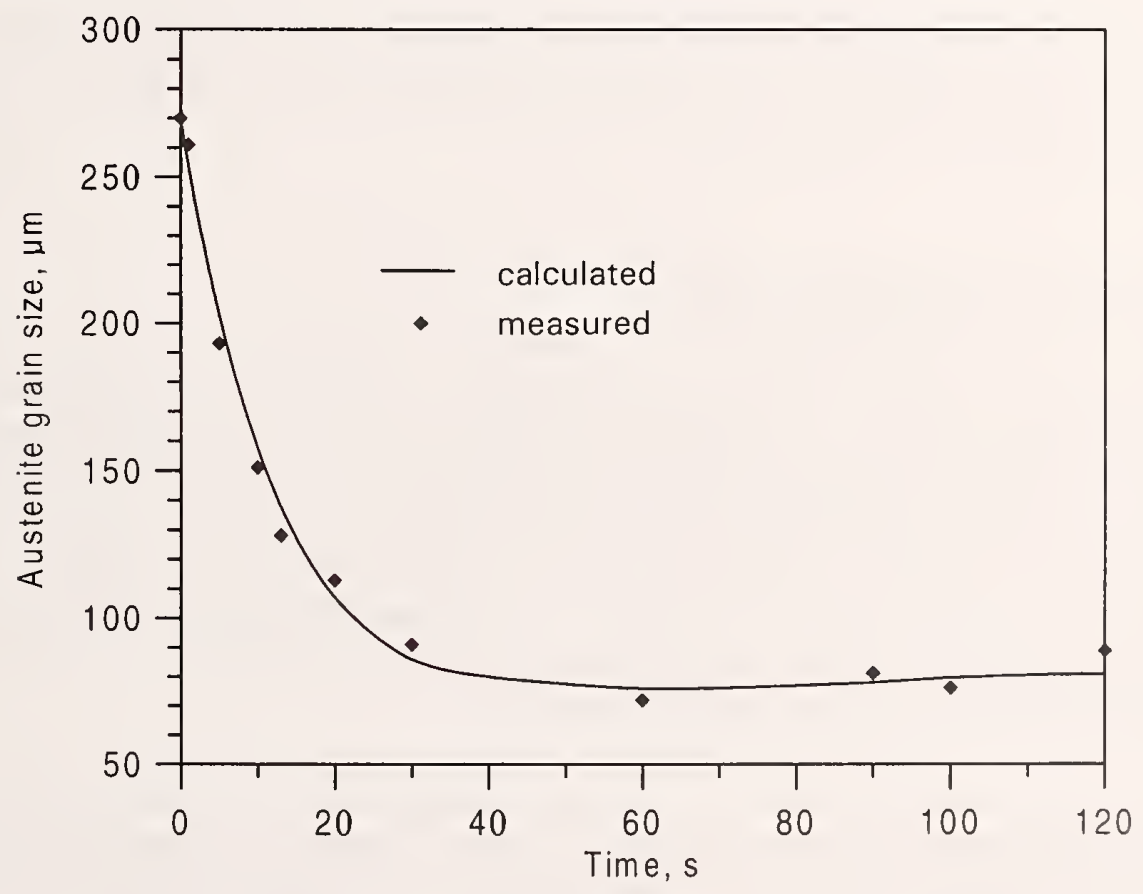

Figure 8. Average austenite grain-size evolution during static recrystallization in the experimental eutectoid steel $\left(D_{0}=270 \mu \mathrm{m} ; T_{d}=900^{\circ} \mathrm{C} ; \varepsilon=0.2\right)$ compared with the model predictions of Choquet et al. [10] (table 5). 


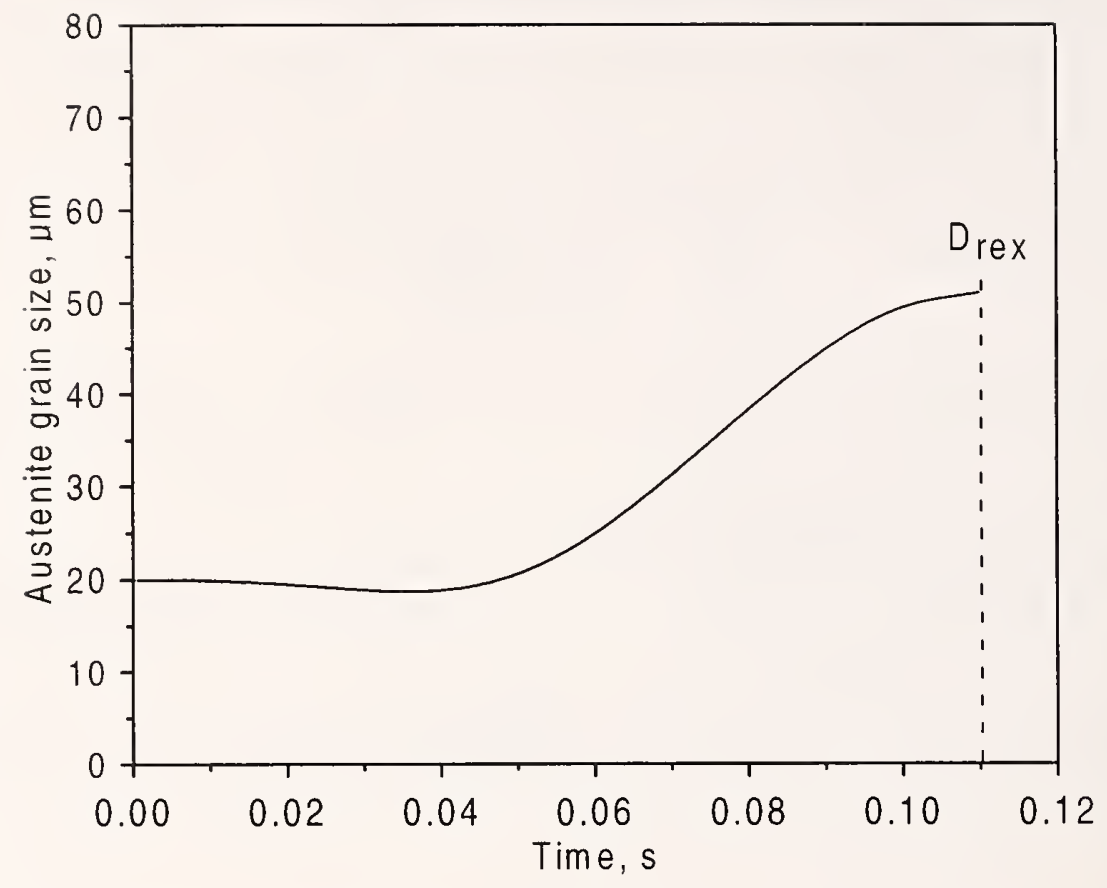

Figure 9. Calculated average austenite grain-size evolution in the VT steel with the assumption of small initial grain size and high deformation temperature $\left(D_{0}=20 \mu \mathrm{m}\right.$; $T_{d}=1180^{\circ} \mathrm{C} ; \varepsilon=0.13 ; \dot{\varepsilon}=1 \mathrm{~s}^{-1}$ ).

\subsubsection{Dynamic Recrystallization Model}

The conventional concept of dynamic recrystallization is based upon the assumption that the critical strain must be reached before the process initiates (fig. 1a). The critical strain depends on the Zener-Hollomon parameter and the initial austenite grain size [6]. The relationships were determined by analysis of the flow curves employing a generalized Voce equation proposed by Beynon and Sellers [6] and by taking into consideration that the decrease in the flow stress, which takes place after recrystallization has initiated, indicates the creation of dislocation-free nuclei. Thus, the effect of dynamic recrystallization on the flow curves relates directly to the volume fraction of recrystallized material.

For the VT steel, selected results of the Zener-Hollomon parameter $Z$ and the initial austenite grain-size effects on the critical strain are listed in table 6, along with measurements of dynamically recrystallized grain size. The relationships for the critical strain and dynamically recrystallized grain size were obtained from all the experimental data for dynamic recrystallization. A complete model for dynamic recrystallization in the VT steel is given in table 7. Similar relationships for the C-Mn and eutectoid steels are given in tables 8 and 9, respectively. Dynamically recrystallized grain size depends solely on the Zener-Hollomon parameter (fig. 10). 
Table 6. Selected data showing the influence of the deformation parameters and the initial austenite grain size on the critical strain for dynamic recrystallization and dynamically recrystallized grain size in the VT steel.

\begin{tabular}{crccc}
\hline$D_{0}, \mu \mathrm{m}$ & $T,{ }^{\circ} \mathrm{C}$ & $\dot{\varepsilon}, \mathrm{s}^{-1}$ & $\varepsilon_{c}$ & $D_{\mathrm{dyn}}, \mu \mathrm{m}$ \\
\hline 25 & 950 & 0.3 & 0.194 & 13.2 \\
28 & 1050 & 0.3 & 0.145 & 20.2 \\
30 & 1150 & 0.3 & 0.132 & 26.2 \\
50 & 950 & 2.0 & 0.321 & 8.10 \\
50 & 1050 & 2.0 & 0.231 & 15.1 \\
50 & 1150 & 2.0 & 0.198 & 20.1 \\
110 & 1150 & 3.0 & 0.291 & 19.3 \\
\hline
\end{tabular}

Table 7. Equations in the dynamic-recrystallization model for the VT steel.

\begin{tabular}{ccl}
\hline Equation & \multicolumn{1}{c}{ Description } \\
\hline $\begin{array}{c}\varepsilon_{c}=\left(4.4 \times 10^{-4}\right) D_{0}^{0.18} Z^{0.15} \\
Q_{d}=312 \mathrm{~kJ} / \mathrm{mol}\end{array}$ & $(\mathrm{T}-13)$ & critical strain $\left(Q_{d} / R T\right)$ \\
$D_{\mathrm{dyn}}=\left(1.4 \times 10^{3}\right) Z^{-0.16}$ & $(\mathrm{~T}-14)$ & dynamically recrystallized grain size $(\mu \mathrm{m})$ \\
$X(t)_{\mathrm{dyn}}=1-\exp \left[-0.4\left[\frac{\varepsilon-\varepsilon_{c}}{\varepsilon_{p}}\right]\right.$ & \\
$\varepsilon_{p}$ & $\left.=1.12 \varepsilon_{c}\right](\mathrm{T}-15)$ & recrystallization kinetics
\end{tabular}


Table 8. Equations in the dynamic-recrystallization model for the C-Mn steel.

Equation (T-17) is from Hodgson [12].

\begin{tabular}{ccl}
\hline \multicolumn{1}{c}{ Equation } & \multicolumn{1}{c}{ Description } \\
$\varepsilon_{c}=\left(4 \times 10^{-4}\right) D_{0}^{0.5} Z^{0.15}$ & $(\mathrm{~T}-16)$ & critical strain \\
$Z=\dot{\varepsilon} \exp \left(Q_{d} / R T\right)$ & \\
$Q_{d}=312 \mathrm{~kJ} / \mathrm{mol}$ & $(\mathrm{T}-17)$ & dynamically recrystallized grain size $(\mu \mathrm{m})$ \\
$D_{\mathrm{dyn}}=\left(1.6 \times 10^{4}\right) Z^{-0.23}$ & & \\
$X(t)_{\mathrm{dyn}}=1-\exp \left[-0.8\left[\frac{\varepsilon-\varepsilon_{c}}{\varepsilon_{p}}\right)^{1.4}\right]$ & $(\mathrm{T}-18)$ & recrystallization kinetics \\
$\varepsilon_{p}=1.23 \varepsilon_{c}$ &
\end{tabular}

Table 9. Equations in the dynamic-recrystallization model for the eutectoid steel.

\begin{tabular}{ccl}
\hline \multicolumn{1}{c}{ Equation } & \multicolumn{1}{c}{ Description } \\
\hline $\begin{array}{c}\varepsilon_{c}=\left(4.3 \times 10^{-4}\right) D_{0}^{0.3} Z^{0.18} \\
Q_{d}=315 \mathrm{~kJ} / \mathrm{mol}\end{array}$ & $(\mathrm{T}-19)$ & critical strain \\
$D_{\mathrm{dyn}}=\left(1.6 \times 10^{4}\right) Z^{-0.2}$ & $(\mathrm{~T}-20)$ & dynamically recrystallized grain size $(\mu \mathrm{m})$ \\
$X(t)_{\mathrm{dyn}}=1-\exp \left[-1.7\left[\frac{\varepsilon-\varepsilon_{c}}{\varepsilon_{p}}\right]^{1.3}\right](\mathrm{T}-21)$ & recrystallization kinetics \\
$\varepsilon_{p}=1.05 \varepsilon_{c}$ &
\end{tabular}




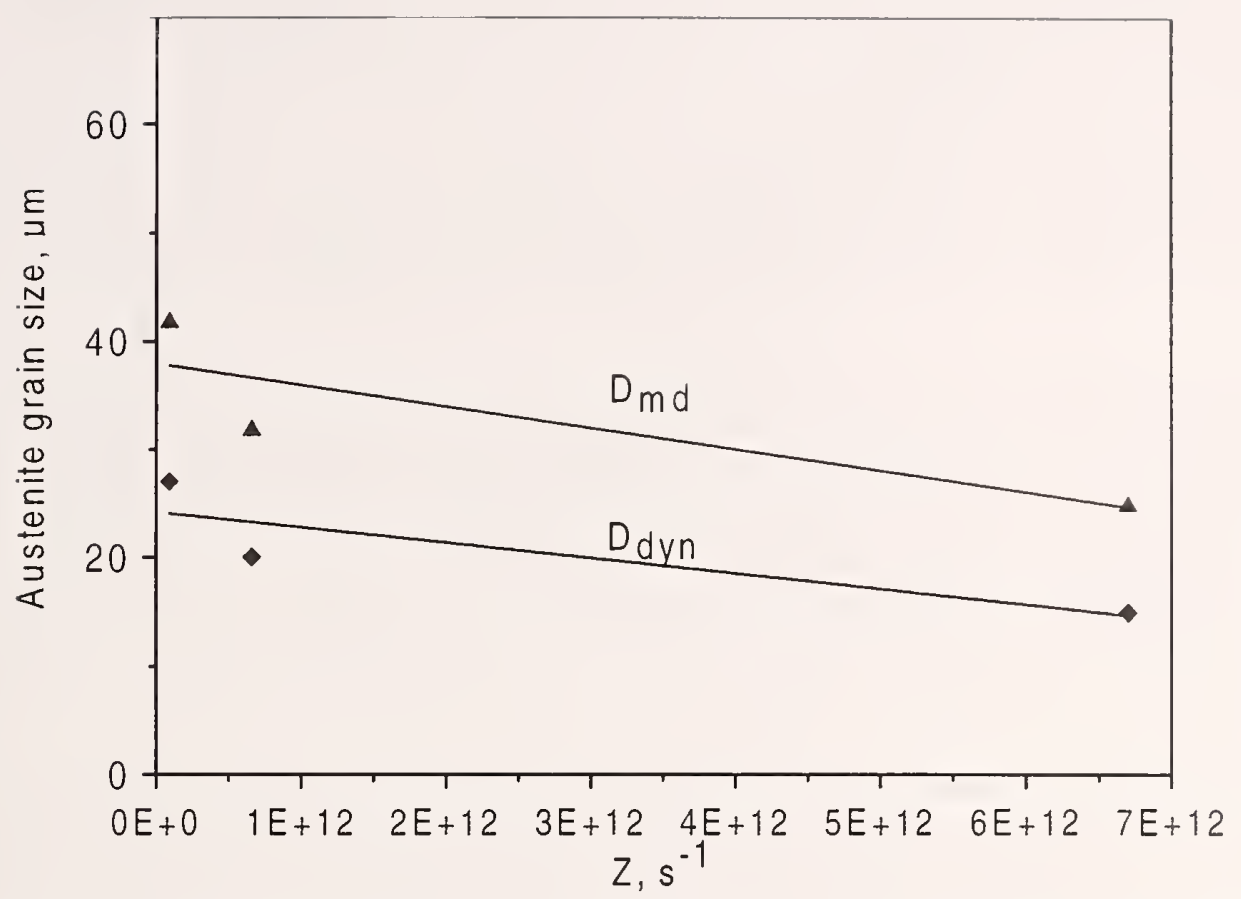

Figure 10. Dependence of dynamically and metadynamically recrystallized grain size in the VT steel (table 7) on the Zener-Hollomon parameter.

\subsubsection{Metadynamic Recrystallization Model}

Once dynamic recrystallization has been initiated during deformation, postdynamic microstructure-restoration processes operate after deformation. The major process leading to the softening of the material during postdynamic processes is static recrystallization, according to Sakai [13], and metadynamic recrystallization, according to Hodgson [12]. Our analysis of the dependence of the postdynamic microstructure-restoration process kinetics on deformation parameters supports Hodgson's view: The kinetics of microstructure-restoration processes in Hodgson's study were strongly dependent on strain rate, weakly dependent on temperature, and apparently not dependent on strain. In contrast, during static recrystallization, the kinetics depend strongly on strain and temperature and weakly on strain rate.

Hodgson's viewpoint on the postdynamic process mechanisms was adopted in this study. Further refinement of the metadynamic recrystallization process was done by Pietrzyk and Kuziak [14], who showed that the grain size during metadynamic recrystallization in Hodgson's experiments [12] varied linearly with the volume fraction recrystallized [eq (T-26) in table 10]. This finding was confirmed by Kuziak [9] for 900A eutectoid steel.

For illustration, predicted and measured changes in the austenite grain size during metadynamic recrystallization of $900 \mathrm{~A}$ eutectoid steel are shown in figure 11 [9]. The set of equations for the metadynamic recrystallization model is given in table 10. The kinetics equation for metadynamic recrystallization has the same form for all the experimental steels; it is adopted from the research conducted by Hodgson [12], and the model incorporates the same type of 
dependence of dynamically and metadynamically recrystallized grain size on the ZenerHollomon parameter. However, metadynamically recrystallized grain size is greater than dynamically recrystallized grain size, as shown in figure 10 for the VT steel.

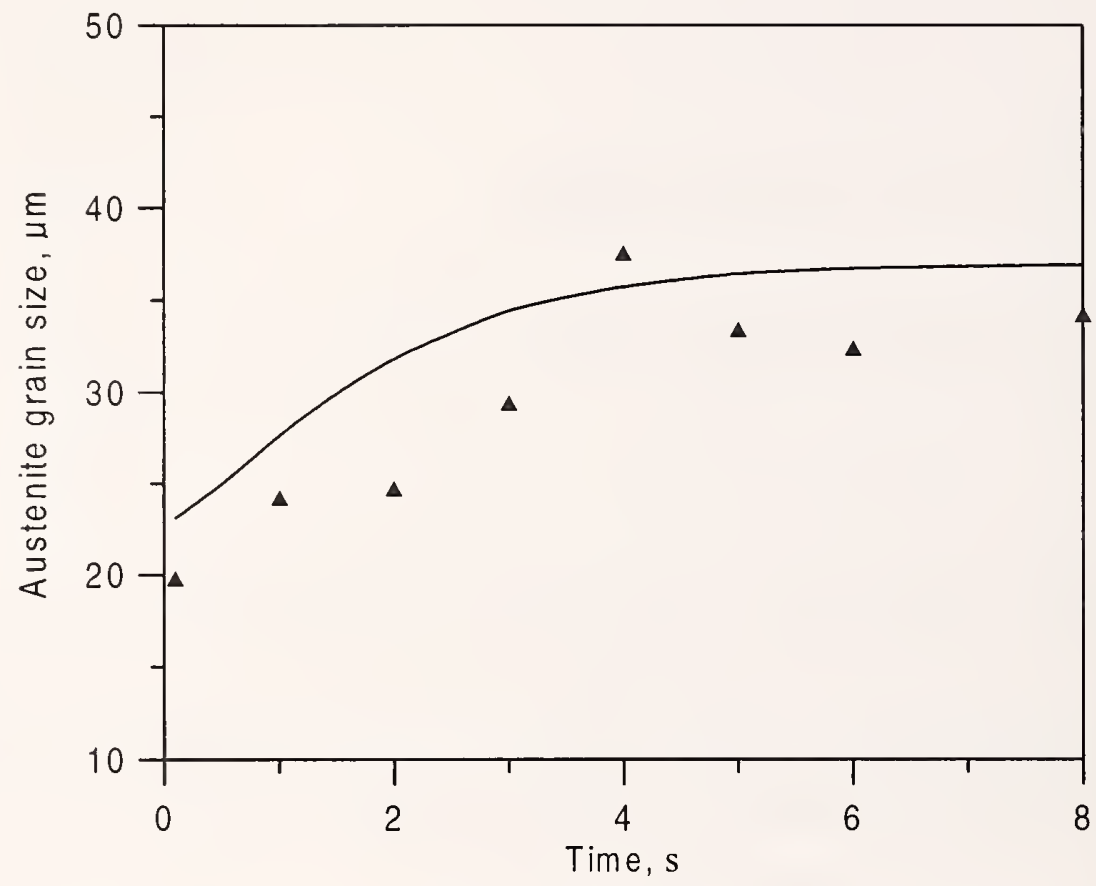

Figure 11. Austenite grain-size evolution during metadynamic recrystallization of the $900 \mathrm{~A}$ eutectoid steel $\left(D_{0}=60 \mu \mathrm{m} ; T_{d}=950^{\circ} \mathrm{C} ; \dot{\varepsilon}=0.2 \mathrm{~s}^{-1}\right)$. For the calculation (curve), a linear dependence of the average grain size on the volume fraction of metadynamically recrystallized material was assumed [see eq (T-26) in table 10].

Table 10. Equations in the metadynamic-recrystallization model for the experimental steels.

Metadynamically recrystallized grain size, $\mu \mathrm{m}$

Recrystallization kinetics for all steels (Hodgson [12])
$\mathrm{C}-\mathrm{Mn} \quad D_{\mathrm{md}}=\left(2.6 \times 10^{4}\right) Z^{-0.23}$

VT $\quad D_{\text {md }}=\left(2.3 \times 10^{4}\right) Z^{-0.16}$

Eutectoid $\quad D_{\mathrm{md}}=\left(2.5 \times 10^{4}\right) Z^{-0.23}$

All steels $\quad D(t)=D_{\mathrm{dyn}}$

$+\left(D_{\mathrm{md}}-D_{\mathrm{dyn}}\right) x(t)_{\mathrm{md}}$

$$
X(t)_{\mathrm{md}}=1-\exp \left[-0.693\left(\frac{t}{t_{0.5}}\right)^{1.3}\right]
$$

$$
t_{0.5}=1.12 Z^{-0.8} \exp \left(\frac{230000}{R T}\right)
$$




\subsubsection{Grain Growth of the Austenite after Recrystallization}

A characteristic feature of the grain growth after recrystallization is an abrupt decrease in the growth rate sometime after the completion of recrystallization. In this study, the approach developed by Roberts et al. [7] was adopted to characterize this behavior quantitatively. In the model of Roberts and coworkers, a parabolic type of equation describes the grain-growth kinetics with two parameter sets, depending on the stage of grain growth.

The best fit of the data on the kinetics of grain growth for the VT steel obtained during the course of this investigation gave the set of constants in the parabolic equation. These constants are listed in table 11 together with the constants for the $\mathrm{C}-\mathrm{Mn}$ and $900 \mathrm{~A}$ eutectoid steel. Following the approach of Roberts and coworkers, we used a 20 -s breakpoint to separate the rapidand slow-growth kinetics ranges. An example of our prediction of the austenite grain growth in the VT steel is given in figure 12. For simplicity, we did not distinguish between the grain growth after static and metadynamic recrystallization. Kuziak had found this approach to be satisfactory for a 900A eutectoid steel [9].

Another approach to grain-growth modeling after static recrystallization, described by Sellars [2], is based on the use of a larger exponent in the equation for the early stage of grain growth; for plain-carbon and microalloyed steels, the exponents are typically in the range 7 to 10. However, the experience gained in this research on recrystallized grain-growth kinetics shows that Sellars's approach leads to overestimation of the final grain size, especially when large interpass times are involved.

Table 11. Constants in the austenite-recrystallized grain-growth model for the experimental steels.

\section{Equations}

$$
\begin{aligned}
& D(t)^{2}=D_{(t=0)}^{2}+t \times 10^{A_{1}-B_{1} / T} \\
& \text { for } t \leq 20 s \\
& D(t)^{2}=D_{(t=20 s)}^{2}+t \times 10^{A_{2}-B_{2} / T} \\
& \text { for } t>20 s
\end{aligned}
$$

\section{Constants}

\begin{tabular}{lll}
\hline C-Mn steel & VT steel & 900A Eutectoid steel \\
\hline $\mathrm{A}_{1}=6.6$ & $\mathrm{~A}_{1}=7.1$ & $\mathrm{~A}_{1}=7.0$ \\
$\mathrm{~B}_{1}=6200$ & $\mathrm{~B}_{1}=7180$ & $\mathrm{~B}_{1}=5900$ \\
$\mathrm{~A}_{2}=8.1$ & $\mathrm{~A}_{2}=9.5$ & $\mathrm{~A}_{2}=8.4$ \\
$\mathrm{~B}_{2}=9000$ & $\mathrm{~B}_{2}=10920$ & $\mathrm{~B}_{2}=8520$ \\
\hline
\end{tabular}




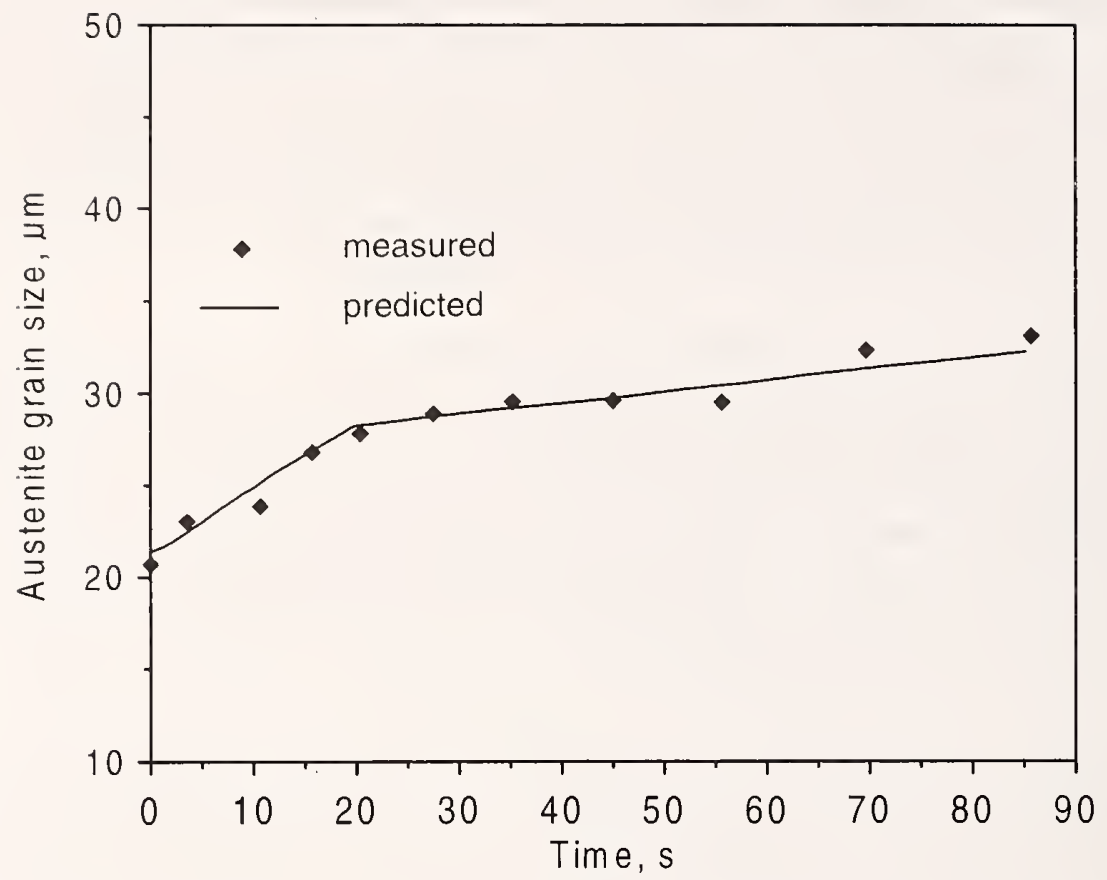

Figure 12. Characterization of the recrystallized austenite grain-growth kinetics in the VT steel based on a modified Roberts equation [7] $\left(D_{\text {rex }}=22 \mu \mathrm{m} ; T_{d}=950^{\circ} \mathrm{C}\right)$.

\subsection{Phase Transformations on Cooling after Hot Working}

\subsubsection{Ferrite-Pearlite Steels}

The kinetics of decomposition of the austenite can be described quantitatively by classical nucleation and growth theory [3]. This approach, however, is time-consuming, and it may not give accurate predictions in many situations. Therefore, we developed an empirical model for the experimental steels that is capable of predicting the basic microstructural parameters of the ferrite-pearlite microstructure: ferrite grain size and volume fraction, pearlite interlamellar spacing, and pearlite colony size. These parameters correlate with austenite grain size before the ferrite transformation and with the cooling rate over the transformation temperature range. The model was developed during the course of the experiments conducted with the dilatometer.

In the experiments, one reheating schedule $\left(1180^{\circ} \mathrm{C}\right.$ for $\left.10 \mathrm{~min}\right)$ was adopted to dissolve vanadium carbonitride precipitates. Variation in austenite grain size was achieved by changing the compression of the specimens at $950^{\circ} \mathrm{C}$.

Selected measurements of the ferrite-pearlite microstructural parameters in VT steels are given in table 12. These data, together with the results of other studies [15-17], were used to develop predictive equations for the microstructural parameters of the VT steels. All the equations developed in the study are summarized in table 13. Although regression analysis gave constants for the VT steels that were slightly different from the C-Mn-steel constants, we decided to use one set of equations for these steels because the results generated by the different 
Table 12. Selected experimental results describing the dependence of the ferritepearlite microstructural parameters in the VT steel on the austenite grain size and cooling rate over the transformation temperature range.

\begin{tabular}{cccccc}
\hline$D_{\gamma}, \mu \mathrm{m}$ & $C_{r},{ }^{\circ} \mathrm{C} / \mathrm{s}$ & $D_{\alpha}, \mu \mathrm{m}$ & $S_{0}, \mu \mathrm{m}$ & $f_{\alpha}$ & $f_{w}$ \\
\hline 55.2 & 0.1 & 19.1 & 0.220 & 0.72 & 0.00 \\
55.2 & 0.3 & 17.8 & 0.168 & 0.69 & 0.00 \\
55.2 & 0.5 & 13.2 & 0.155 & 0.63 & 0.00 \\
55.2 & 1.0 & 10.8 & 0.139 & 0.65 & 0.05 \\
55.2 & 2.5 & 10.9 & 0.130 & 0.57 & 0.18 \\
45.4 & 0.5 & 15.0 & 0.157 & 0.70 & 0.00 \\
41.9 & 2.5 & 10.7 & 0.122 & 0.68 & 0.12 \\
40.0 & 0.1 & 12.6 & 0.230 & 0.75 & 0.00 \\
38.8 & 1.0 & 9.2 & 0.132 & 0.70 & 0.03 \\
37.7 & 1.0 & 11.3 & 0.140 & 0.72 & 0.00 \\
30.1 & 0.1 & 12.1 & 0.200 & 0.75 & 0.00 \\
34.4 & 0.5 & 13.2 & 0.152 & 0.74 & 0.00 \\
26.8 & 2.5 & 8.7 & 0.119 & 0.62 & 0.15 \\
\hline
\end{tabular}

Table 13. Predictive equations for the calculation of the ferrite-pearlite microstructural parameters.

For the VT steel-

$$
D_{\alpha}=\frac{D_{\gamma}}{1+\left(0.036+0.0233 C_{r}^{0.5}\right) D_{\gamma}}
$$

For the other steels-

$$
D_{\alpha}=[3.85-5.9(\% \mathrm{C})-1.56(\% \mathrm{Mn})+8.5(\% \mathrm{~V})-20(\% \mathrm{~N})] D_{\gamma}^{0.58} C_{r}^{-0.26}
$$

For all steels-

$$
\begin{gathered}
S_{0}=0.1307+1.027(\% \mathrm{C})-1.933(\% \mathrm{C})^{2}-0.1108(\% \mathrm{Mn})+0.0305 C_{r}^{-0.52} \\
C_{r}=\text { cooling rate in }{ }^{\circ} \mathrm{C} / \mathrm{s} \\
f_{\mathrm{eq}}=1-\left[\frac{\% \mathrm{C}}{0.789-0.1671(\% \mathrm{Mn})+0.1607(\% \mathrm{Mn})^{2}-0.0448(\% \mathrm{Mn})^{3}}\right] \\
f_{w}=f_{\mathrm{eq}}-0.829 \exp \left(-0.210 C_{r}\right)-1.0097 \exp \left(-0.08 D_{\gamma}\right) \\
f_{\alpha}=f_{\mathrm{eq}}-5.48\left[1-\exp \left(-0.0106 C_{r}\right)\right]-0.723\left[1-\exp \left(-0.0009 D_{\gamma}\right)\right]
\end{gathered}
$$


sets of equations agreed within experimental error. We assumed that the equations listed in table 13 are valid for the austenite grain size before the transformation of less than $100 \mu \mathrm{m}$. The reference state for the calculation of the ferrite volume fraction is the equilibrium content of this phase in a steel. We used a commercial computer program (Thermocalc) to calculate this parameter; it can also be obtained with eq (T-32). We also estimated the Widmanstätten or nonequiaxed ferrite volume fraction in the experiments. Increasing the austenite grain size and cooling rate is known to increase the propensity for the formation of nonequiaxed ferrite. On the basis of the measurements, we suggest that the nonequiaxed ferrite volume fraction depends exponentially on the austenite grain size and cooling rate (table 13). By setting the nonequiaxed ferrite volume fraction to zero, we could place a border between the nonequiaxed and equiaxed ferrite regions on the austenite-grain-size and cooling-rate coordinates. An illustration of the criterion developed for nonequiaxed ferrite formation is given in figure 13. 
(a)

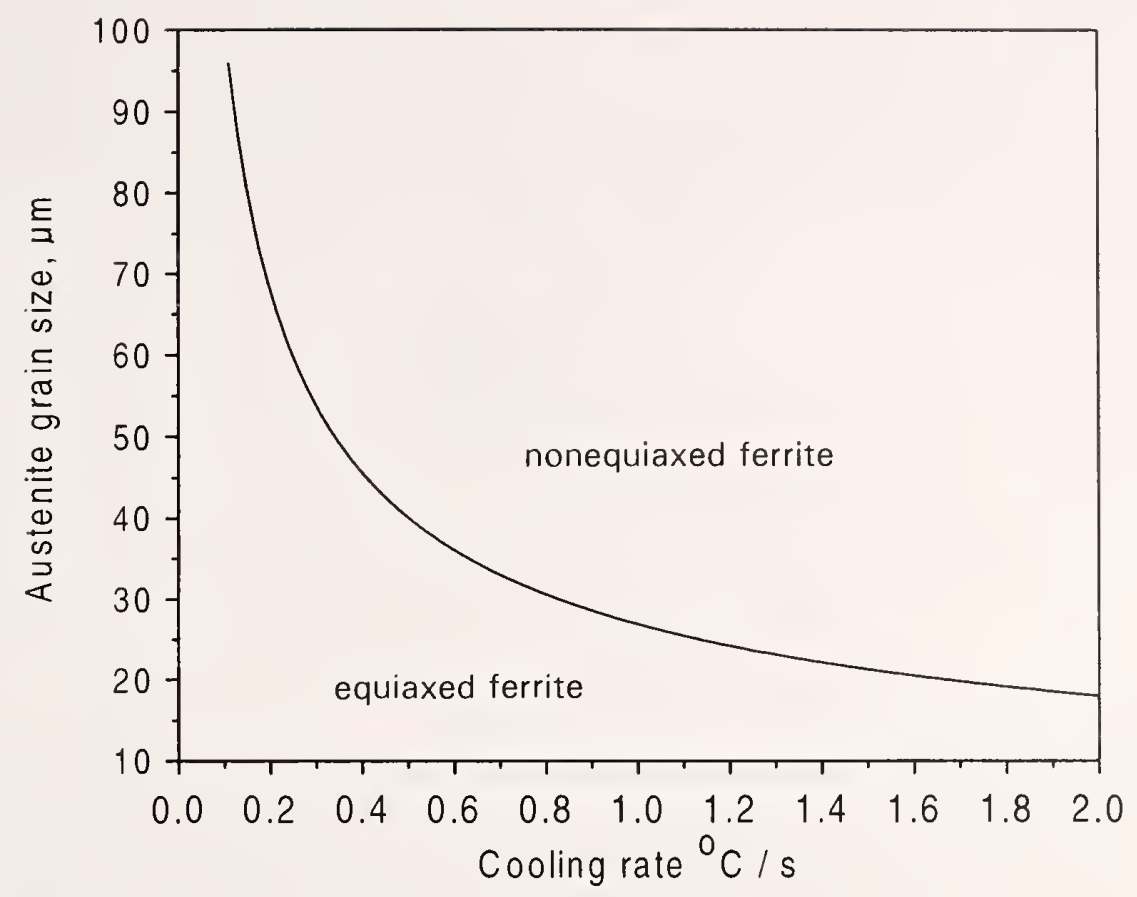

(b)

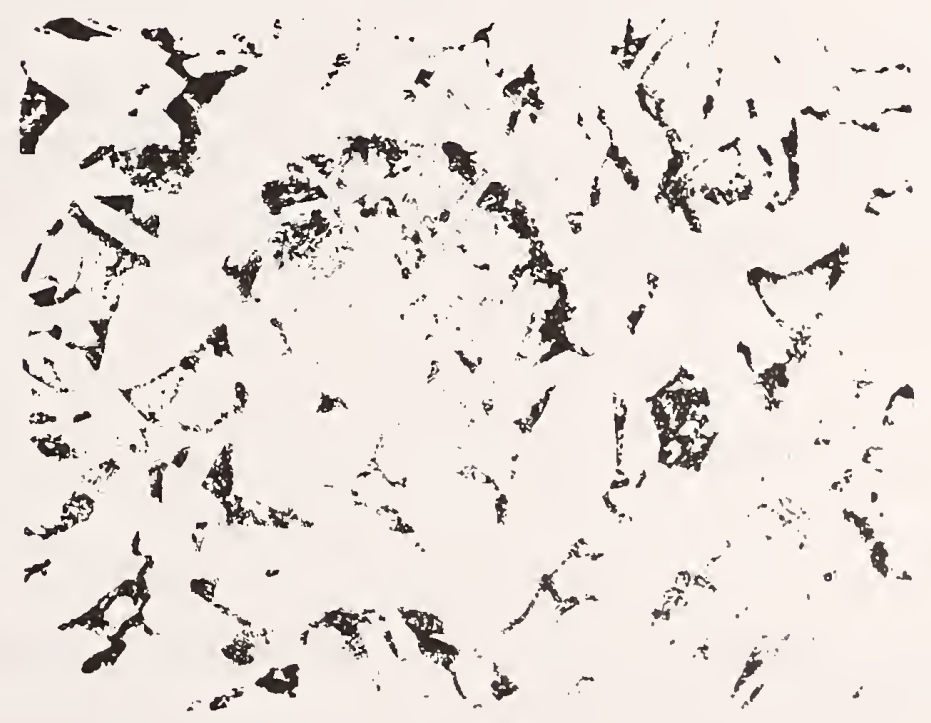

Figure 13. (a) Conditions for the occurrence of nonequiaxed ferrite in the VT steel: (b) microstructure $(400 \times)$ developed after cooling at a rate of $1^{\circ} \mathrm{C} / \mathrm{s}\left(D_{0}=70 \mu \mathrm{m}\right)$. Widmanstätten structure was observed in this specimen. 


\subsubsection{A Eutectoid Steel}

A mathematical model for pearlite transformation in eutectoid steels was developed during the research conducted by Kuziak [9], which is based upon the fundamental studies of Campbell et al. [18] and Umemoto et al. [19]. To describe the pearlite transformation quantitatively, we must be able to calculate the incubation time $\tau$ and changes in the pearlite volume fraction $X(t)_{p}$ as a function of time. The following equations quantitatively describe these parameters under isothermal conditions $[18,19]$ :

$$
\tau=\frac{K T \exp \left(\frac{Q}{R T}\right)}{\left(T_{0}-T\right)^{w}}
$$

and

$$
X(t)_{p}=1-\exp \left[-b(T)\left[\frac{t^{n}}{D_{\gamma}^{m}}\right)\right],
$$

where $t$ is the transformation time, $D_{\gamma}$ is austenite grain size before the transformation, and $T_{0}$ is the equilibrium transformation temperature, which was computer calculated. The values of the constants and parameters in eqs (3) and (4) are given in table 14, and the measured and calculated incubation periods and transformation kinetics are compared in figures 14 and 15 .

Equations (3) and (4) were developed during the course of the isothermal tests conducted with the dilatometer. By means of quantitative analysis of the specimens after the experiments, we were able to relate the pearlite interlamellar spacing and the pearlite nodule and colony sizes to the chemical composition, pearlite transformation temperature, and austenite grain size of a particular steel (see table 15). Using eqs (3) and (4) and the additivity rule [20], we calculated the progress of the pearlite transformation during continuous cooling. We used the following formulation of the additivity rule, combining it with eq (3), to calculate the the transformation starting temperature during continuous cooling:

$$
\int_{0}^{t} \frac{d t}{\tau}=1 .
$$

Table 14. Constants in the equations for the incubation period and the pearlite transformation kinetics in the eutectoid steel (Kuziak [9]).

$$
\begin{aligned}
& K=2.6-1.44(\% \mathrm{C})-2.95(\% \mathrm{C})^{2}+0.69(\% \mathrm{Mn})+1.5(\% \mathrm{Mn})^{2}+13.9(\% \mathrm{Cr})+65.5(\% \mathrm{Cr})^{2} \\
& \quad n=1.96, \quad m=1.94, \quad w=4.65, \quad Q=114500 \mathrm{~J} / \mathrm{mol} \\
& \ln [b(T)]=-\left(2.546 \times 10^{-4}\right) T^{2}-0.279 T-72.23 \\
& \quad T \text { in degrees Celsius }
\end{aligned}
$$




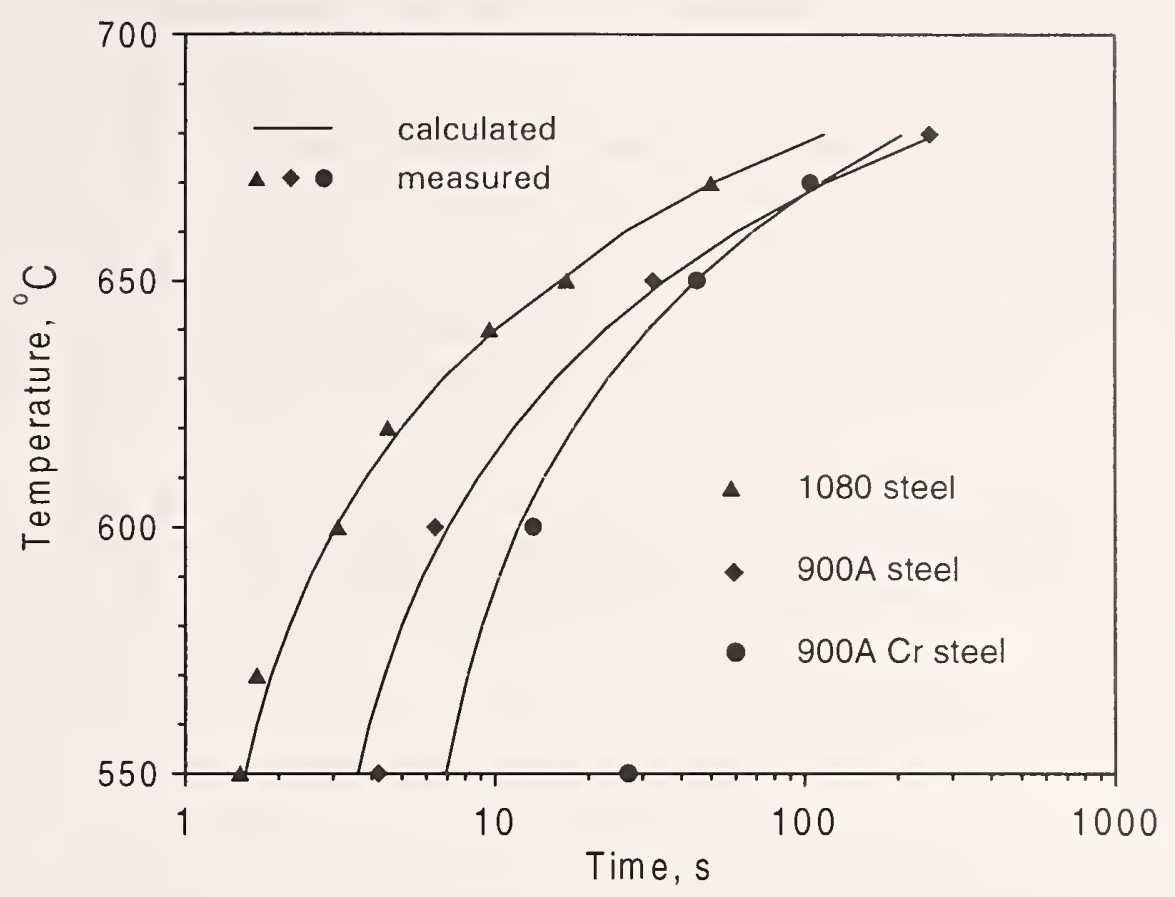

Figure 14. Model-predicted time-temperature-transformation curves (solid lines) versus experimental data (symbols) for different eutectoid steels [9].

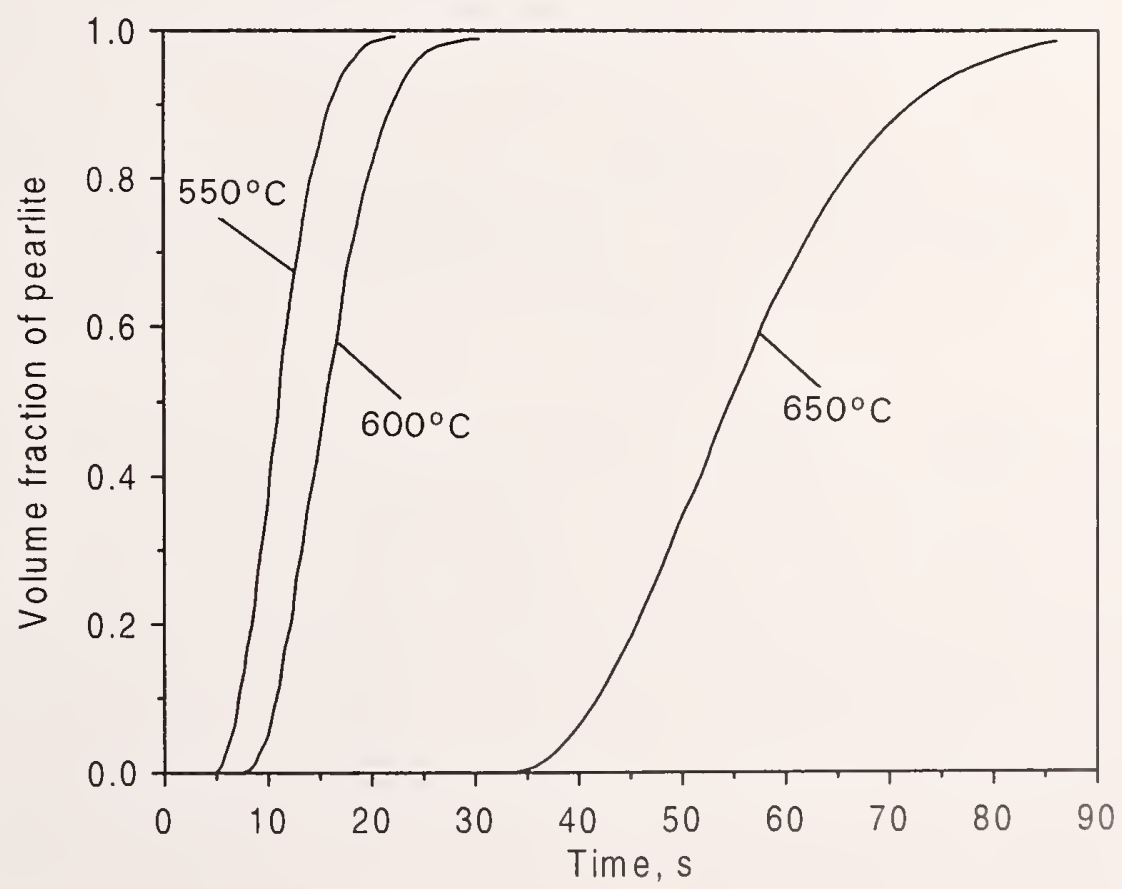

Figure 15. Model-predicted effects of the transformation temperature on the kinetics of pearlite transformation in $900 \mathrm{~A}$ eutectoid steel $\left(D_{0}=60 \mu \mathrm{m}\right)$ [9]. 
A procedure developed by Campbell et al. [18] was the basis for calculating the increase in the pearlite volume fraction as a function of transformation time during continuous cooling. As an example, the calculated and measured transformation start and finish temperatures for specimens of $900 \mathrm{~A}$ eutectoid steel cooled in the dilatometer [9] are shown in figure 16. Equation (5) was used to calculate $T_{p}$ in table 15 .

Table 15. Predictive equations for the quantitative description of the pearlite microstructure.

$$
\begin{aligned}
\frac{1}{S_{0}}= & A-B T_{p} \\
& \mathrm{~A}=129.28-54.373(\% \mathrm{Mn})-4.378(\% \mathrm{Cr})-17.5(\% \mathrm{Si}) \\
& \mathrm{B}=0.1783-0.0723(\% \mathrm{Mn})-0.0121(\% \mathrm{Cr})-0.0274(\% \mathrm{Si}) \\
\frac{1}{D_{c}}= & 0.857-0.001189 T_{p} \\
N_{d}= & \frac{6500\left[1-\exp \left(-0.016 D_{\gamma}\right)\right]^{0.6}}{\left(T_{0}-T_{p}\right)^{1.2}}
\end{aligned}
$$

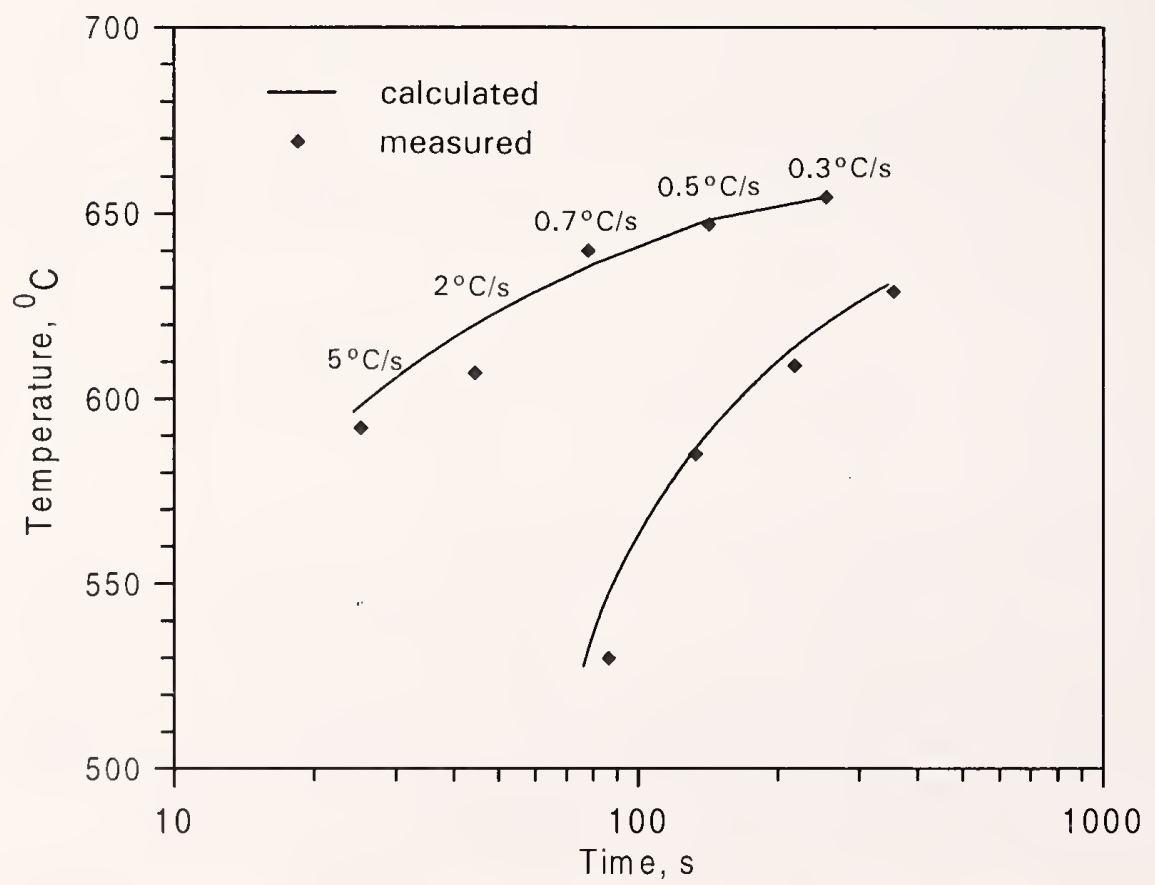

Figure 16. Model-calculated and measured values of the pearlite-transformation start and finish temperatures in the 900A eutectoid steel [9]. 


\section{Microstructure-Mechanical-Property Relationships}

\subsection{Ferrite-Pearlite Steels}

One of the most successful approaches to the prediction of mechanical properties in products made of plain carbon steels was developed by Gladman et al. [1]. It relates the yield strength, ultimate tensile strength, and impact transition temperature to the microstructural parameters of the ferrite-pearlite microstructure. In trying to rationalize the results obtained in this study, we found that the equations of Gladman and coworkers were unsatisfactory for predicting the yield and ultimate tensile strengths for our experimental steels.

Following this observation, we developed new equations from measurements of mechanical properties of diverse products rolled from steels with a carbon content from 0.05 to 0.6 mass percent. We took an approach similar to that of Gladman and coworkers. In the correlation analysis, data from 60 specimens were included. For illustration, a description of and selected data from 13 specimens are listed in tables 16 and 17 . The best-fit equations developed for the average yield and ultimate tensile strengths of all the specimens are given in table 18. Major differences between these equations and Gladman's consist in the linear law of mixtures for the yield-strength calculation and the inclusion of the nonlinear dependence of the ultimate tensile strength on the pearlite interlamellar spacing, which followed our observation that the pearlite interlamellar spacing plays a significant role in shaping the ultimate tensile strength when the ferrite loses its continuity in the microstructure. Figure 17 illustrates the predictive capability of the equations developed in this study.

A model for the precipitation-induced increases in yield strength and ultimate tensile strength was developed by using the approach of Hodgson and Gibbs [21]. These researchers assumed that the contribution of the vanadium carbonitride precipitates to the overall strengthening effect depends linearly on the nitrogen and vanadium contents and logarithmically on the cooling rate.

The dependence of the strengthening effect on cooling rate is known to reach a maximum within a cooling-rate range of 5 to $10^{\circ} \mathrm{C} / \mathrm{s}$, depending on steel composition and processing route. However, since the cooling rate of air-cooled products is typically less than $5^{\circ} \mathrm{C} / \mathrm{s}$, a logarithmic representation of the cooling-rate effect on the strength properties is justified for all the rolling processes considered in this study.

Although it is not found in the equation developed by Hodgson and Gibbs, the contribution of carbon to precipitation-strengthening is included in the analysis of the effect of vanadium carbonitride on the strength properties; the effect of carbon content on the transformation temperature justifies its inclusion. Most vanadium precipitation occurs during ferrite transformation (interphase precipitation) and in the ferrite after transformation. Increasing the carbon content should lead to a decrease in the mean particle size of vanadium carbonitride by depressing the precipitation start temperature. Consequently, precipitation-strengthening components should be increased as the carbon content increases. Our correlation analysis for the model development is based on the results of this investigation and the data of Sawada et al. [16] and Burnet [17]. The increases in yield strength and ultimate tensile strength originating from the vanadium carbonitride precipitates were estimated by subtracting structure-related values of these parameters (calculated from the equations listed in table 18) from the measured values of yield strength and ultimate tensile strength. The predictive relationships for the calculation of precipitation-related increases in yield and ultimate tensile strengths are given in table 19, and the predictions of these equations for different products, in table 20. 
Table 16. Selected chemical compositions and forms of the steel products used for the development of the microstructure-mechanical-properties relationships.

\begin{tabular}{|c|c|c|c|c|c|c|}
\hline \multicolumn{6}{|c|}{ Content } & \multirow{2}{*}{$\begin{array}{c}\text { Steel } \\
\text { product form }\end{array}$} \\
\hline No. & $\mathrm{C}$ & $\mathrm{Mn}$ & $\mathrm{Si}$ & $\mathrm{P} / \mathrm{S}$ & $\mathrm{N}$ & \\
\hline 1 & 0.04 & 0.23 & 0.05 & $\begin{array}{l}0.010 \\
0.015\end{array}$ & 0.008 & 8-mm-diam. rod \\
\hline 2 & 0.05 & 0.31 & 0.05 & $\begin{array}{l}0.010 \\
0.016\end{array}$ & 0.007 & 10-mm-diam. rod \\
\hline 3 & 0.18 & 0.57 & 0.26 & $\begin{array}{l}0.028 \\
0.026\end{array}$ & 0.009 & 12-mm-diam. rod \\
\hline 4 & 0.65 & 0.52 & 0.21 & $\begin{array}{l}0.014 \\
0.012\end{array}$ & 0.006 & 10-mm-diam. rod \\
\hline 5 & 0.19 & 1.20 & 0.33 & $\begin{array}{l}0.019 \\
0.021\end{array}$ & 0.007 & 12-mm-diam. rod \\
\hline 6 & 0.22 & 1.23 & 0.34 & $\begin{array}{l}0.059 \\
0.038\end{array}$ & 0.009 & 14-mm-diam. rod \\
\hline 7 & 0.33 & 1.20 & 0.52 & $\begin{array}{l}0.015 \\
0.028\end{array}$ & 0.008 & 8-mm-diam. rod \\
\hline 8 & 0.20 & 1.15 & 0.35 & $\begin{array}{l}0.044 \\
0.029\end{array}$ & 0.005 & 8-mm-diam. rod \\
\hline 9 & 0.19 & 1.31 & 0.36 & $\begin{array}{l}0.024 \\
0.030\end{array}$ & 0.007 & I-beam \\
\hline 10 & 0.18 & 1.32 & 0.35 & $\begin{array}{l}0.023 \\
0.028\end{array}$ & 0.008 & I-beam \\
\hline 11 & 0.20 & 1.32 & 0.39 & $\begin{array}{l}0.033 \\
0.022\end{array}$ & 0.009 & I-beam \\
\hline 12 & 0.48 & 0.86 & 0.22 & $\begin{array}{l}0.026 \\
0.024\end{array}$ & 0.009 & I-beam \\
\hline 13 & 0.42 & 1.01 & 0.61 & $\begin{array}{l}0.029 \\
0.042\end{array}$ & 0.007 & $20-\mathrm{mm}$-thick plate \\
\hline
\end{tabular}


Table 17. Measured microstructural parameters and strength properties of the products specified in table 16 (strength properties predicted from the relationships in table 18 are also included).

\begin{tabular}{|c|c|c|c|c|c|c|c|}
\hline \multirow{3}{*}{ No. } & \multirow{2}{*}{\multicolumn{3}{|c|}{$\begin{array}{c}\text { Measured } \\
\text { Microstructural Parameters }\end{array}$}} & \multicolumn{4}{|c|}{ Strength Properties } \\
\hline & & & & \multicolumn{2}{|c|}{$\sigma_{y}, \mathrm{MPa}$} & \multicolumn{2}{|c|}{$\sigma_{u}, \mathrm{MPa}$} \\
\hline & $f_{\alpha}$ & $D_{\alpha}, \mu \mathrm{m}$ & $S_{0}, \mu \mathrm{m}$ & meas. & pred. & meas. & pred. \\
\hline 1 & 0.90 & 23.6 & 0.220 & 278 & 232 & 390 & 408 \\
\hline 2 & 0.91 & 18.8 & 0.201 & 272 & 240 & 417 & 405 \\
\hline 3 & 0.78 & 18.4 & 0.168 & 331 & 328 & 530 & 509 \\
\hline 4 & 0.15 & 8.20 & 0.245 & 450 & 437 & 630 & 793 \\
\hline 5 & 0.71 & 13.9 & 0.155 & 380 & 395 & 582 & 542 \\
\hline 6 & 0.65 & 10.6 & 0.182 & 421 & 447 & 635 & 600 \\
\hline 7 & 0.51 & 9.73 & 0.158 & 482 & 461 & 690 & 654 \\
\hline 8 & 0.57 & 9.10 & 0.158 & 430 & 452 & 636 & 613 \\
\hline 9 & 0.61 & 17.2 & 0.182 & 402 & 398 & 550 & 575 \\
\hline 10 & 0.67 & 15.1 & 0.185 & 400 & 402 & 567 & 565 \\
\hline 11 & 0.64 & 19.2 & 0.221 & 390 & 393 & 582 & 576 \\
\hline 12 & 0.20 & 9.43 & 0.230 & 460 & 453 & 770 & 780 \\
\hline 13 & 0.34 & 10.5 & 0.213 & 448 & 452 & 750 & 740 \\
\hline
\end{tabular}
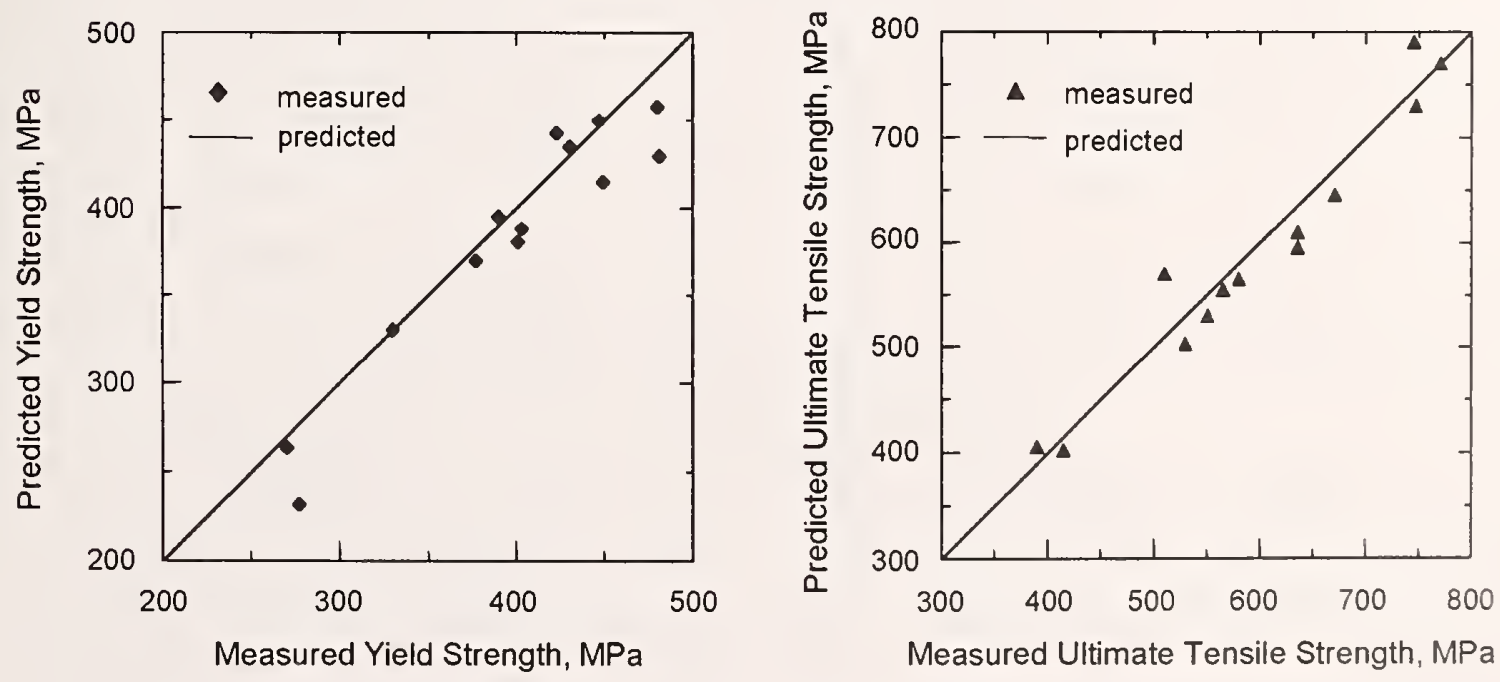

Figure 17. Model-predicted versus measured values of yield and ultimate tensile strengths for various products. 
Table 18. New relationships for the contributions of structure and chemical composition to the yield and ultimate strengths in plain-carbon steels. Equation (T-42) is from Gladman et al. [1]

$$
\begin{aligned}
& \sigma_{y}= f_{\alpha}\left[77.7+59.5(\% \mathrm{Mn})+9.1 D_{\alpha}^{-0.5}\right]+\left[145.5+3.5 S_{0}^{-0.5}\right]+478(\% \mathrm{~N})^{0.5}+1200(\% \mathrm{P}) \\
& \sigma_{u}=f_{\alpha}\left[20+2440(\% \mathrm{~N})^{0.5}+18.5 D_{\alpha}\right]+\left[750\left(1-f_{\alpha}\right)\right]+\left[\left(1-f_{\alpha}^{0.5}\right)\left(3 S_{0}^{-0.5}\right)\right]+92.5(\% \mathrm{Si}) \\
& \text { ITT }=f_{\alpha}\left[-46-11.5 D_{\alpha}\right]+\left(1-f_{\alpha}\right)\left[-335+5.6 S_{0}^{-0.5}-13.3 D_{c}^{-0.5}+\left(3.48 \times 10^{6}\right) t_{c}\right] \\
& \quad+49(\% \mathrm{Si})+762(\% \mathrm{~N})^{0.5}+0.22\left(\Delta \sigma_{y}\right)_{p} \\
& \quad t_{c}=\text { carbide thickness in } \mathrm{mm}
\end{aligned}
$$

Table 19. Relationships for calculating precipitation-strengthening additions.

$$
\begin{aligned}
& \left(\Delta \sigma_{y}\right)_{p}=19.9(\% \mathrm{C})+552.8(\% \mathrm{C})^{2}+590(\% \mathrm{~V})+8650(\% \mathrm{~N})+19.9 \ln \left(C_{r}\right) \\
& \left(\Delta \sigma_{u}\right)_{p}=160+4.8(\% \mathrm{C})+176(\% \mathrm{C})^{2}+414(\% \mathrm{~V})+5370.4(\% \mathrm{~N})+23 \ln \left(C_{r}\right)
\end{aligned}
$$

\begin{tabular}{|c|c|c|c|c|c|c|c|c|}
\hline \multirow{2}{*}{$\begin{array}{l}\text { Product } \\
\text { number }\end{array}$} & \multicolumn{8}{|c|}{ Chemical composition, mass percent } \\
\hline & $\mathrm{C}$ & $\mathrm{Mn}$ & $\mathrm{Si}$ & $P$ & S & V & $\mathrm{Al}$ & $\mathrm{N}$ \\
\hline 1. I-beam & 0.19 & 1.43 & 0.32 & 0.022 & 0.016 & 0.10 & 0.005 & 0.016 \\
\hline 2. $20-\mathrm{mm}$ flat & 0.17 & 1.12 & 0.27 & 0.014 & 0.019 & 0.06 & 0.008 & 0.012 \\
\hline 3. $20-\mathrm{mm}$ flat & 0.20 & 1.36 & 0.32 & 0.014 & 0.017 & 0.12 & 0.004 & 0.012 \\
\hline 4. V-shape & 0.25 & 0.72 & 0.17 & 0.016 & 0.016 & 0.05 & 0.005 & 0.009 \\
\hline \multirow{3}{*}{$\begin{array}{l}\text { Product } \\
\text { number }\end{array}$} & \multirow{3}{*}{$\begin{array}{l}C_{r}, \\
{ }^{\circ} \mathrm{C} / \mathrm{s}\end{array}$} & \multicolumn{3}{|c|}{ Microstructural parameters } & \multicolumn{4}{|c|}{ Yield strength } \\
\hline & & \multirow{2}{*}{$f_{\alpha}$} & \multirow{2}{*}{$\begin{array}{l}D_{\alpha} \\
\mu \mathrm{m}\end{array}$} & \multirow{2}{*}{$\begin{array}{l}S_{0}, \\
\mu \mathrm{m}\end{array}$} & \multicolumn{4}{|c|}{$\sigma_{y}, \mathrm{MPa}$} \\
\hline & & & & & \multicolumn{2}{|c|}{ measured } & \multicolumn{2}{|c|}{ predicted } \\
\hline 1 & 2.5 & 0.68 & 9.80 & 0.170 & \multicolumn{2}{|c|}{600} & \multicolumn{2}{|c|}{585} \\
\hline 2 & 1.2 & 0.72 & 18.5 & 0.231 & \multicolumn{2}{|c|}{450} & \multicolumn{2}{|c|}{458} \\
\hline 3 & 1.2 & 0.69 & 12.7 & 0.210 & \multicolumn{2}{|c|}{525} & \multicolumn{2}{|c|}{536} \\
\hline 4 & 0.5 & 0.62 & 13.2 & 0.181 & \multicolumn{2}{|c|}{435} & \multicolumn{2}{|c|}{420} \\
\hline
\end{tabular}

Table 20. Precipitation-strengthening components of the yield- and ultimate-tensile-strength calculations for different products employing equations (T-40) through (T-44). 
A relatively good characterization of the effect of various parameters on the impact transition temperature can be obtained from the equation of Gladman et al. [1], which is given in table 18. The negative effect of the vanadium-carbonitride precipitates on the impact transition temperature can be estimated by assuming a linear dependence of impact transition temperature on the precipitation-related increases in yield strength, with the constant equal to 0.22 .

\subsection{A Eutectoid Steel}

The mean true interlamellar spacing $S_{0}$ is the most important parameter affecting the strength properties of the pearlite microstructure. Traditionally, a Hall-Petch type of relationship is used to characterize the effect of this parameter on the yield and ultimate tensile strengths. However, in this study, we took an approach suggested by Dollar et al. [22], in which the yield and ultimate tensile strengths correlate with $S_{0}{ }^{-1}$ instead of $S_{0}{ }^{-0.5}$. In the predictive equations, we used the mean free path for slip $M$ in the pearlitic ferrite to characterize strength instead of the mean true interlamellar spacing. To obtain the predictive equations for the yield and ultimate tensile strengths in fully eutectoid steels, a correlation analysis was based on results published in reference 9 , which were measurements of rails and bars (average of three specimens). In that study, different strengths were achieved by varying the chemical composition and cooling rate of the experimental materials during heat treatment. The best correlation was achieved with two sets of constants for small and large values of the mean free path for slip in the ferrite. This result can be associated with the different deformation mechanisms in fine and coarse pearlites [22]. The equations relating yield and ultimate tensile strengths to the mean free path for slip in the ferrite are given in table 21 .

Table 21. Equations for the yield and ultimate tensile strengths in eutectoid steels (Kuziak [9]).

$$
\text { For } \begin{aligned}
S_{0} \geq & 0.15 \mu m- \\
\sigma_{y} & =308+0.07 M^{-1} \\
\sigma_{u} & =706+0.072 M^{-1}+122(\% \mathrm{Si})
\end{aligned}
$$

For $S_{0}<0.15 \mu m-$

$$
\begin{aligned}
& \sigma_{y}=259+0.087 M^{-1} \\
& \sigma_{u}=773+0.058 M^{-1}+122(\% \mathrm{Si})
\end{aligned}
$$

where $M=2\left(S_{0}-t\right) ; t=0.15 S_{0}(\% \mathrm{C})$ in micrometers 


\section{Laboratory Experimental Validation of the Microstructural Evolution Models}

\subsection{Laboratory Experiments and the Linkage to the Finite-Element Codes}

Mathematical models for static, dynamic, and metadynamic recrystallization and for grain growth after recrystallization were used in computer-simulated thermomechanical processing of the experimental steels. The computational procedure is described in figure 18. At the beginning of the calculation, strain is checked. If the strain has reached the critical value for dynamic recrystallization, the volume fraction of recrystallized material is calculated. (This fraction is assumed to recrystallize metadynamically after deformation. The rest of the deformed material is assumed to recrystallize statically.) If the critical strain is not reached, static recrystallization prevails throughout the material after deformation. The pause between consecutive deformations may not be long enough for complete recrystallization; in this case, the retained strain is calculated from the predicted volume fraction of recrystallized material by using equation [12],

$$
\varepsilon_{r}^{i}=[1-X(t)] \varepsilon_{i-1},
$$

where $\varepsilon_{i-1}$ is the total strain imposed on a specimen during the previous deformation and $X(t)$ is total volume recrystallized by different mechanisms. To calculate microstructural evolution, the retained strain is added to the current strain imposed on a specimen. At high temperatures and after long intervals between deformations, the recrystallization processes will be complete; in this case, grain growth follows recrystallization. Therefore, recrystallization kinetics are essential in the control of grain size during processing.

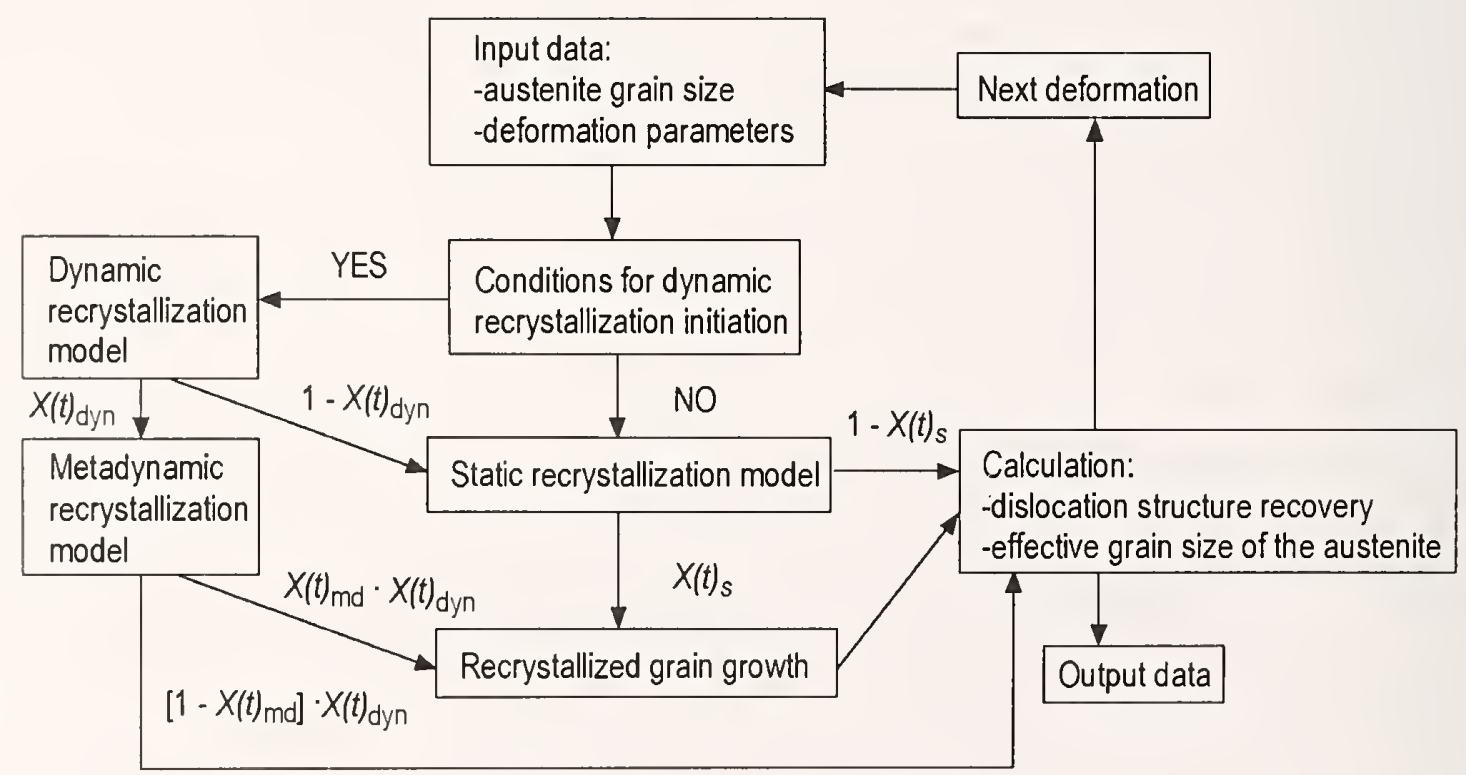

Figure 18. Procedure for calculating microstructural evolution during thermomechanical processing of the experimental steels. 
The computational procedure described in this section was verified in laboratory experiments conducted in the dilatometer that simulated thermomechanical processing. We used a commercial program to calculate strain, strain rate, and temperature distributions in the deformed specimens during the simulations [4]. Then, from these parameters, we used a specially developed computer program coded in FORTRAN77 and based upon the procedure shown in figure 18 to calculate the austenite microstructural evolution.

Experiments were conducted to evaluate the model predictions. In this section, mechanicalproperty values represent the average of three to four specimens. Microstructural parameters are the average of about 200 measurements of one specimen. The data included from reference 9 represent the average of three specimens. The results of this study and another by Kuziak [9] on the eutectoid steel confirmed the good predictive capability of the computational procedure described in this section.

For illustration, we discuss an experiment in which the C-Mn and VT steels were deformed twice; some details of the experiment are given in table 22. The model-predicted and measured changes in the austenite grain size (average of three specimens) in the central region of the deformed specimens are compared in figures 19 and 20.

For further experiments (section 7), this procedure was incorporated into the FEM codes for rolling flats, plates, rods, and rails. Metal flow in these codes was calculated by using the general plain-strain approach [22,23]. A solution was obtained for a rigid-plastic body [23] that obeys the Levy-Mises flow rule. Effective stress was calculated from flow curves developed for the experimental steels in compression experiments, which were conducted in a hydraulic-pressbased hot-deformation apparatus and in the dilatometer. The nonuniformity of plastic deformation was corrected by using an inverse method [24]. We obtained a mathematical description of flow behavior in the experimental steels from the Voce equation [6] by using the constants given in table 23. Only one form of the Voce equation (specified in table 23) was used in the FEM calculation. The effect of dynamic recrystallization was included automatically during the calculation, because this effect is directly related to the volume fraction of recrystallized material. [25]:

The real velocity field in the FEM calculation was determined by optimizing this equation

$$
W=\int_{V} \sigma_{i} \dot{\varepsilon}_{i} d V+\lambda \int_{V} \nabla v d V+\int_{S} \tau_{f}|v| d S,
$$

Table 22. Characterization of the two-deformation experiment conducted in the dilatometer on C-Mn and VT steel specimens.

\begin{tabular}{cccc}
\hline Reheating & First deformation & Second deformation & $\begin{array}{c}\text { Cooling rate between } \\
\text { deformations }\end{array}$ \\
\hline \multirow{3}{*}{$1150^{\circ} \mathrm{C}$ for $10 \mathrm{~min}$} & $T_{d}=1000^{\circ} \mathrm{C}$ & $T_{d}=950^{\circ} \mathrm{C}$ & \\
& $\varepsilon=0.29$ & $\varepsilon=0.32$ & $1{ }^{\circ} \mathrm{C} / \mathrm{s}$ \\
& $\dot{\varepsilon}=2.2 \mathrm{~s}^{-1}$ & $\dot{\varepsilon}=2.7 \mathrm{~s}^{-1}$ & \\
\hline
\end{tabular}




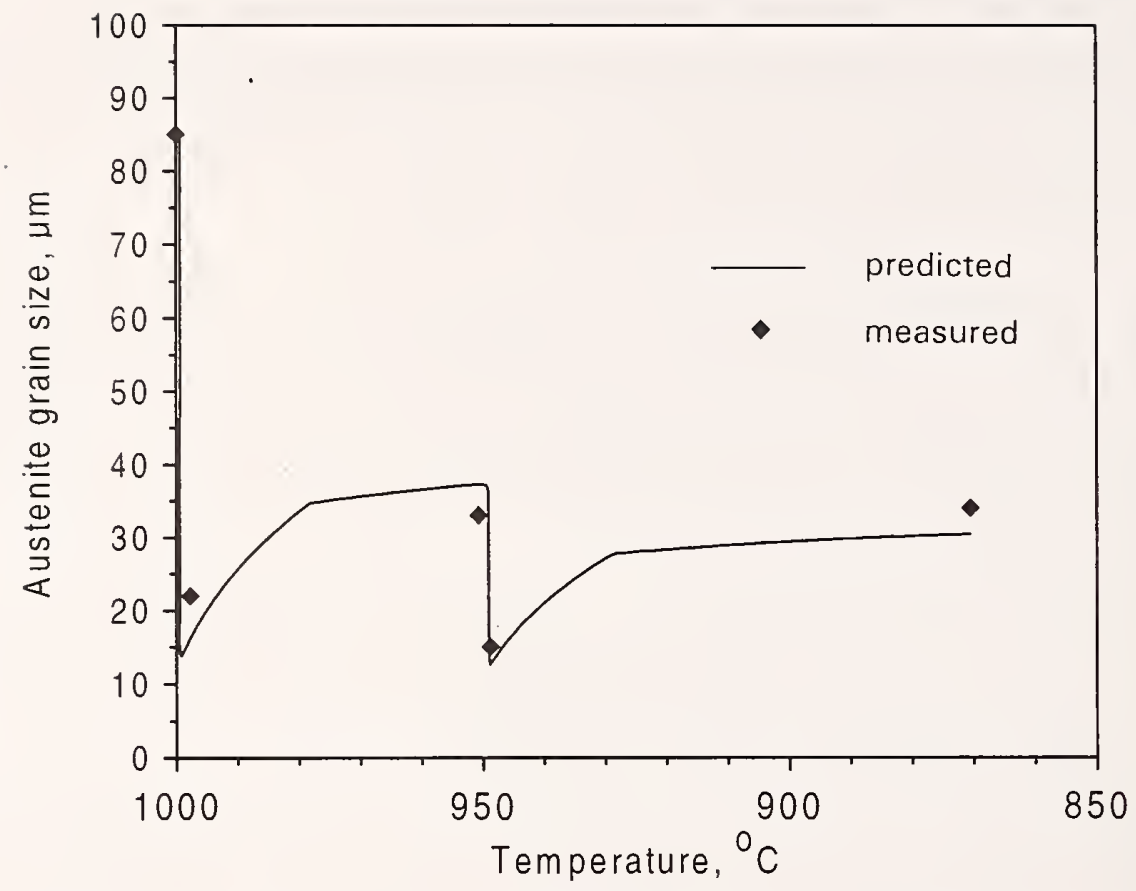

Figure 19. Austenite grain size in the $\mathrm{C}-\mathrm{Mn}$ steel specimen center during the two-deformation experiment compared with predicted values $\left(D_{0}=85 \mu \mathrm{m}\right)$.

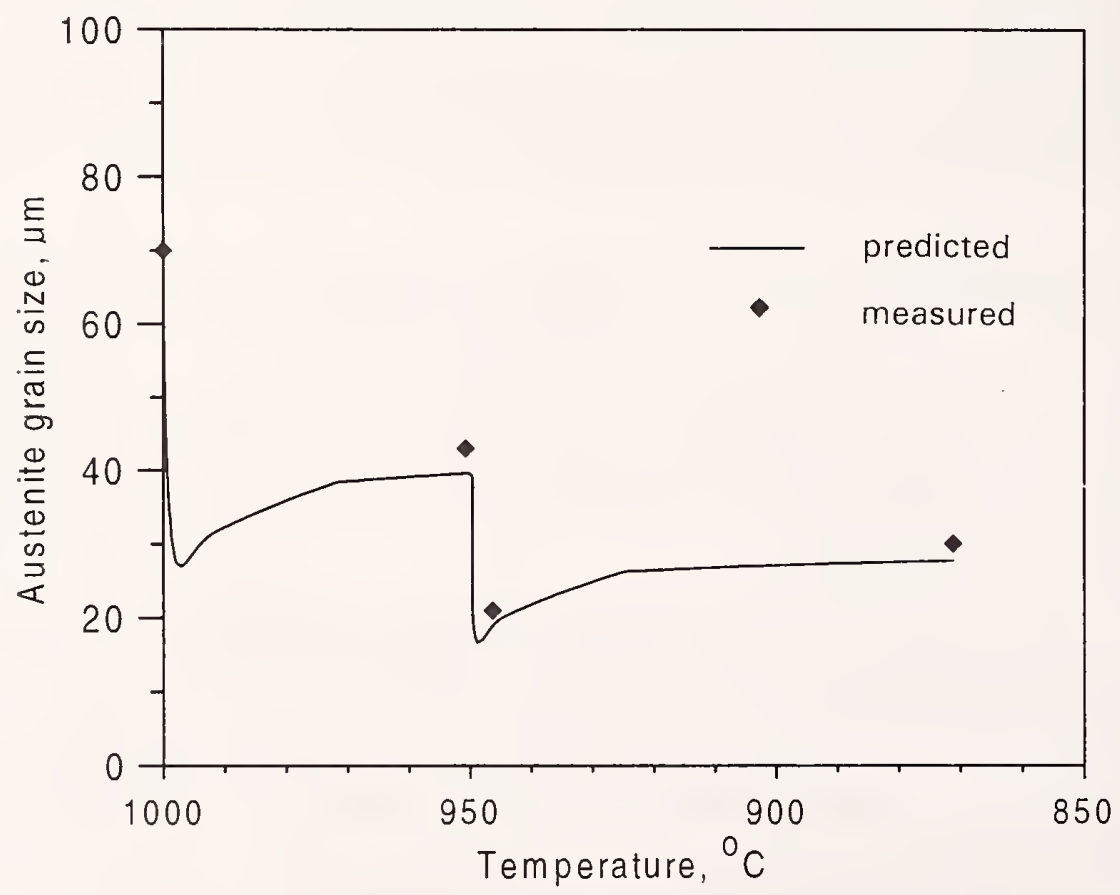

Figure 20. Austenite grain size in the VT steel specimen center during the two-deformation experiment compared with predicted values $\left(D_{0}=72 \mu \mathrm{m}\right)$. 
where $\lambda$ is a penalty coefficient, $|v|$ is the relative velocity at the tool-material interface, $S$ is the boundary surface, $\tau_{f}$ is the vector of boundary traction, and $V$ is the control volume.

The temperature field in a deformed material was calculated by employing the FEM solution of the general heat-transfer equation

$$
\nabla^{T}(\kappa \nabla T)+Q=C_{P} \rho \frac{\partial T}{\partial t}
$$

where $\mathrm{\kappa}$ is the material's thermal conductivity, $Q$ is heat generated during deformation, $C_{P}$ is specific heat, and $\rho$ is density.

The microstructural evolution models developed in this study were validated during the course of the laboratory experiments. Described below are the main results obtained from the press-compression and flat-rolling experiments.

Table 23. Voce equations [6] for the stress-strain curves of the experimental steels.

$$
\begin{aligned}
& \text { For C-Mn steel- } \\
& \begin{aligned}
\sigma(\varepsilon)=\sigma_{0}[1-\exp (-9.1 \varepsilon)]^{0.32} \\
\sigma_{0}=1.35 Z^{0.3}
\end{aligned} \\
& \text { For VT steel- } \\
& \begin{aligned}
\sigma(\varepsilon)=\sigma_{0}[1-\exp (-7 \varepsilon)]^{0.4} \\
\sigma_{0}=1.5 Z^{0.4}
\end{aligned} \\
& \text { For } 900 \text { A eutectoid steel- } \\
& \sigma(\varepsilon)=\sigma_{0}[1-\exp (-3.4 \varepsilon)]^{0.27} \\
& \sigma_{0}=1.84 Z^{0.14}
\end{aligned}
$$

\subsection{Press Compression of Carbon-Manganese Steel}

\subsubsection{Experimental Procedures}

Cylindrical specimens, $60 \mathrm{~mm}$ in diameter and $90 \mathrm{~mm}$ long, were machined from hotrolled billets of steel whose chemical composition is given in table 24 . The aspect (height-todiameter) ratio was kept at 1.5 to promote homogeneous deformation. All specimens were heated to $1175^{\circ} \mathrm{C}$, held at this temperature for $20 \mathrm{~min}$, air-cooled to the testing temperature, and then subjected to two-deformation experiments conducted by compression in a $100-\mathrm{kN}$ hydraulic press. During compression, a nearly constant strain rate of $0.2 \mathrm{~s}^{-1}$ was maintained. The initial austenite grain size resulting from the reheating procedure was $160 \mu \mathrm{m}$. Temperature changes during experiments were monitored with thermocouples mounted in the drilled hole; the tips of the thermocouples coincided with the centers of the specimens. 
Figure 21 shows (schematically) the processing schedule employed in the experiment. The first deformation was applied at $1050^{\circ} \mathrm{C}$. Following the deformation, the specimens were placed in still air and allowed to cool to the temperature of the second deformation $(820,720$, or $650^{\circ} \mathrm{C}$ ). Deformations at 720 and $650^{\circ} \mathrm{C}$ were performed in the two-phase region of the $\mathrm{Fe}-\mathrm{C}$ equilibrium system. In the second deformation, homogeneous strains were also varied.

After the experiment, the specimens were sectioned, and the yield strength, ultimate tensile strength, reduction in area, elongation, and hardness were measured in the central regions of the specimens.

Table 24. Chemical composition (mass percent) of the cylindrical specimens compressed in the hydraulic press.

\begin{tabular}{cccccc}
\hline $\mathrm{C}$ & $\mathrm{Mn}$ & $\mathrm{Si}$ & $\mathrm{P}$ & $\mathrm{S}$ & $\mathrm{N}$ \\
\hline 0.21 & 1.37 & 0.28 & 0.033 & 0.021 & 0.0065 \\
\hline
\end{tabular}

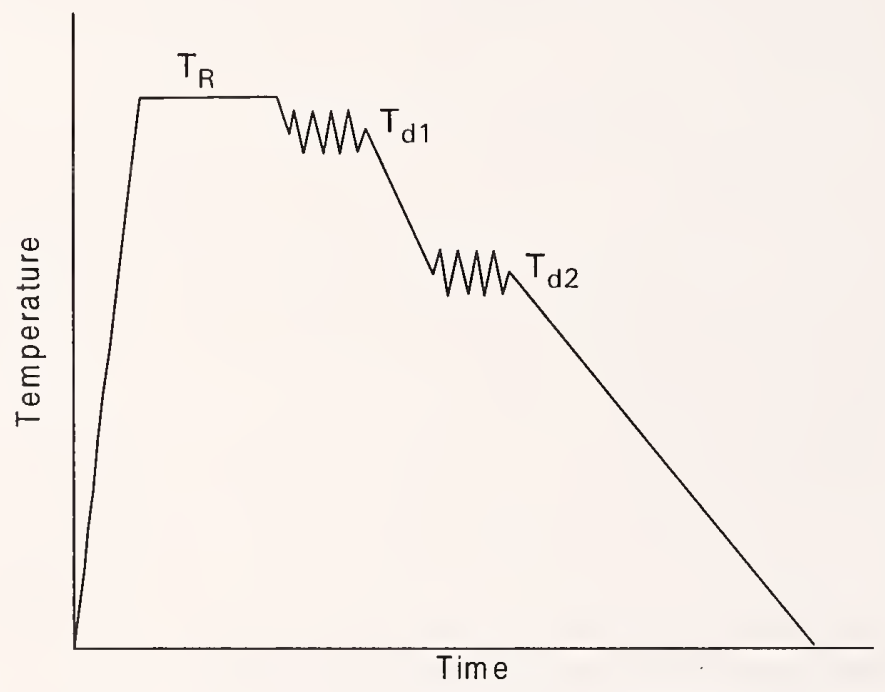

Figure 21. Schematic of the two-deformation experiment conducted on the hydraulic press: $T_{R}=1175^{\circ} \mathrm{C}$ for $20 \mathrm{~min} ; T_{d 1}=1050^{\circ} \mathrm{C} ; T_{d 2}=820,720$, or $650^{\circ} \mathrm{C}$. Reduction range: 1 st stage $=0.35 ; 2$ nd stage $=0.2,0.5,0.8$. 


\subsubsection{Thermomechanical Behavior during Compression}

The thermomechanical part of the modeling is based on a coupled FEM solution of the rigid-plastic-flow formulation and general heat-transfer equation describing the temperature field in the deformation zone. We used a commercial program [4] to calculate the temperature, strain, and strain-rate distribution, together with the microstructural evolution, during the two-stage deformation. Measured cooling curves, such as that in figure 22, and the profile of the specimens after deformation were used to estimate the boundary conditions and friction coefficient during the deformation.

An example of the calculated temperature and strain distributions after the second deformation is shown in figure 23. As expected, in the compression experiment, severe variations in the deformation conditions resulted from rapid heat transfer to the dies. Such thermomechanical behavior significantly affects microstructural evolution in both the austenite and the ferrite regions. This feature of the process, specifically the calculated austenite grain-size distribution after the first deformation at $1050^{\circ} \mathrm{C}$, is shown in figure 24 .

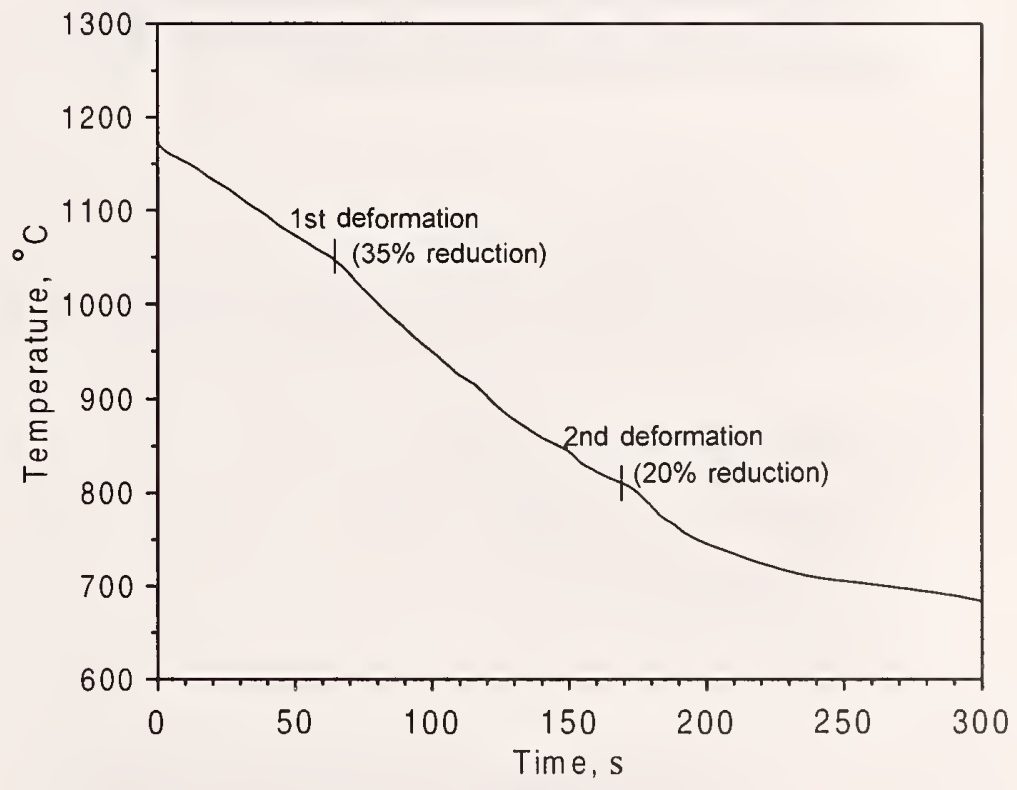

Figure 22. Cooling curve recorded by a thermocouple located at the center of the cylindrical C-Mn specimen subjected to the two-step deformation schedule in the hydraulic press. 
(a)

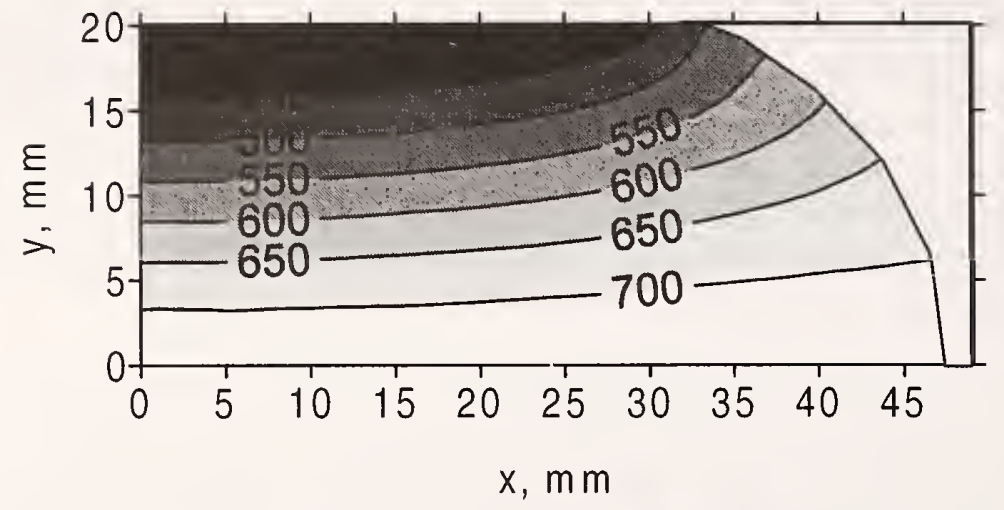

(b)

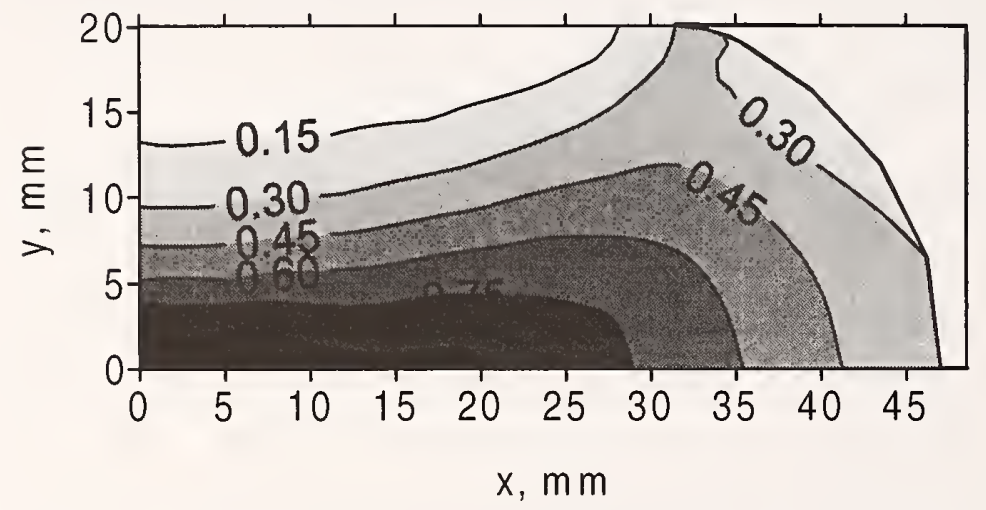

Figure 23. Calculated distribution of (a) temperature and (b) effective strain on a cross section of the cylindrical specimen after the second deformation.

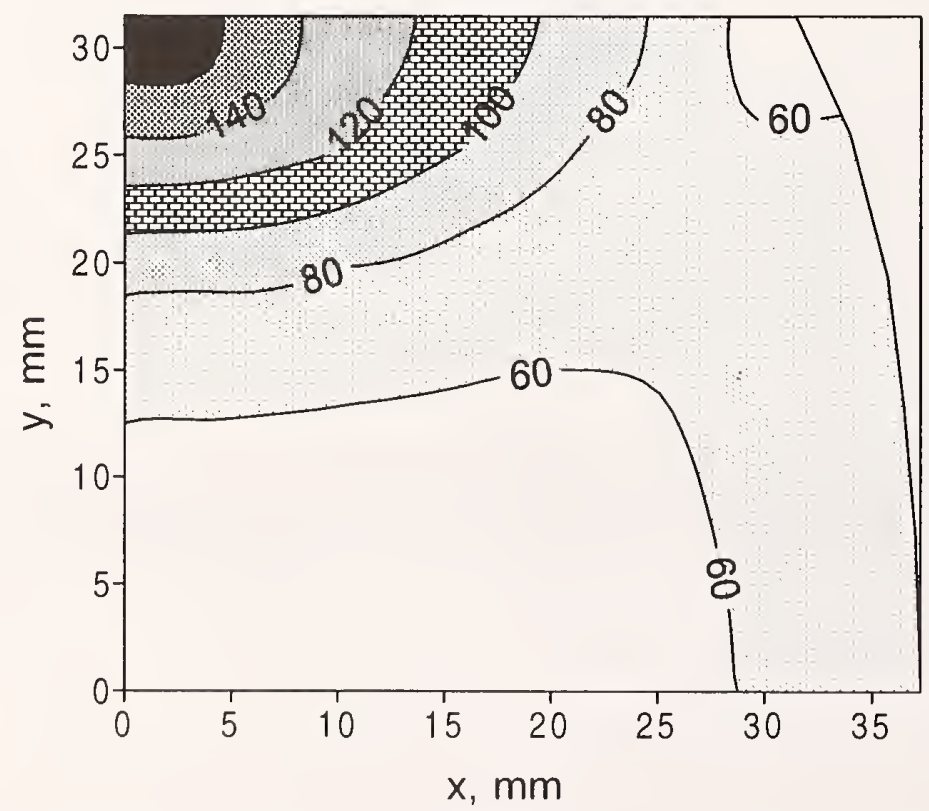

Figure 24. Calculated distribution of the austenite grain size (in micrometers) after the first deformation of the cylindrical specimen at $1050^{\circ} \mathrm{C}$. 


\subsubsection{Effect of Processing Conditions on the Mechanical Properties}

From the results of the present investigation, we constructed a quantitative description of the strengthening mechanisms operating in the steels. After deformation in the austenite region and the subsequent phase transformation, the dislocation density in the ferrite structure is relatively low. However, deformation in the two-phase region results in a significant increase in the dislocation densities in the ferrite grains. The contribution of dislocations to the strengthening is very complex; usually it is caused by interactions between the forest and mobile dislocations and the substructure. An example of the correlation between the accumulated strain in the ferrite region and hardness is presented in figure 25. The contribution of dislocations to the strengthening at a specific temperature is described by equation [26]

$$
\sigma_{d}=\alpha G b \rho_{g}^{0.5}
$$

where $\alpha$ is a constant, $G$ is shear modulus, $b$ is Burgers vector, and $\rho_{g}$ is forest-dislocation density. Since dislocation measurements are tedious and often inaccurate, an approach developed by Majta et al. [27] was adopted in this study. Based upon results published elsewhere [28], the correlation between dislocation density and the deformation temperature was found to be

$$
\rho_{d}=\rho_{0} \mathrm{~B} \exp \left(\varepsilon_{a}-1\right)\left(\frac{\mathrm{A}}{\mathrm{FDT}}\right)^{\mathrm{s}},
$$

(a)

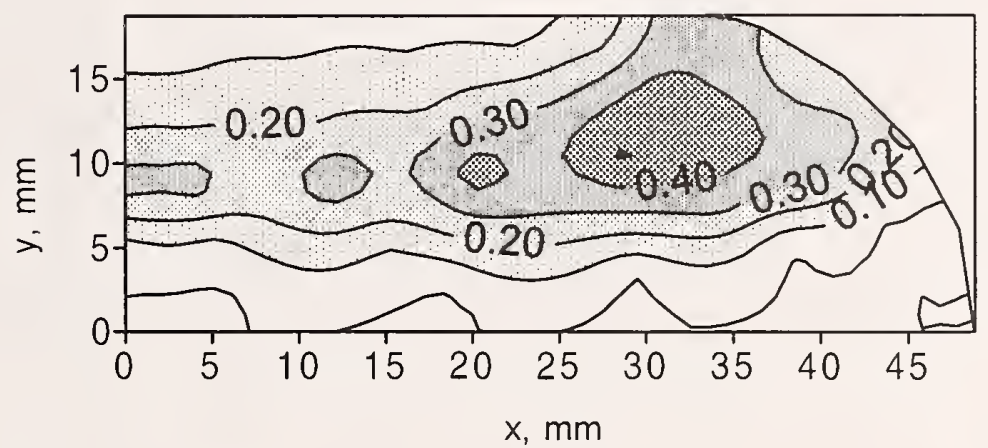

(b)

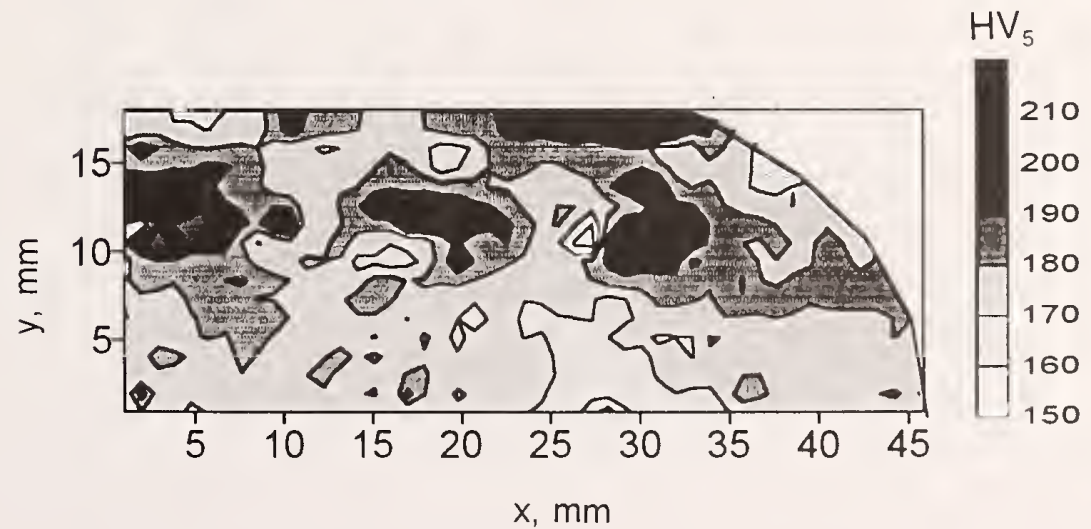

Figure 25. Comparison of (a) the computed effective strain in the ferrite phase and (b) the measured hardness distribution. 
where A, B, and s are constants, $\rho_{0}$ is initial dislocation density, FDT is the finish deformation temperature, and $\varepsilon_{a}$ is the strain retained in the microstructure after deformation. From published data [28], we inferred that the best fit to the observed experimental data could be obtained when $\mathrm{A}=1030, \mathrm{~B}=1.8$, and $\mathrm{s}=8.8$ and when we assumed $\rho_{0}=10^{10} / \mathrm{m}^{2}$. Although the applicability range of eq (10) is limited, it does correlate well with experimental data published in the literature.

The yield-strength predictions for the deformation condition used in the experiment were obtained by calculating the structure-related yield strength and the dislocation-related component of yield strength. Next, we calculated total yield strength using the root-sum-of-squares method [29]:

$$
\sigma_{\mathrm{tot}}=\left(\sigma_{s}^{2}+\sigma_{d}^{2}\right)^{\frac{1}{2}} .
$$

The results of the tensile test are shown in table 25 and are compared with the predicted results in table 26. A good correspondence between the experimental and predicted data was obtained for most of the deformation schedules.

Table 25. Measured mechanical properties and microstructural parameters at the center of the press-compressed specimens whose chemical composition is given in table 24 .

\begin{tabular}{ccccccccc}
\hline No. & $\begin{array}{c}T_{d 2}, \\
{ }^{\circ} \mathrm{C}\end{array}$ & $\begin{array}{c}\text { Strain } \\
\text { at } T_{d 2}\end{array}$ & $\begin{array}{c}D_{\alpha}, \\
\mu \mathrm{m}\end{array}$ & $f_{\alpha}$ & $\begin{array}{c}S_{0}, \\
\mu \mathrm{m}\end{array}$ & $\begin{array}{c}\sigma_{y}, \\
\mathrm{MPa}\end{array}$ & $\begin{array}{c}\sigma_{u}, \\
\mathrm{MPa}\end{array}$ & $\mathrm{HV}_{5}$ \\
\hline 1 & & 0.5 & 16.9 & 0.69 & 0.17 & 375 & 580 & 197 \\
2 & 820 & 1.1 & 10.5 & 0.69 & 0.18 & 390 & 587 & 190 \\
3 & & 1.6 & 8.70 & 0.67 & 0.15 & 405 & 601 & 177 \\
4 & & 0.5 & 12.1 & 0.63 & 0.16 & 390 & 584 & 199 \\
5 & 720 & 1.1 & 8.40 & 0.69 & 0.15 & 401 & 586 & 185 \\
6 & & 1.6 & 7.60 & 0.64 & 0.15 & 479 & 604 & 218 \\
7 & & 0.5 & 7.00 & 0.69 & 0.16 & 425 & 599 & 195 \\
8 & 650 & 1.1 & 6.80 & 0.64 & 0.16 & 410 & 590 & 205 \\
9 & & 1.6 & 5.80 & 0.68 & 0.14 & 502 & 620 & 208 \\
\hline
\end{tabular}


Table 26. Comparison of measured (table 25) and calculated yield strengths in the compressed specimens.

\begin{tabular}{|c|c|c|c|c|c|c|}
\hline \multirow{4}{*}{$\begin{array}{l}\text { Effective } \\
\text { strain in } \\
\text { 2nd stage }\end{array}$} & \multicolumn{6}{|c|}{ Temperature of the second deformation, ${ }^{\circ} \mathrm{C}$} \\
\hline & \multicolumn{2}{|c|}{820} & \multicolumn{2}{|c|}{720} & \multicolumn{2}{|c|}{650} \\
\hline & \multicolumn{6}{|c|}{$\sigma_{y}, \mathrm{MPa}$} \\
\hline & measured & calculated & measured & calculated & measured & calculated \\
\hline 0.5 & 375 & 354 & 390 & 392 & 425 & 473 \\
\hline 1.1 & 390 & 391 & 401 & 427 & 410 & 495 \\
\hline 1.6 & 405 & 401 & 479 & 456 & 502 & 528 \\
\hline
\end{tabular}

\subsubsection{Effect of Processing Conditions on Microstructure}

The microstructural parameters measured by means of metallography are presented in table 25. The most interesting results of our experiment relate to the deformation in the twophase region. The ferrite-transformation starting temperature, as calculated and observed in the experiment, was in the range 710 to $735^{\circ} \mathrm{C}$. Since the strain and cooling rates in the specimens were kept constant, the amount of strain retained in the ferrite increased as the deformation temperature decreased. Figure 26 shows a calculated distribution of retained strain in ferrite after deformation at $650^{\circ} \mathrm{C}$. Inhomogeneity in plastic deformation and temperature resulted in the nonuniform distribution of the retained strain. Increasing the amount of deformation before and after the transformation start temperature causes grain refinement, but to different levels and by different mechanisms. The evolution of the ferrite-pearlite microstructure in deformed specimens is shown as a function of effective strain in figure 27.

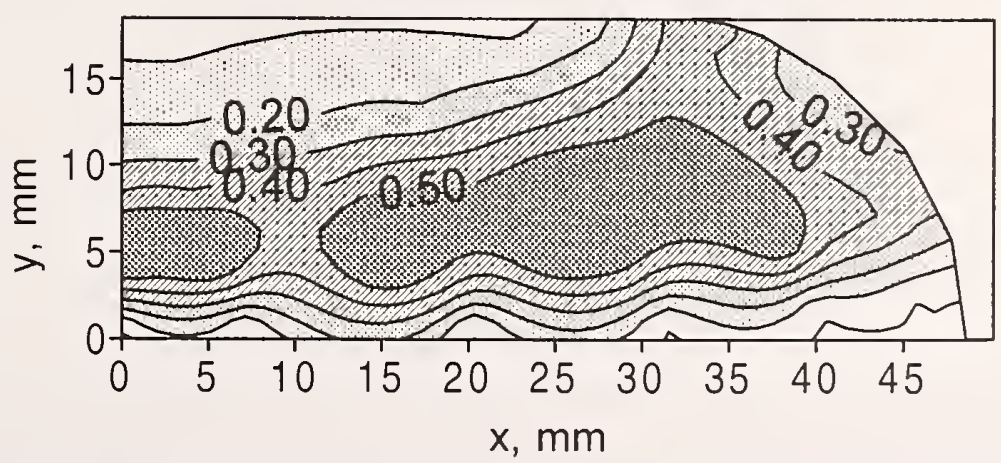

Figure 26. Calculated distribution of the retained strain concentrated in the ferrite after the second deformation at $650^{\circ} \mathrm{C}$. 
The microstructures of the specimens are significantly diverse; thus, inhomogeneity in the plastic deformation. which is caused by increasing total reduction, plays an important role in the microstructural evolution during diffusional transformations. Figure $27 \mathrm{c}$ clearly shows significant ferrite grain refinement in the slip bands. From transmission-electron microscopy, we learned that dislocation density increased significantly in 20 to 30 percent of the ferrite grains of specimens deformed near the transformation temperature. Nevertheless, most grains of these specimens are dislocation-free (fig. 28). As expected, high dislocation densities were observed in the ferrite grains in specimens deformed at lower temperatures. In specimens deformed at $650^{\circ} \mathrm{C}$, dislocation densities increased in about half the grains. This observation suggests that the evolution of dislocations during plastic deformation in the two-phase region should be included in the mechanical-properties model.

In the two-phase region, ferrite is softer than austenite. Thus, when the primary nucleated ferrite grains link to form a continuous layer at the austenite boundaries or deformation bands, deformation should concentrate in the ferrite. Strain has a strong effect on ferrite grain refinement at temperatures just below $A_{r 3}$. As shown elsewhere [26] and confirmed in the present work, at $650^{\circ} \mathrm{C}$ the ferrite occupies most of the available austenite grain-boundary area. Thus, the deformation of this microstructure should lead to longer, pancake-shape ferrite layers (with similar dimensions and volume fractions) at the austenite grain boundaries plus finer, straininduced ferrite grains at the ferrite-austenite interfaces. In the example shown in figure 29 , large ferrite grains are present in the specimens compressed at $820^{\circ} \mathrm{C}$. These grains were produced by transformation from statically recrystallized austenite. 
(a)

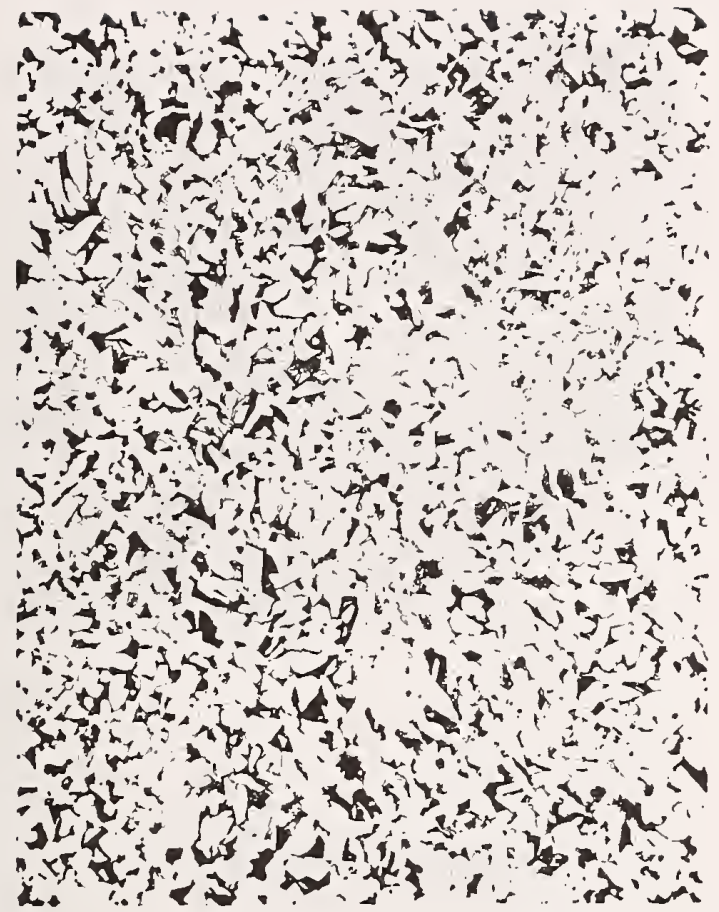

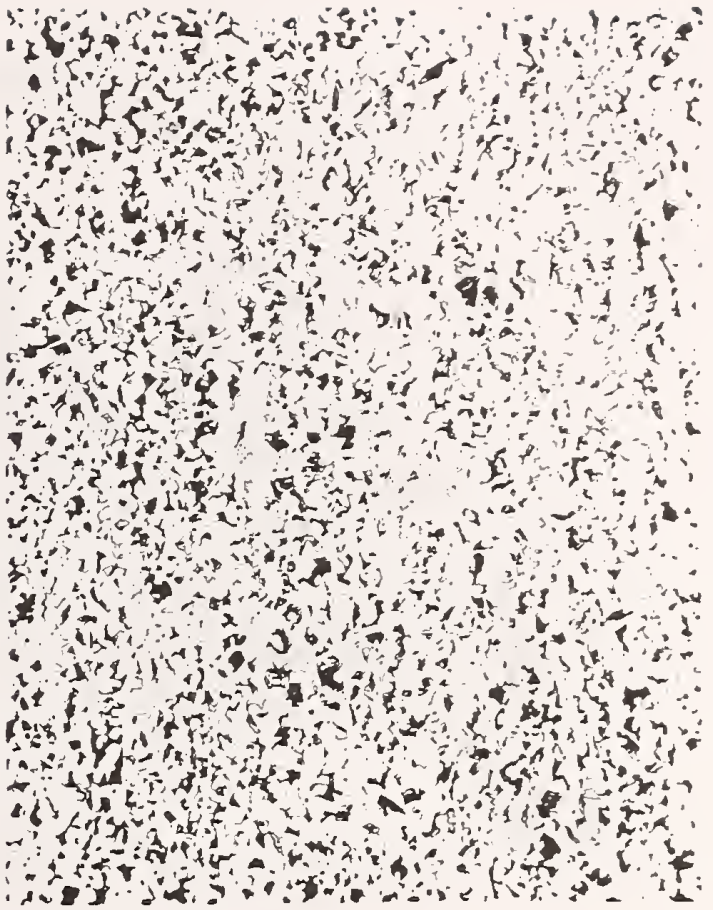

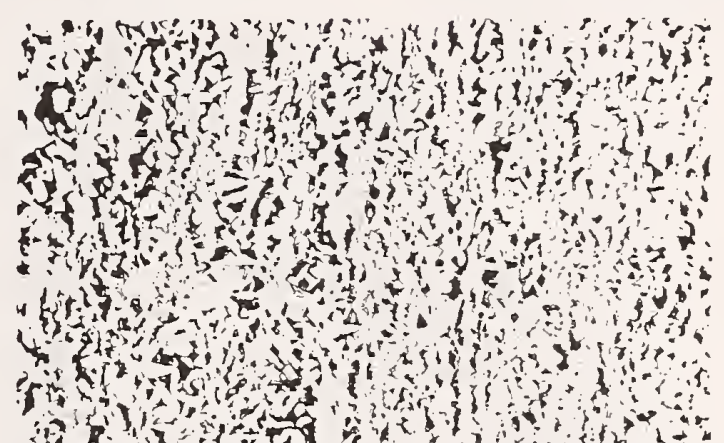

(c)

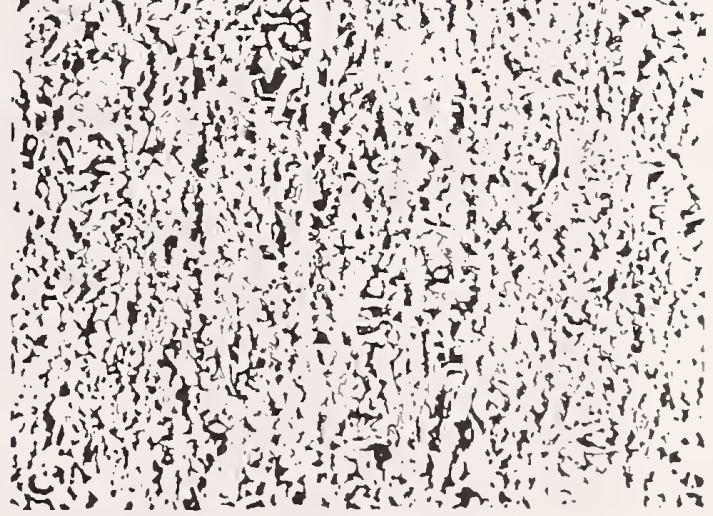

Figure 27. Ferrite-pearlite microstructures in the compressed cylinders with different amounts of deformation at $820^{\circ} \mathrm{C}$. (a) $\varepsilon=0.4$; (b) $\varepsilon=1.1$ : (c) $\varepsilon=1.6$ Light microscopy (100x). 
(a)

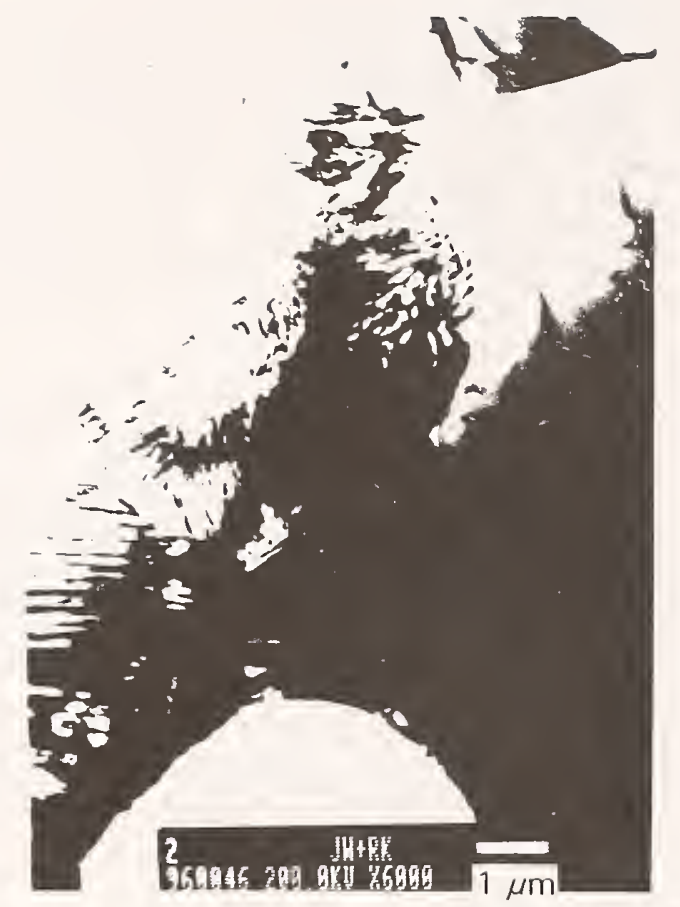

(b)
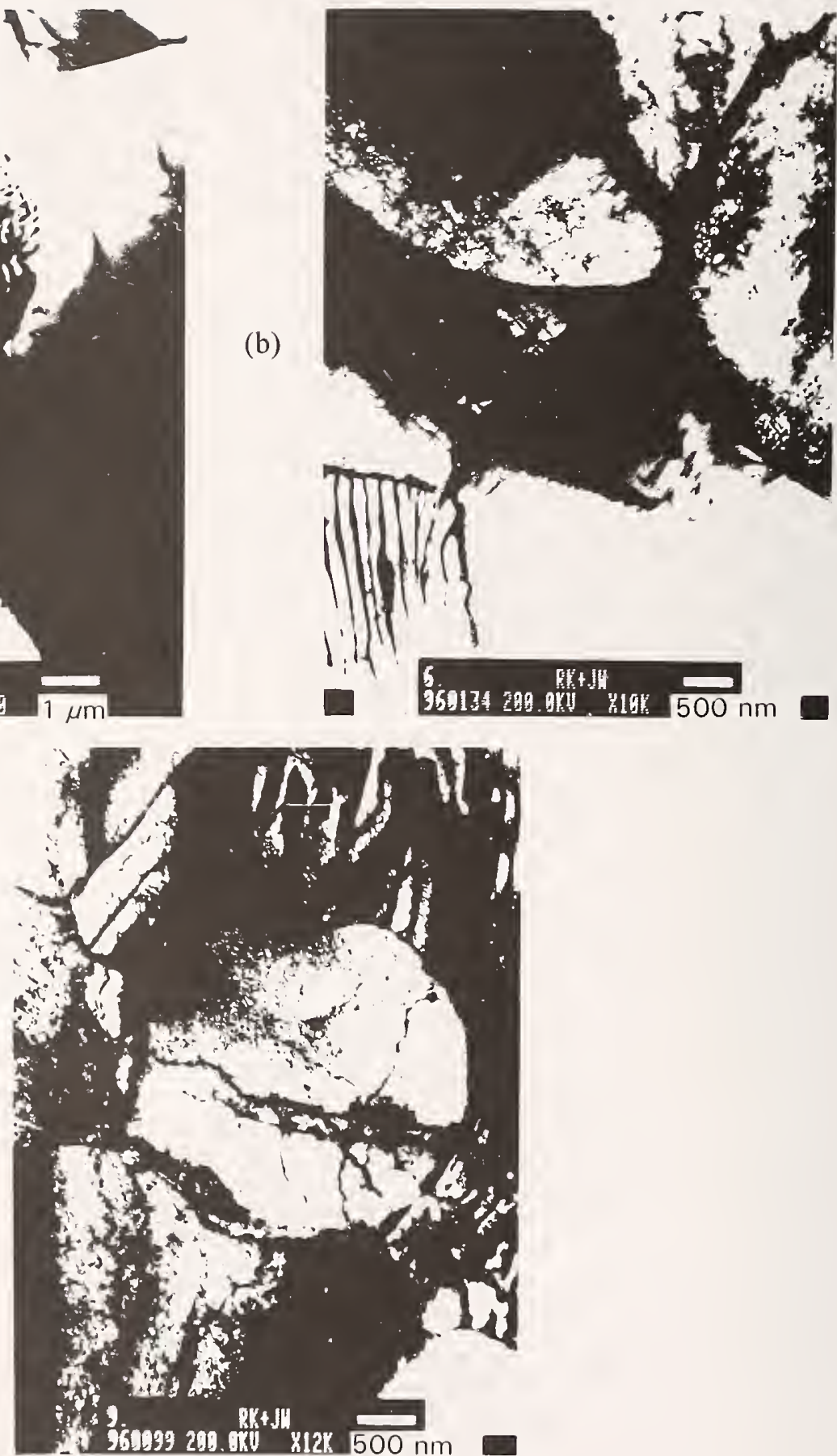

Figure 28. Transmission-electron micrographs of specimens deformed at different temperatures and strains: (a) $T_{d}=820^{\circ} \mathrm{C}, \varepsilon=0.4$; (b) $T_{d}=720^{\circ} \mathrm{C}, \varepsilon=1.1$; (c) $T_{d}=650^{\circ} \mathrm{C}, \varepsilon=1.6$. 
(a)

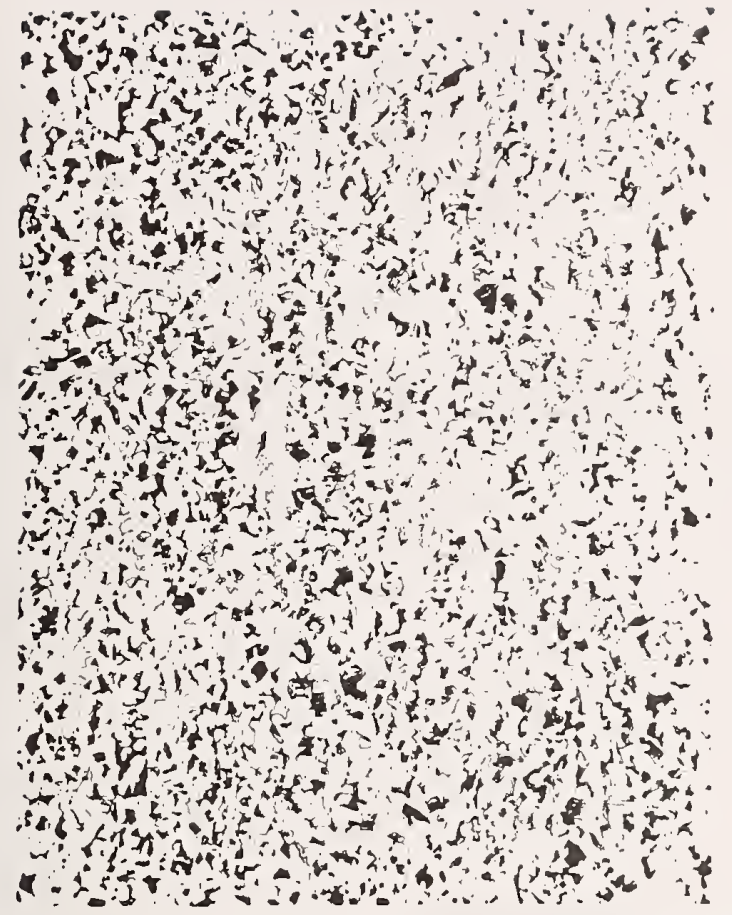

(b)

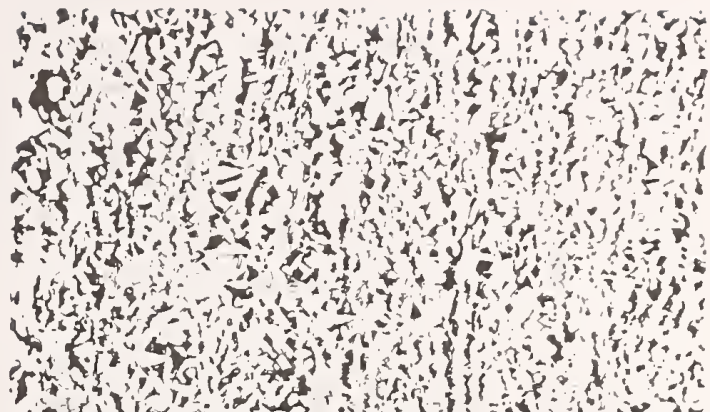

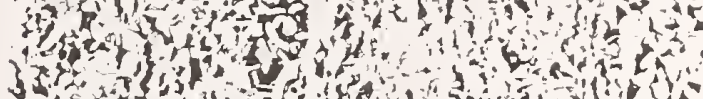
3. 73 ,

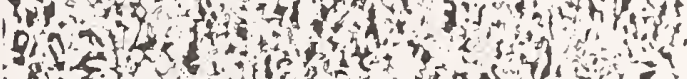
(3) F

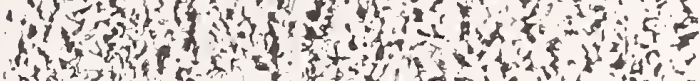

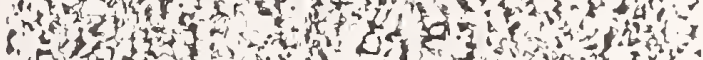
Thy of

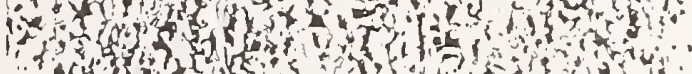

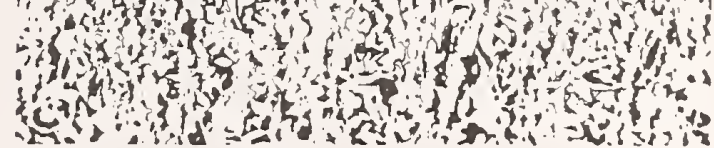

(c)

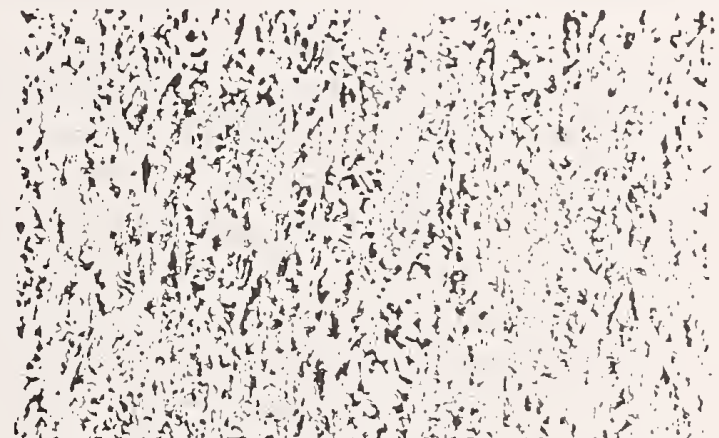

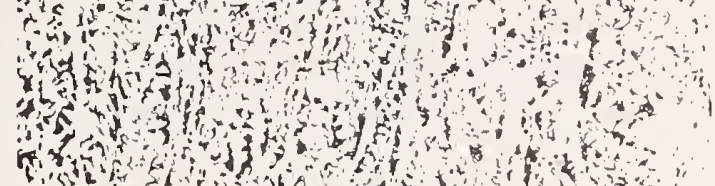

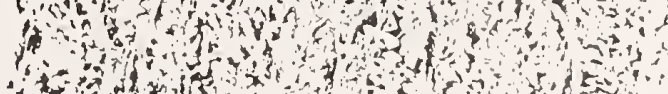

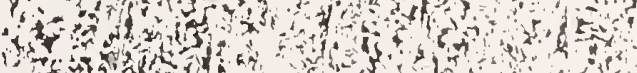

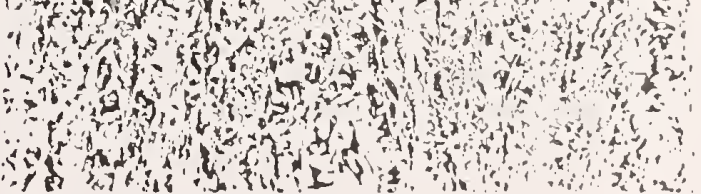

Figure 29. Microstuctures $(100 \times)$ obtained at different deformation temperatures: (a) $820^{\circ} \mathrm{C}$; (b) $720^{\circ} \mathrm{C}$; (c) $650^{\circ} \mathrm{C}$. After the second deformation, $\varepsilon=1.1$. 


\subsection{Forging of Vanadium-Treated Microalloyed Medium-Carbon Steel}

Over the last decade, microalloyed medium-carbon steels have become a cost-saving substitute for the quenched-and-tempered grades traditionally used to produce forged automotive components. However, their use is restricted to components that do not undergo excessive impact loading during service. The limitations of microalloyed forging steels are related to the specific morphological features of the ferrite-pearlite microstructure that can be modified only to a certain degree. Furthermore, the dispersion of fine precipitates that harden the ferrite matrix substantially lowers the ductility of forgings. Optimal properties depend on the complicated interaction between thermomechanical processing parameters and the chemical composition of the steel.

The severe service conditions for automotive components require steels with a combination of high strength and good ductility, which can be attained only by a high degree of microstructural refinement, well-balanced volume fractions, and a favorable distribution of the ferrite and pearlite phases. The pursuit of more economical processing and less microalloy consumption demands good control over the forging operations. The first step toward these goals is mathematical modeling of microstructural evolution during thermomechanical processing.

In this section, we give an example of our mathematical modeling to determine the processing routes that will achieve an optimal balance between the strength and toughness of forged steels.

\subsubsection{Experimental Procedures}

The chemical composition of the steel investigated in this study is given in table 27 . The material was a $100-\mathrm{kg}$ laboratory heat cast into $25-\mathrm{kg}$ ingots. With an industrial hydraulic press, as-cast ingots were forged into square bars and machined into blocks $55 \mathrm{~mm} \times 55 \mathrm{~mm}$ in cross section and $120 \mathrm{~mm}$ in length. During the experiment, the reheating temperature and time, forging starting temperature, and cooling rate after deformation were controlled. One deformation was applied to reduce the length of the blocks from 55 to $20 \mathrm{~mm}$. During the forging experiments, temperature changes were monitored with thermocouples inserted into drilled holes. The tips of the thermocouples coincided with the symmetrical center of the billets. The processing schedules are described in table 28. One variant of the forging schedules included accelerated cooling with pressurized air. Specimens for mechanical-property measurements and quantitative metallography were extracted from the forged blanks after cooling to ambient temperature. The mean-linear-intercept method was used to measure ferrite grain size and pearlite interlamellar spacing.

Table 27. Chemical composition (mass percent) of the VT medium-carbon steel selected for the forging experiment conducted with a hydraulic press.

\begin{tabular}{cccccccc}
\hline $\mathrm{C}$ & $\mathrm{Mn}$ & $\mathrm{Si}$ & $\mathrm{P}$ & $\mathrm{S}$ & $\mathrm{V}$ & $\mathrm{Al}_{\text {tot }}$ & $\mathrm{N}$ \\
\hline 0.29 & 1.42 & 0.38 & 0.023 & 0.015 & 0.14 & 0.035 & 0.014 \\
\hline
\end{tabular}


Table 28. Deformation schedules applied to the block specimens of the VT mediumcarbon steel (table 27) during simulation of forging on the hydraulic press.

\begin{tabular}{cccc}
\hline $\begin{array}{c}\text { Deformation } \\
\text { schedule }\end{array}$ & $\begin{array}{c}20 \text {-min } \\
\text { reheating temperature, } \\
{ }^{\circ} \mathrm{C}\end{array}$ & $\begin{array}{c}\text { Forging starting } \\
\text { temperature, } \\
{ }^{\circ} \mathrm{C}\end{array}$ & Cooling \\
\hline $\mathrm{A}$ & 1100 & 1050 & still air \\
$\mathrm{B}$ & 1200 & 1100 & still air \\
$\mathrm{C}$ & 1200 & 1150 & forced cooling at $1.5^{\circ} \mathrm{C} / \mathrm{s}$ \\
\hline
\end{tabular}

\subsubsection{Mathematical Modeling}

An interesting feature of the forging process was the possibility of initiating dynamic recrystallization in the central part of the deformed material. The substantial drop in temperature precludes dynamic recrystallization in the areas near the surface. However, since the critical strain for dynamic recrystallization $(\sim 0.21)$ is very small for deformation start temperatures, this process may initiate at the beginning of deformation.

The three deformation schedules used in the simulated-forging experiments (table 28) produced quite different changes in the specimen microstructures, which our mathematical model was able to predict fairly well. For illustration, the cooling curve obtained for schedule $\mathrm{A}$ is shown in figure 30 , and the calculated distributions of strain and temperature at the end of schedule B processing are shown in figure 31.

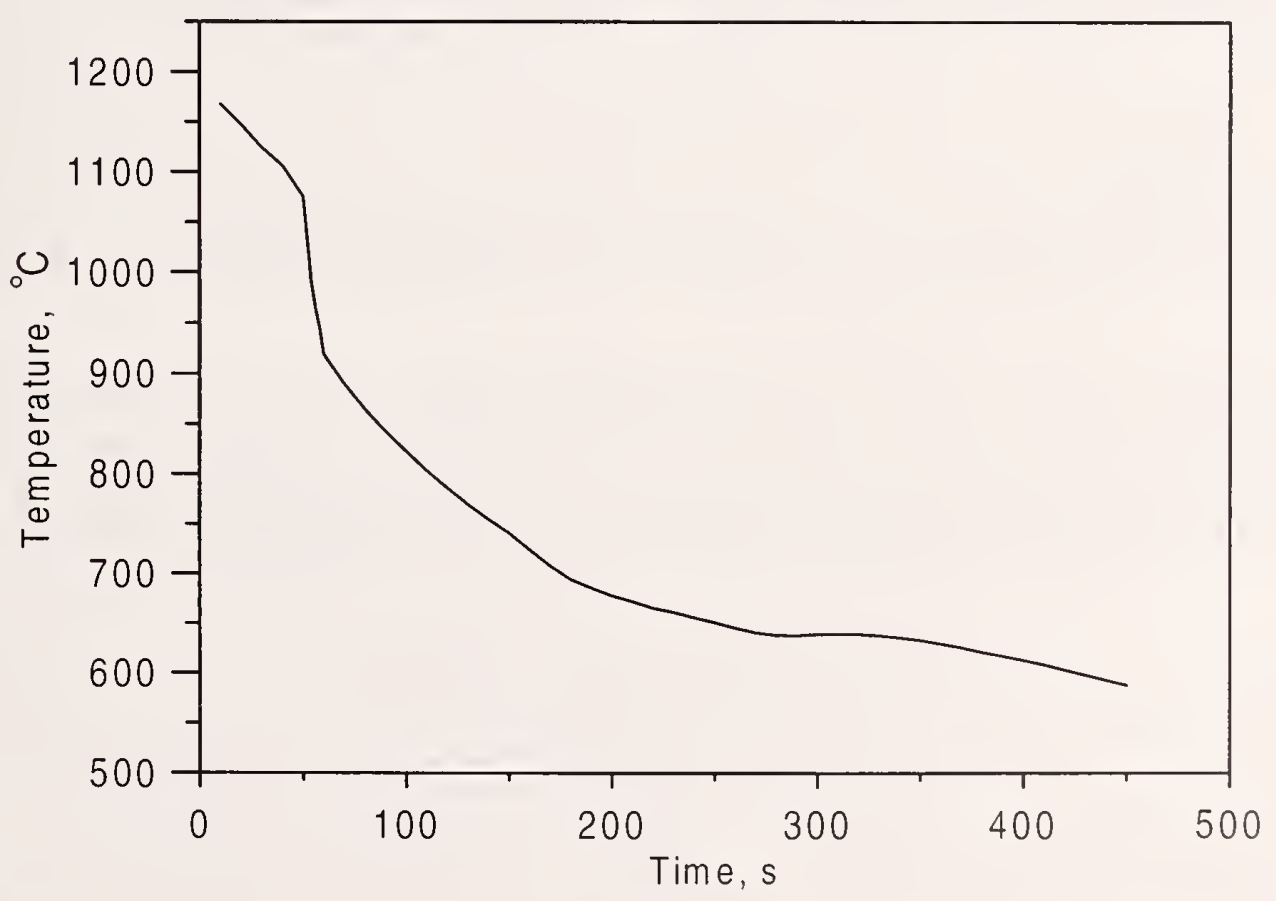

Figure 30. A cooling curve obtained during the forging experiment (schedule A). The thermocouple was mounted at the symmetrical center of the specimen. 

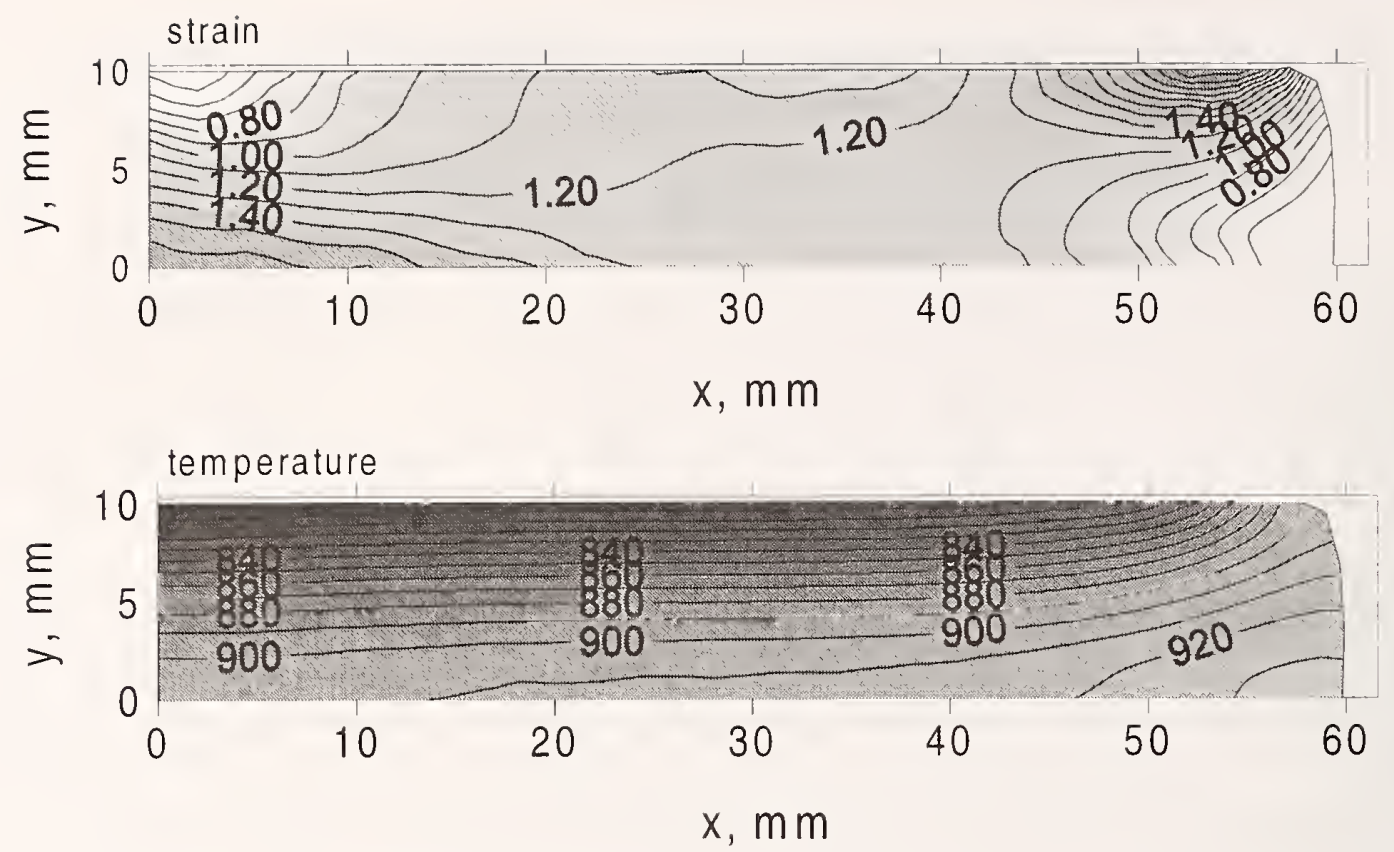

Figure 31. Finite-element calculation of the effective strain and temperature distribution in the specimen at the end of deformation (schedule B). Since the forging process is symmetrical, only one quarter of the specimen is shown.

The nonuniformity of deformation parameters in the processed material caused some inhomogeneity in the distribution of recrystallized grain size, which was maintained upon cooling to the transformation temperature (fig. 32). The initial austenite grain sizes used in the calculations shown in figure 32 were measured in specimens quenched after the reheating stage; the values were 40,180 , and $180 \mu \mathrm{m}$ for processing schedules $\mathrm{A}, \mathrm{B}$, and $\mathrm{C}$, respectively. The measured austenite grain sizes in the forged blanks prior to the transformation and the predicted values are compared in table 29. Predicted and measured microstructural parameters in the center of the forged blanks cooled to ambient temperature are compared in table 30 . To calculate the values, we used the relationships given in table 13. The corresponding ferrite-pearlite microstructures are shown in figure 33.

The capability of our equations to predict strength properties is demonstrated in table 31 . We used the commercial computer program to estimate the amount of vanadium and nitrogen soluble in the austenite at the reheating temperature, and their precipitation-strengthening contribution to yield strength and ultimate tensile strength were calculated from the equations in table 19. 
(a)

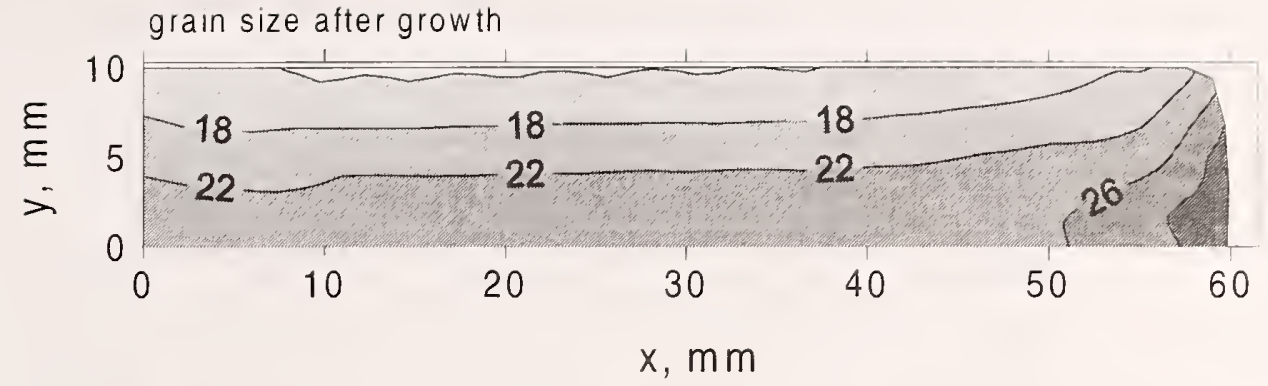

(b)

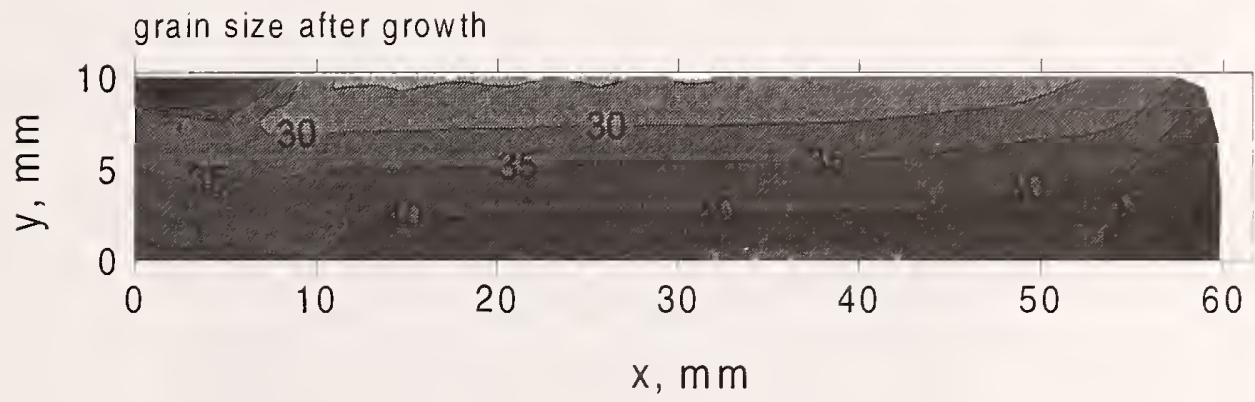

(c)

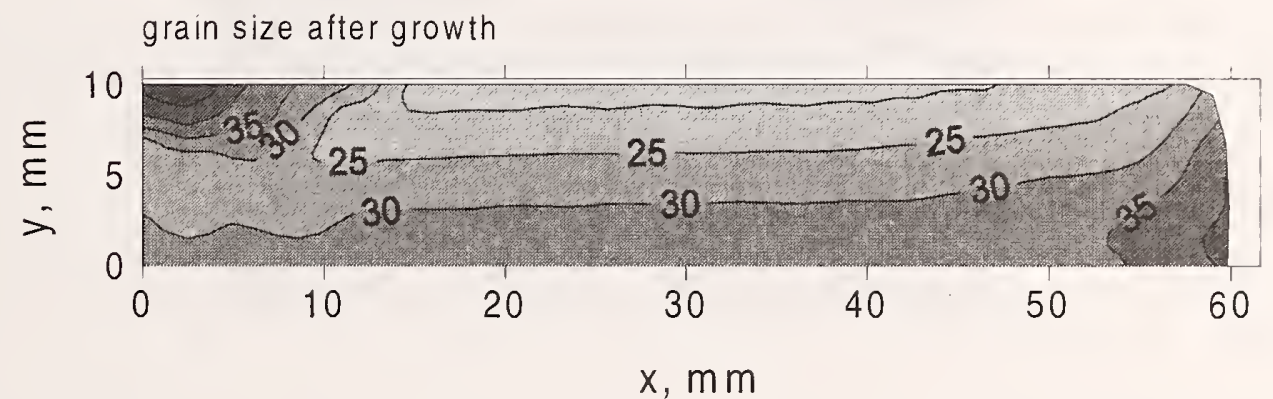

Figure 32. Calculated austenite grain-size distribution in the forged blanks after cooling to the transformation temperature.

Table 29. Comparison of the measured and predicted austenite grain sizes in the center of the forged blanks prior to transformation.

\begin{tabular}{ccc}
\hline \multirow{2}{*}{$\begin{array}{c}\text { Deformation } \\
\text { schedule }\end{array}$} & \multicolumn{2}{c}{ Austenite grain size, $\mu \mathrm{m}$} \\
\cline { 2 - 3 } & measured & predicted \\
\hline A & 25 & 22 \\
B & 33 & 30 \\
C & 43 & 40 \\
\hline
\end{tabular}


Table 30. Comparison of the measured and predicted parameters of the ferrite-pearlite microstructure in the center of the forged blanks after cooling to ambient temperature.

\begin{tabular}{ccccccc}
\hline \multirow{2}{*}{$\begin{array}{c}\text { Deformation } \\
\text { schedule }\end{array}$} & \multicolumn{2}{c}{ Microstructural parameters } \\
\cline { 2 - 7 } & \multicolumn{2}{c}{$f_{\alpha}$} & \multicolumn{2}{c}{$D_{\alpha}, \mu \mathrm{m}$} & \multicolumn{2}{c}{$S_{0}, \mu \mathrm{m}$} \\
\cline { 2 - 7 } & measured & predicted & measured & predicted & measured & predicted \\
\hline A & 0.57 & 0.59 & 9.20 & 7.3 & 0.162 & 0.165 \\
B & 0.50 & 0.56 & 10.5 & 8.5 & 0.159 & 0.165 \\
C & 0.42 & 0.43 & 8.70 & 6.0 & 0.147 & 0.132 \\
\hline
\end{tabular}

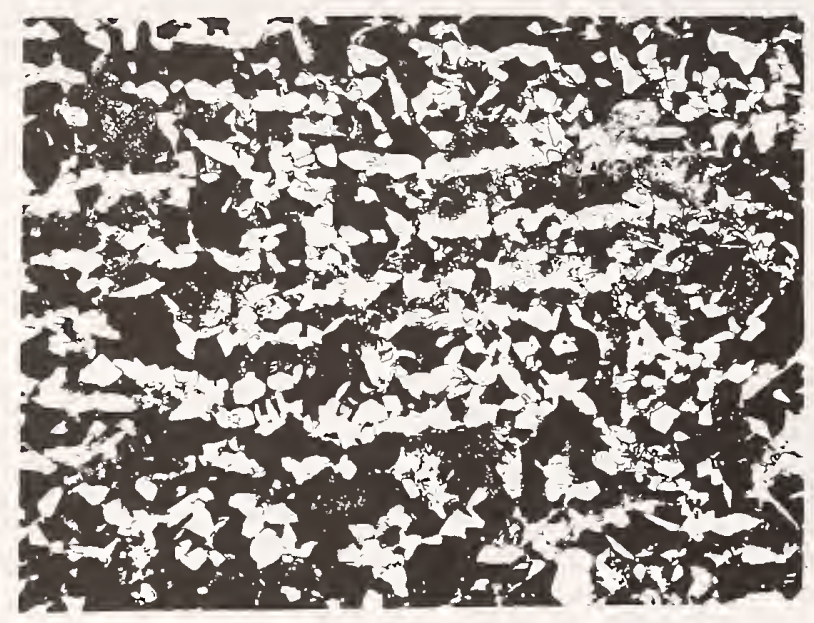

(a)

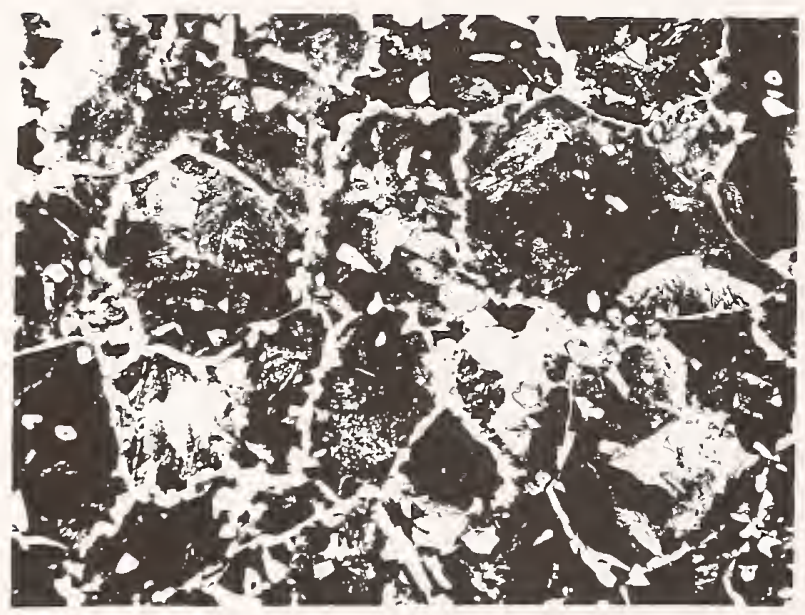

(b)

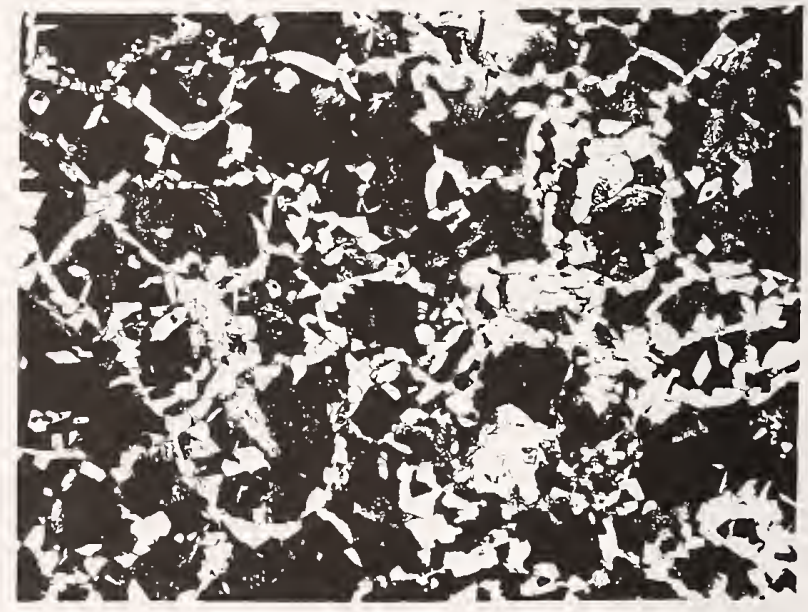

(c)

Figure 33. Ferrite-pearlite microstructure $(200 \times)$ in the central part of the forged blanks after cooling to ambient temperature. (a) Schedule A; (b) Schedule B; (c) Schedule C. 
Table 31. Comparison of the measured (average of three specimens) and predicted strength properties of the forged blanks.

\begin{tabular}{ccccc}
\hline \multirow{2}{*}{$\begin{array}{c}\text { Deformation } \\
\text { schedule }\end{array}$} & \multicolumn{2}{c}{$\sigma_{y}, \mathrm{MPa}$} & \multicolumn{2}{c}{$\sigma_{u}, \mathrm{MPa}$} \\
\cline { 2 - 5 } & measured & predicted & measured & predicted \\
\hline $\mathrm{A}$ & 630 & 626 & 870 & 864 \\
$\mathrm{~B}$ & 665 & 651 & 900 & 873 \\
$\mathrm{C}$ & 705 & 729 & 963 & 988 \\
\hline
\end{tabular}

\subsection{Flat Rolling of 900A Eutectoid Steel}

To verify thermomechanical and microstructural evolution models for the flat rolling of steels, we conducted flat-rolling experiments on $900 \mathrm{~A}$ eutectoid steel. Small block specimens $(50 \mathrm{~mm} \times 38 \mathrm{~mm} \times 400 \mathrm{~mm})$ were rolled into 20 - $\mathrm{mm}$ flats and cooled in still air. The rolling schedule consisted of two passes, which are detailed in table 32. The schedule was repeated several times, and the specimens were quenched at different stages of the rolling process to determine austenite grain-size evolution. The initial austenite grain size after reheating was estimated in a block specimen quenched just after its removal from the furnace. During rolling, temperature was monitored with two thermocouples mounted in holes drilled one above the other, just below the contact surface and in the center of the blocks, respectively. An example of the measured and predicted temperature changes is shown in figure 34 .

Generally, the thermomechanical model characterized the temperature changes well. The most important feature of the process was a very rapid drop of temperature in the subsurface area. We also observed a small increase of temperature in the central region of the specimen. However, the temperatures usually equalized during the intervals between passes.

For the rolling schedule applied in the experiment, static recrystallization was the major microstructure-restoration process. In the process under investigation, the large deformations resulted in very fast static recrystallization. As a consequence, grain growth controlled the grain size before the second pass and after the last. Calculated and measured changes of the austenite grain size in the specimen during rolling are shown in figure 35 . The measured and calculated strength properties of the flat are compared in table 33. Generally, the computer calculations compared fairly well with the results obtained in the experiment.

Table 32. Description of the flat-rolling experiment of the $900 \mathrm{~A}$ eutectoid steel.

\begin{tabular}{ccccc}
\hline Reheating & $\begin{array}{c}\text { Time pause } \\
\text { after reheating }\end{array}$ & $\begin{array}{c}\text { First } \\
\text { deformation }\end{array}$ & $\begin{array}{c}\text { Time pause after } \\
\text { first deformation }\end{array}$ & $\begin{array}{c}\text { Second } \\
\text { deformation }\end{array}$ \\
\hline $\begin{array}{c}1174^{\circ} \mathrm{C} \\
\text { for } 20 \mathrm{~min}\end{array}$ & $22 \mathrm{~s}$ & $38 \rightarrow 28 \mathrm{~mm}$ & $25 \mathrm{~s}$ & $28 \rightarrow 20 \mathrm{~mm}$ \\
\hline
\end{tabular}




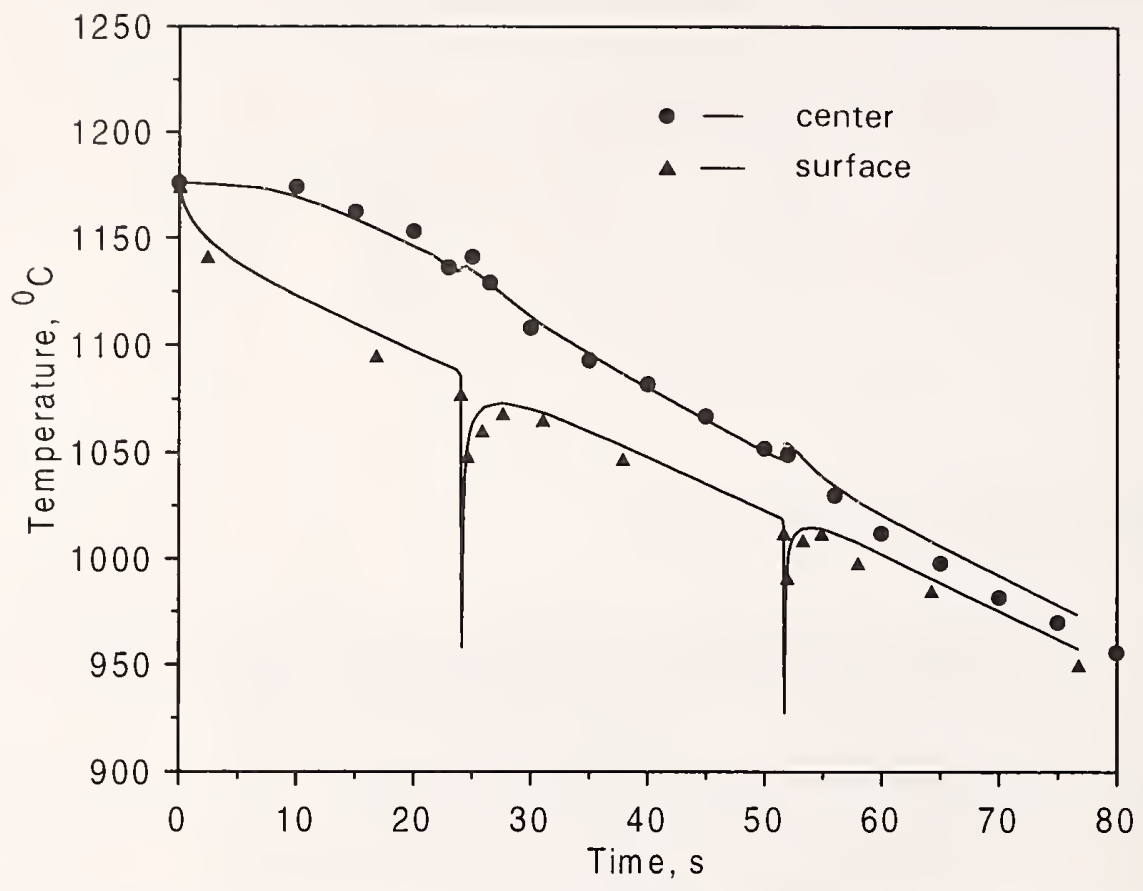

Figure 34. Calculated (lines) versus measured (symbols) temperature changes during laboratory-mill two-pass rolling of the eutectoid steel on the into 20 -mm-thick plate.

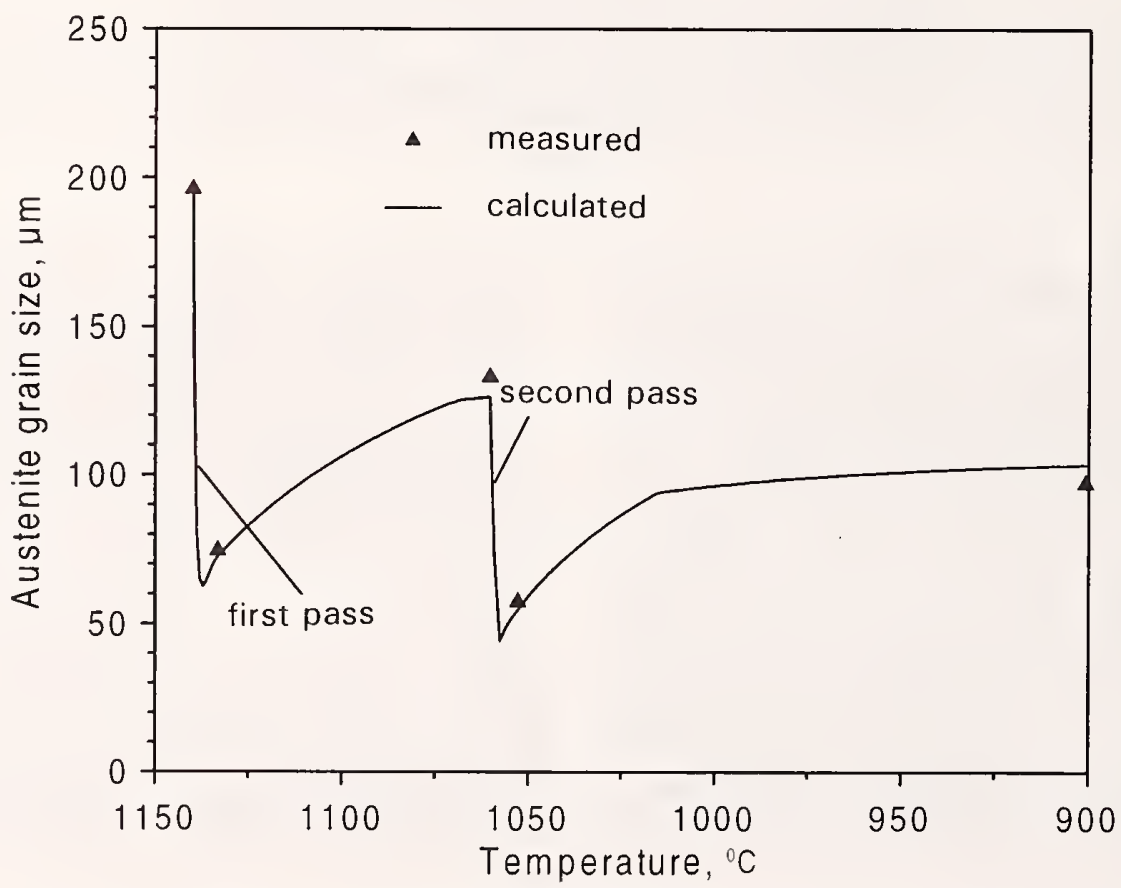

Figure 35. Changes of austenite grain size with temperature and time during $20-\mathrm{mm}$ thick flat rolling of the eutectoid steel. Calculations and measurements were made at the center of the specimen. 
Table 33. Comparison of the measured and predicted microstructural parameters and mechanical properties of the $20-\mathrm{mm}$ flat of $900 \mathrm{~A}$ steel cooled to ambient temperature after rolling according to the schedule in table 32.

\begin{tabular}{|c|c|c|c|c|c|}
\hline \multicolumn{6}{|c|}{ Microstructural parameters } \\
\hline \multicolumn{2}{|c|}{$D_{c}, \mu \mathrm{m}$} & \multicolumn{2}{|c|}{$N_{d}, \mu \mathrm{m}$} & \multicolumn{2}{|c|}{$S_{0}, \mu \mathrm{m}$} \\
\hline measured & predicted & measured & predicted & measured & predicted \\
\hline 30.2 & 35.1 & 8.7 & 7.5 & 0.12 & 0.11 \\
\hline \multicolumn{6}{|c|}{ Mechanical properties } \\
\hline \multicolumn{3}{|c|}{$\sigma_{y}, \mathrm{MPa}$} & \multicolumn{3}{|c|}{$\sigma_{u}, \mathrm{MPa}$} \\
\hline measured & \multicolumn{2}{|c|}{ predicted } & measured & \multicolumn{2}{|c|}{ predicted } \\
\hline 650 & \multicolumn{2}{|c|}{666} & 1086 & \multicolumn{2}{|c|}{1077} \\
\hline
\end{tabular}

\section{Industrial Experiments}

Successful validation of the microstructure and thermomechanical models in the laboratory experiments led to implementation of these models in industrial practice.

The following industrial experiments were conducted in this study:

- plate rolling of VT microalloyed medium-carbon steel

- rod rolling of C-Mn, VT microalloyed medium-carbon, and eutectoid steels

- rail rolling of eutectoid steel

The experiments were motivated by industry's need to rationalize manufacturing technologies and chemical compositions of particular steels. In this section, mechanical-property measurements represent the average of three to four specimens, and the microstructural parameters are the average of about two hundred measurements of one specimen. Described below are the most important results obtained from the experiments.

\subsection{Plate Rolling}

Plate rolling is the most frequently modeled process. Plastic flow, heat transfer, and microstructural evolution calculations are represented in the model by FEM codes.

In this research program, we tested our model by plate rolling VT microalloyed mediumcarbon steel; its chemical composition is given in table 34 . The rolling schedule (table 35 ) consisted of 14 passes of 5- to 27-percent reduction with approximately 20 -s intervals between passes to reduce a $140-\mathrm{mm}$-thick slab to a $14-\mathrm{mm}$-thick plate. The surface temperature measured in the experiment (table 35) was used to adjust the temperature distribution in the model. 
On the basis of experimental results and computer simulations, we postulated that, in multipass rolling, the last five to six passes were crucial in the development of the final microstructure. Calculation of the microstructural evolution showed that, during the last few passes of plate rolling, static recrystallization restored the austenite microstructure. This process proceeded very rapidly, and substantial grain growth was noted between the last two consecutive passes. The fast recrystallization kinetics and grain-growth rate were promoted by the small size of the austenite grains that were present after the preliminary passes and by the high deformation temperatures during the last few passes.

Calculated changes in the austenite grain size in the midthickness of the workpiece during the last seven passes of the rolling are shown in figure 36. Also included in this figure is the austenite grain size measured in the specimen cut from the plate after the finish pass and water quench. The grain sizes indicated in figure 36 refer to the state after grain growth just before the next pass.

Table 34. Chemical composition (mass percent) of the VT medium-carbon steel rolled into 14-mm-thick plate.

\begin{tabular}{cccccccc}
\hline $\mathrm{C}$ & $\mathrm{Mn}$ & $\mathrm{Si}$ & $\mathrm{P}$ & $\mathrm{S}$ & $\mathrm{V}$ & $\mathrm{Al}_{\text {tot }}$ & $\mathrm{N}$ \\
\hline 0.24 & 0.70 & 0.21 & 0.017 & 0.017 & 0.033 & 0.001 & 0.007 \\
\hline
\end{tabular}

Table 35. Deformation schedule used to roll the VT steel (table 34) from a $140-\mathrm{mm} \times 160-\mathrm{mm}$ slab to a $14-\mathrm{mm}$-thick plate.

\begin{tabular}{ccc}
\hline & \multicolumn{2}{c}{ Deformation schedule } \\
\cline { 2 - 3 } Pass no. & relative reduction & temperature, ${ }^{\circ} \mathrm{C}$ \\
\hline 1 & 0.05 & 1185 \\
3 & 0.12 & \\
4 & 0.15 & 1163 \\
5 & 0.14 & \\
6 & 0.17 & \\
7 & 0.16 & \\
8 & 0.19 & \\
9 & 0.18 & \\
10 & 0.23 & \\
11 & 0.27 & \\
12 & 0.23 & \\
13 & 0.22 & 965 \\
14 & 0.17 & \\
\hline
\end{tabular}




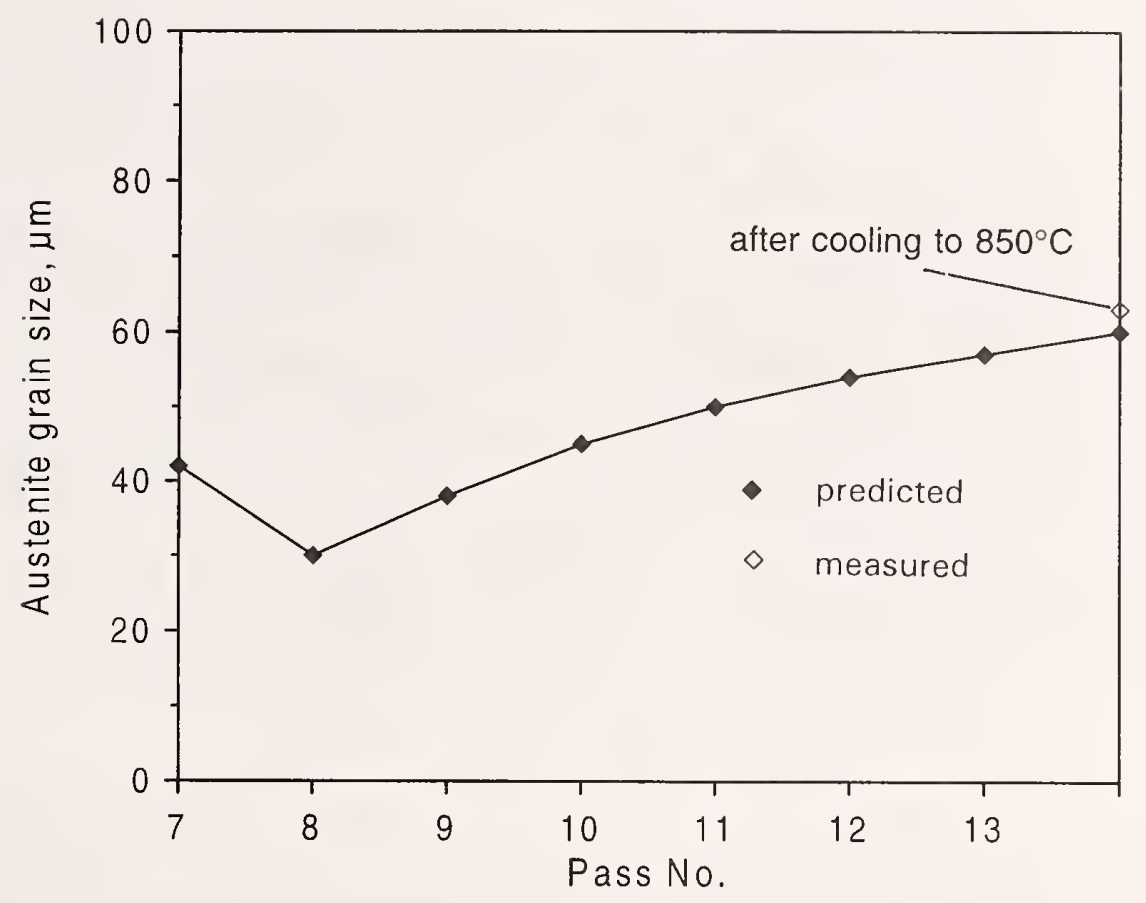

Figure 36. Austenite grain-size development in the VT medium-carbon steel during the last seven passes in the rolling of 14-mm-thick plate. Results of the calculation refer to the state after grain growth, either during time intervals after consecutive passes or after cooling to $850^{\circ} \mathrm{C}$ after the last pass.

The results of the final microstructural parameters and mechanical-property predictions, together with the measured values, are given in table 36. An example of the ferrite-pearlite microstructure in the midthickness of the plate is shown in figure 37 . On the basis of the experimental results, we postulate that the rolling model gives a good representation of the microstructural events taking place during the plate-rolling experiments.

Table 36. Measured and predicted microstructural parameters and mechanical properties of 14-mm-thick plate of VT medium-carbon steel rolled according to the schedule listed in table 35.

\begin{tabular}{|c|c|c|c|c|c|c|c|}
\hline & \multicolumn{3}{|c|}{ Microstructural parameters } & \multicolumn{4}{|c|}{ Mechanical properties } \\
\hline & $f_{\alpha}$ & $D_{\alpha}, \mu \mathrm{m}$ & $S_{0}, \mu \mathrm{m}$ & $\sigma_{y}, \mathrm{MPa}$ & $\sigma_{u}, \mathrm{MPa}$ & $27-J$ & ITT, ${ }^{\circ} \mathrm{C}$ \\
\hline measured & 0.62 & 12.5 & 0.234 & 410 & 572 & & 24 \\
\hline predicted & 0.60 & 10.7 & 0.22 & 430 & 580 & & 22 \\
\hline
\end{tabular}




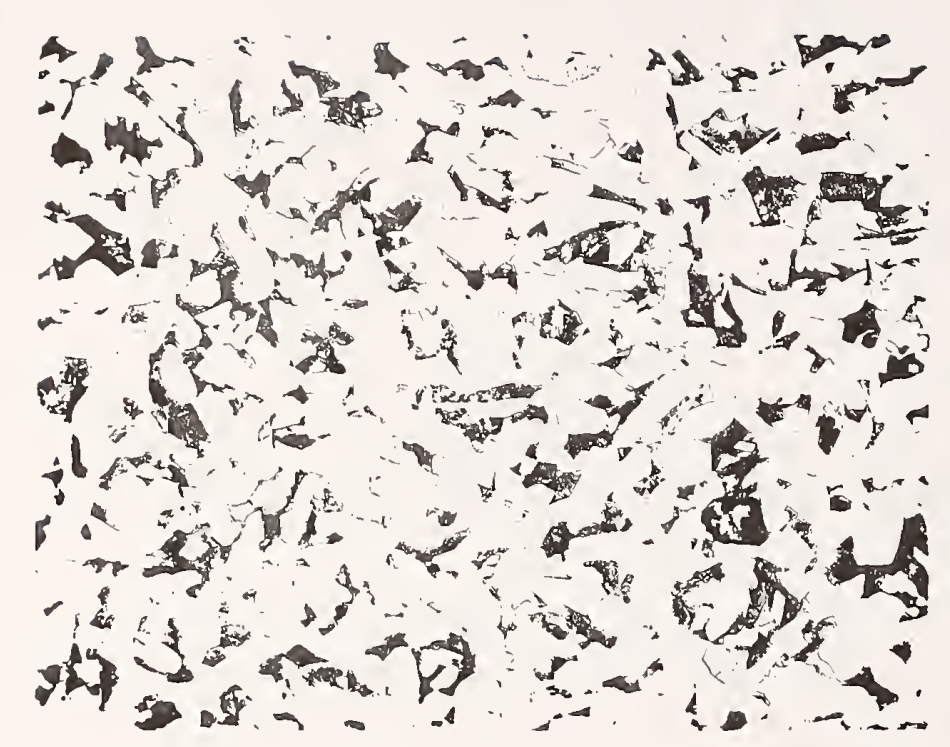

Figure 37. Ferrite-pearlite microstructure of the 14-mm-thick VT medium-carbon steel cooled to ambient temperature after rolling $(200 \times)$.

\subsection{Rod Rolling}

The rod-rolling process has stimulated many experiments and theoretical considerations related to the mechanisms of microstructural restoration in deformed austenite. Some researchers believe that dynamic recrystallization initiation takes place during the last few passes at low temperatures [30-32] and that it is related to the strain accumulation due to the short intervals between consecutive passes. Despite a long history of experimental efforts to understand the dynamic and postdynamic recrystallization mechanisms, our knowledge of the role of these processes in microstructural development is still far from satisfactory.

\subsubsection{Experimental Procedures}

The chemical compositions of the steels investigated in the industrial experiments are given in table 37; they are different from the compositions of steels used in the laboratory experiments. Vanadium was added to the plain-carbon steels to increase the yield strength of the rods from 520 to $550 \mathrm{MPa}$. Continuously cast VT-steel and conventionally cast eutectoid- and C-Mnsteel ingots were rolled into preliminary slabs, which were then rolled into 8-mm-diameter rods. The rod-rolling process consisted of several stages, including reheating, roughing passes, intermediate and finish rolling, and cooling in the cooling bed. The finish rolling in the rod-rolling process consisted of six consecutive passes with a very short interval $(\leq 0.2 \mathrm{~s})$ between passes. At different stages during the rolling, the specimens were cut and quenched for austenite grainsize measurement at the entry to the last stand and approximately $15 \mathrm{~s}$ after the last pass. The temperature of the rods was measured with an infrared pyrometer. Specimens for mechanicalproperty testing and quantitative metallography were taken from the rods after cooling in the cooling bed. Austenite and ferrite grain sizes and pearlite interlamellar spacing were measured by the mean-linear-intercept method. 
We determined that the finish rolling and cooling in the cooling bed are the most important stages in the development of the final microstructure in the rods. Therefore, our experimental and theoretical efforts on rod rolling focused on these stages.

Table 37. Chemical composition (mass percent) of plain-carbon, VT, and eutectoid steels rolled into 8 -mm-diameter rods.

\begin{tabular}{cccccccc}
\hline Steel & $\mathrm{C}$ & $\mathrm{Mn}$ & $\mathrm{Si}$ & $\mathrm{P}$ & $\mathrm{S}$ & $\mathrm{Al}_{\text {tot }}$ & $\mathrm{N}$ \\
\hline plain carbon & 0.22 & 1.23 & 0.34 & 0.060 & 0.038 & 0.044 & 0.007 \\
VT & 0.18 & 1.34 & 0.33 & 0.024 & 0.021 & 0.006 & 0.009 \\
eutectoid & 0.71 & 1.15 & 0.28 & 0.018 & 0.019 & 0.005 & 0.006 \\
\hline
\end{tabular}

\subsubsection{Validation of the Model}

For rod rolling of VT steel, the results of the finite-element calculations of strain, strain rate, and temperature distribution in the cross section of the workpiece at the end of the first and last passes are shown in figures 38 and 39. The results of the calculations for the rolling of the eutectoid and $\mathrm{C}-\mathrm{Mn}$ steels are essentially the same.

The model predicted strong inhomogeneity of the plastic flow during the rolling. The temperatures of the rods entering the first pass were very stable, in the range 900 to $925^{\circ} \mathrm{C}$. However, the most striking feature of the process was the increase in temperature at the exit from the last stand-approximately $100^{\circ} \mathrm{C}$ more than that in the initial state (fig. 40). This increase, attributed to the plastic work during deformation, was confirmed by infrared-pyrometer measurements.

The measured initial austenite grain size at the entrance to the finishing stand was approximately $20 \mu \mathrm{m}$ for all the experimental steels. Predicted austenite grain-size evolution in the eutectoid steel during the rod-rolling process is shown in figure 40. Our microstructural evolution model predicts that dynamic recrystallization initiates in the second pass in all these steels as a result of strain accumulation due to the short interval between passes. The distribution of the volume fraction of the recrystallized material and the retained strain in the cross section of the workpiece after first pass are illustrated in figure 38. As a consequence of dynamic recrystallization initiation, metadynamic recrystallization occurred during the interval between passes. However, the short intervals precluded a full recovery of the dislocation structure.

On cooling following rolling, significant grain growth occurred in the eutectoid steel rods. Measured austenite grain size was within the range 35 to $45 \mu \mathrm{m} 15 \mathrm{~s}$ after the last pass. Thus, the grain-growth process diminished the beneficial effect of dynamic recrystallization on austenite grain refinement. In the $\mathrm{C}-\mathrm{Mn}$ and VT steels rods, grain growth was less intense: austenite grain sizes were 20 to $25 \mu \mathrm{m} 15 \mathrm{~s}$ after the last pass. 


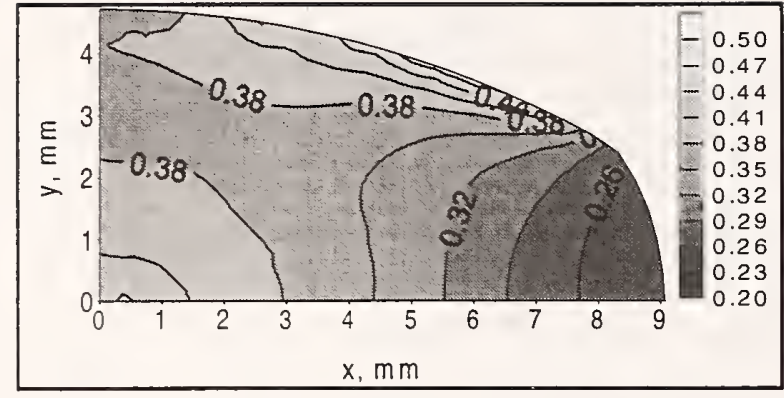

(a)

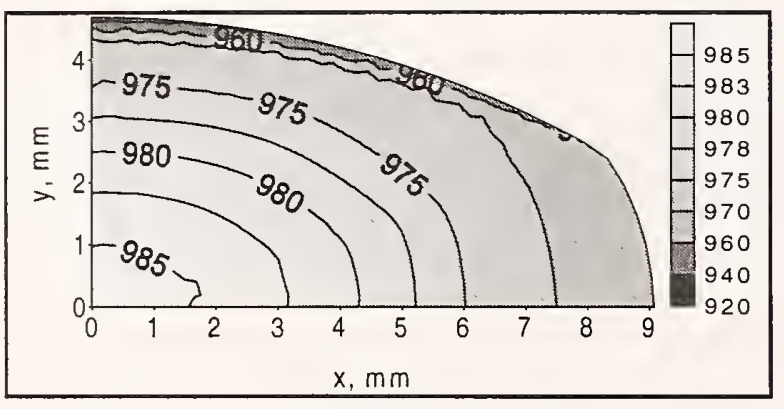

(c)

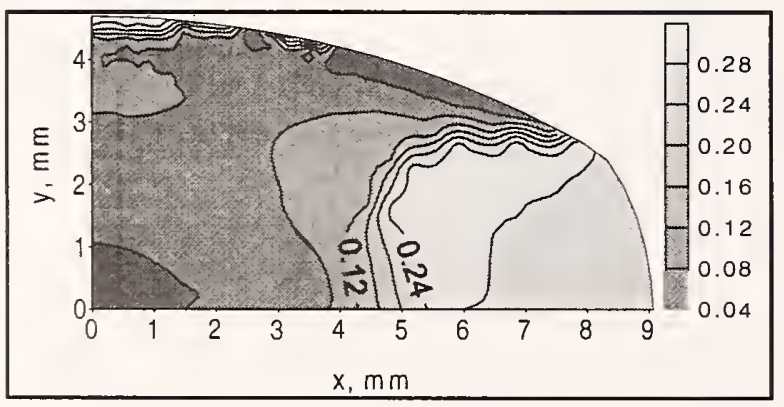

(e)

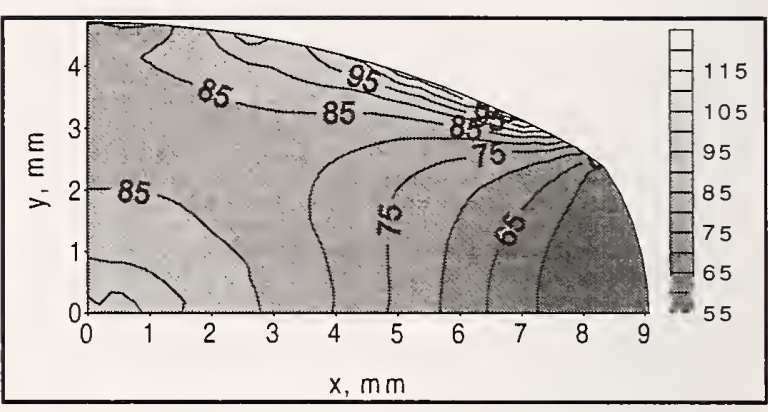

(b)

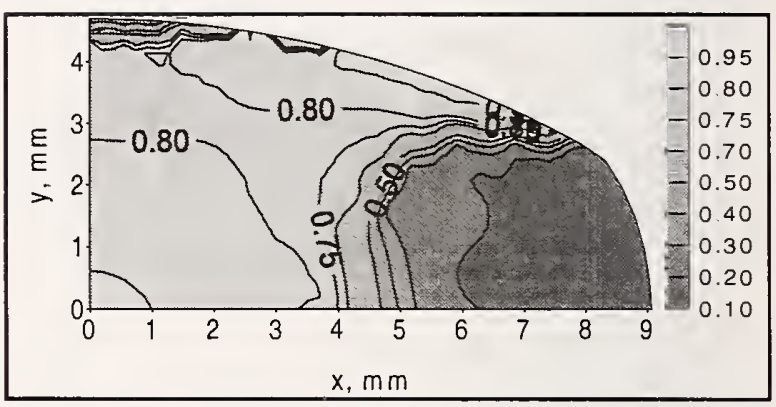

(d)

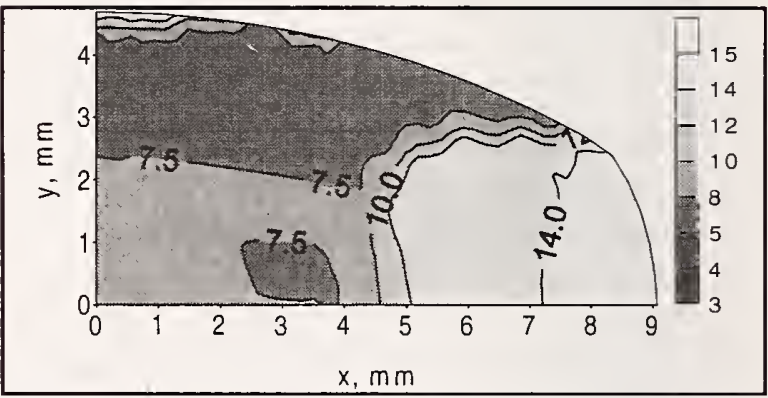

(f)

Figure 38. Calculated deformation parameters and the state of the austenite microstructure at the end of the first pass during finish rolling of 8-mm-diameter rod of the VT steel: (a) effective strain; (b) effective strain rate; (c) temperature (in degrees Celsius); (d) recrystallized volume fraction; (e) retained strain; (f) austenite grain size (in micrometers). Owing to the two-axial symmetry, only one quarter of the cross section is shown. 


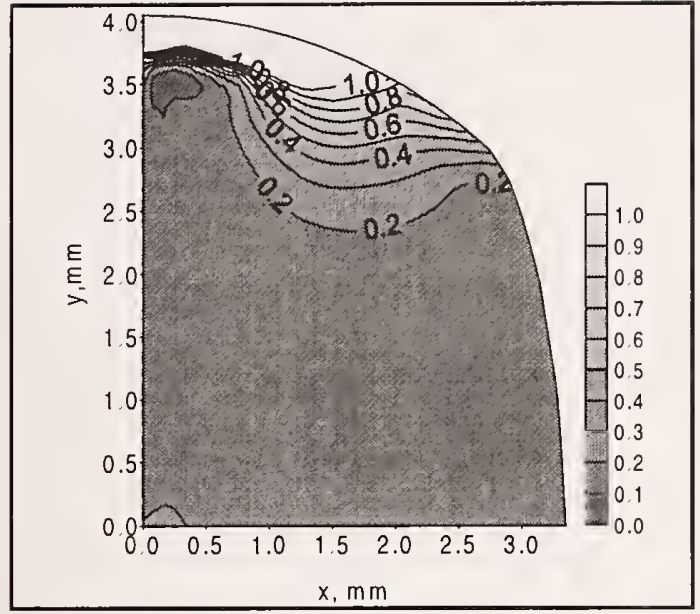

(a)

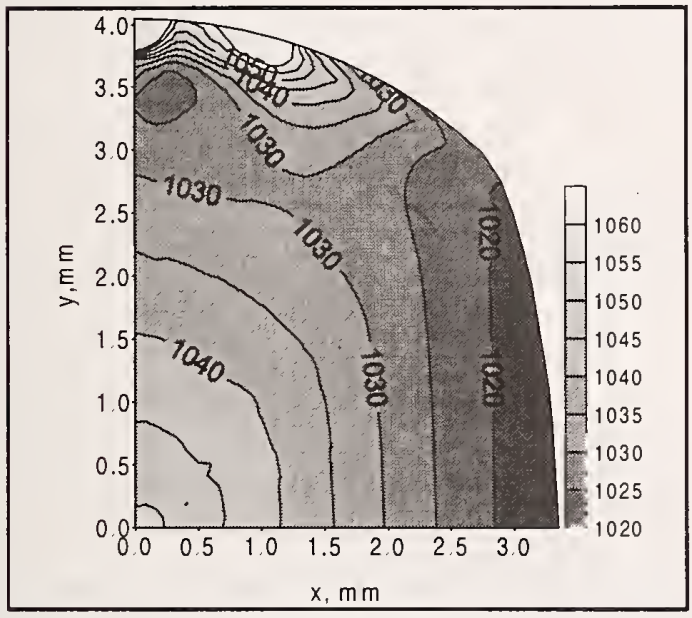

(c)

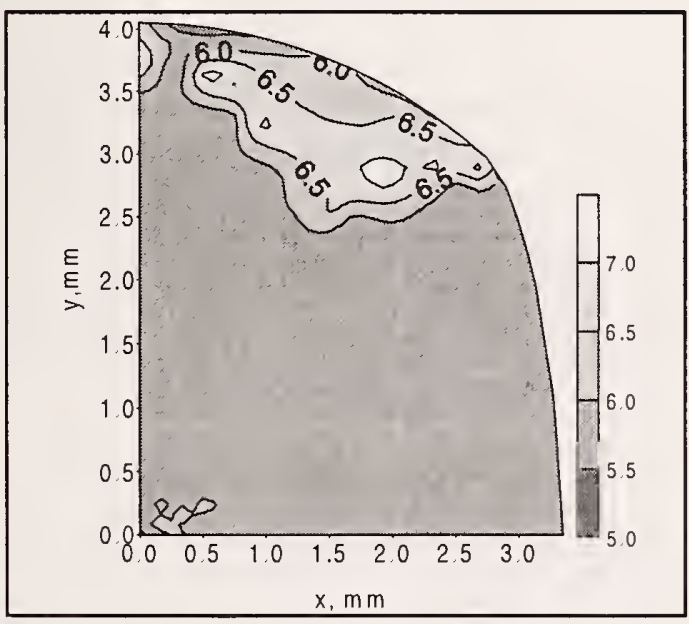

(e)

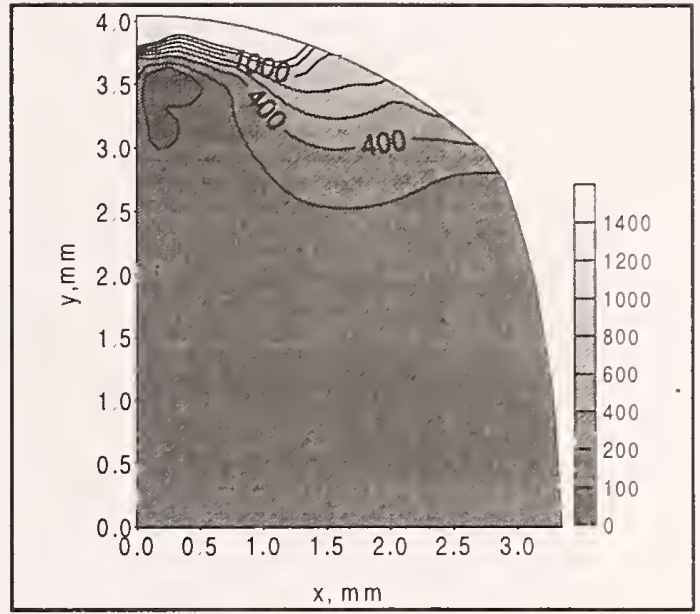

(b)

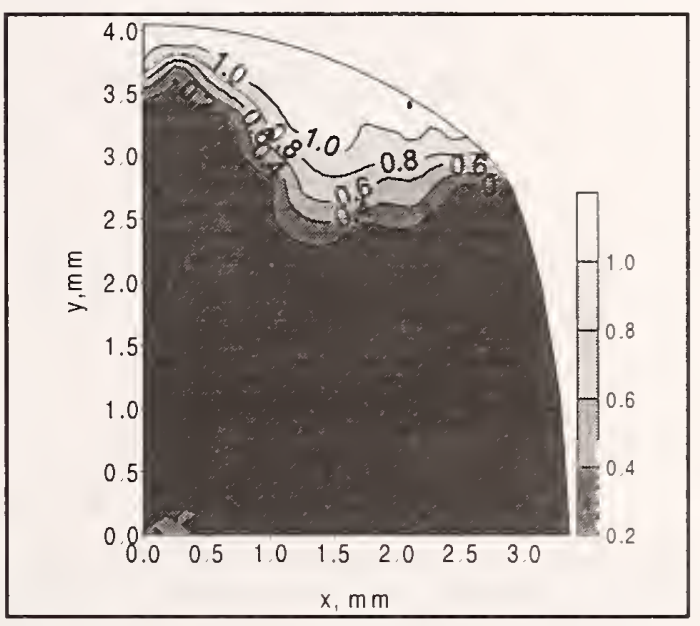

(d)

Figure 39. Calculated deformation parameters and the state of the austenite microstructure at the end of the last pass during finish rolling of 8-mm-diameter rod of the VT steel: (a) effective strain; (b) effective strain rate; (c) temperature (in degrees

Celsius); (d) recrystallized volume fraction: (e) austenite grain size (in micrometers). Owing to the two-axial symmetry, only one quarter of the cross section is shown. 


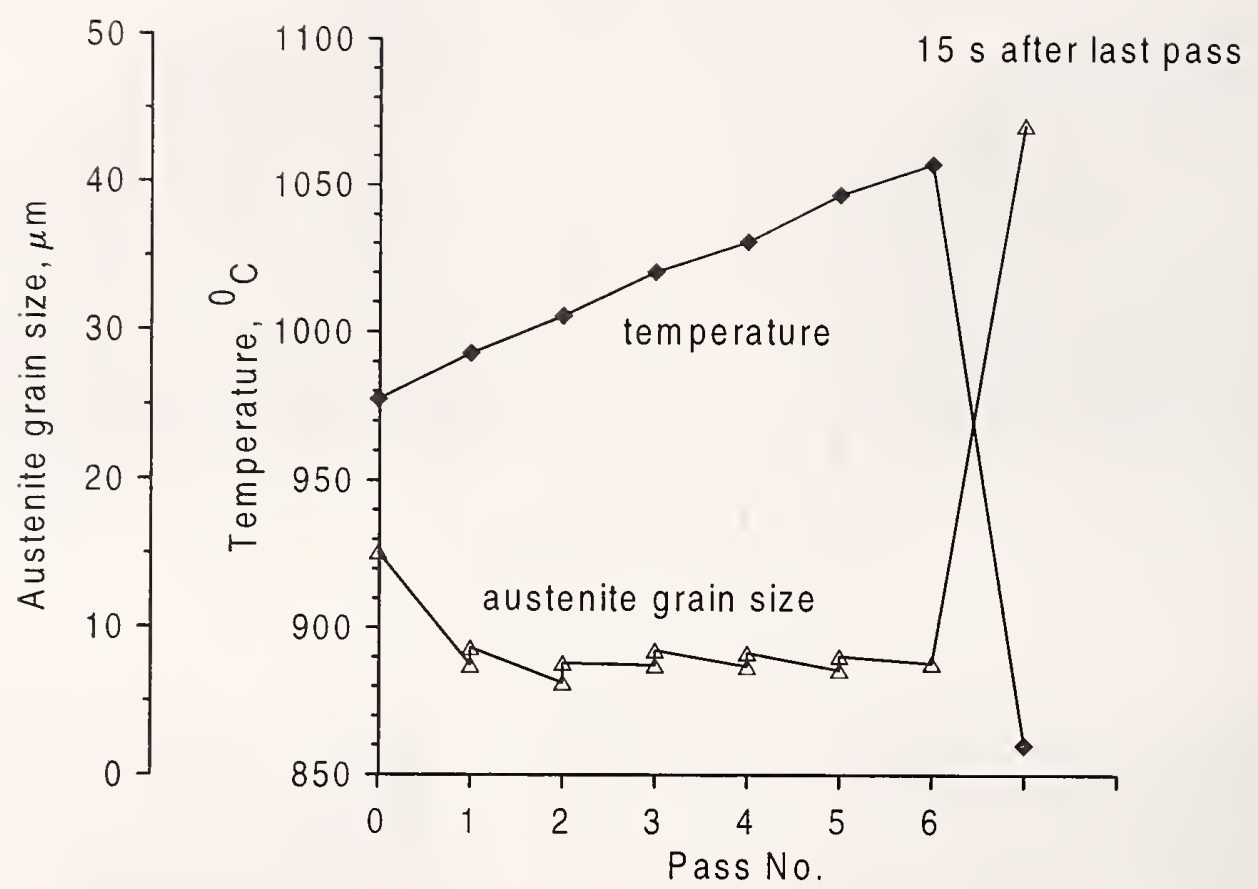

Figure 40. Calculated temperatures and austenite grain sizes during finish rolling of 8-mm-diameter rod of the eutectoid steel.

The most important feature of the cooling process pertains to the heat-transfer conditions. The rods were cut and collected at the exit of the rolling stand in bundles of 10 to 15 rods, and the bundles were transferred into the cooling bed. The cooling history of a particular rod depends on its location in the bundle. Approximate cooling curves were obtained during the laboratory experiment in which the rods' arrangement and the heat-transfer conditions were very close to those in the rolling mill. For illustration, cooling curves for eutectoid steel rods arranged in a 12-rod bundle are illustrated in figure 41.

Estimates of the rods' cooling rates $\left(1\right.$ to $\left.2.5^{\circ} \mathrm{C} / \mathrm{s}\right)$ over the diffusional transformation temperature range were used to calculate the microstructural parameters and strength properties. The measured and calculated results of microstructural parameters and strength properties are listed in table 38. The eutectoid steel rods experienced the most significant variations in microstructural parameters and mechanical properties caused by the diverse cooling conditions in the bundle. The $\mathrm{C}-\mathrm{Mn}$ and VT steels rods were less sensitive to variations in cooling rate. 


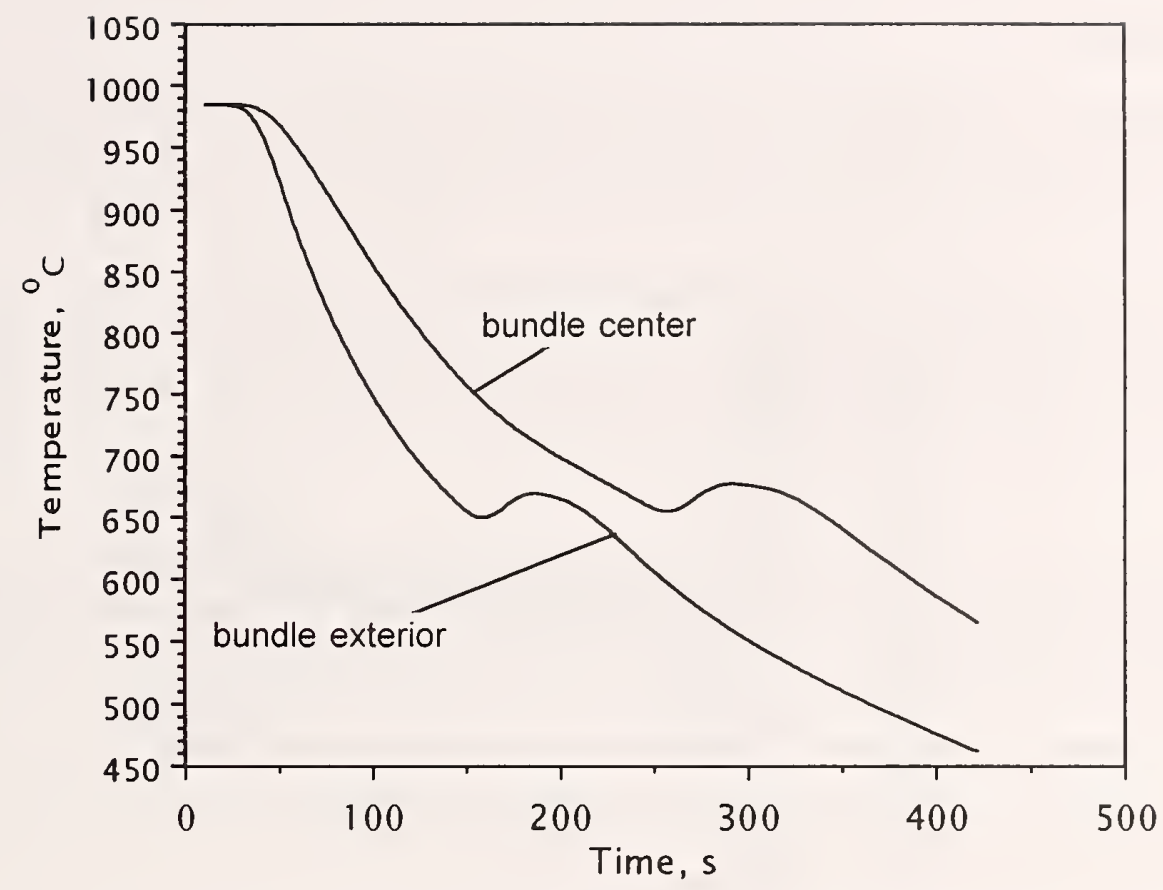

Figure 41. Cooling curves of the 8-mm-diameter rods of the eutectoid steel at different locations in the 12-rod bundle. Data are from a laboratory experiment.

Table 38. Measured (M) versus predicted (P) microstructural parameters and mechanical properties of 8-mm-diameter rods of the $\mathrm{C}-\mathrm{Mn}, \mathrm{VT}$, and eutectoid steels.

\begin{tabular}{|c|c|c|c|c|c|c|c|c|c|c|c|c|c|c|}
\hline & \multicolumn{10}{|c|}{ Microstructural parameters } & \multicolumn{4}{|c|}{ Mechanical properties } \\
\hline & \multicolumn{2}{|c|}{$f_{\alpha}$} & \multicolumn{2}{|c|}{$N_{d}, \mu \mathrm{m}$} & \multicolumn{2}{|c|}{$D_{\alpha}, \mu \mathrm{m}$} & \multicolumn{2}{|c|}{$D_{c}, \mu \mathrm{m}$} & \multicolumn{2}{|c|}{$S_{0}, \mu \mathrm{m}$} & \multicolumn{2}{|c|}{$\sigma_{y}, \mathrm{MPa}$} & \multicolumn{2}{|c|}{$\sigma_{\mathcal{u}}, \mathrm{MPa}$} \\
\hline & M & $\mathrm{P}$ & $\mathrm{M}$ & $\mathrm{P}$ & M & $P$ & $\mathrm{M}$ & $\mathrm{P}$ & M & $P$ & $\mathrm{M}$ & $\mathrm{P}$ & $\mathrm{M}$ & $\mathrm{P}$ \\
\hline $\mathrm{C}-\mathrm{Mn}$ & 0.66 & 0.62 & & & 11.6 & 12.1 & & & 0.18 & 0.20 & 407 & 392 & 635 & 618 \\
\hline VT & 0.65 & 0.63 & & & 9.6 & 10.1 & & & 0.17 & 0.18 & 550 & 540 & 690 & 670 \\
\hline $\begin{array}{l}\text { Eutectoid } \\
\text { bundle exterior } \\
\text { bundle center }\end{array}$ & & & $\begin{array}{l}15 \\
23\end{array}$ & $\begin{array}{l}18 \\
28\end{array}$ & & & $\begin{array}{l}6 \\
8\end{array}$ & $\begin{array}{r}9 \\
13\end{array}$ & $\begin{array}{l}0.15 \\
0.17\end{array}$ & $\begin{array}{l}0.16 \\
0.18\end{array}$ & $\begin{array}{l}580 \\
540\end{array}$ & $\begin{array}{l}560 \\
530\end{array}$ & $\begin{array}{l}1020 \\
1000\end{array}$ & $\begin{array}{r}1010 \\
998\end{array}$ \\
\hline
\end{tabular}




\subsection{Rail Rolling}

In Poland, rails are manufactured mainly from a 900A eutectoid-grade steel, UIC-60, whose chemical composition is similar to that in table 1. The rolling of UIC-60 rail was used to demonstrate the capability of our model to predict microstructural evolution during this process.

Seventeen passes, generally Bartscherer-type passes, were used in the process. Owing to the complexity of the material flow and heat transfer, the generalized plain-strain model used in the FEM calculations was too complicated to use for the entire process. However, several consecutive passes were modeled successfully with this approach, which was sufficient to calculate the development of the final grain size in the rail.

For example, the distribution of deformation parameters after the last pass in the rail-rolling process is shown in figure 42 . In this case, a severe nonuniformity of deformation and temperature existed in the workpiece. Simulation of the austenite grain-size evolution in the rail's head during the last five passes is shown in figure 43; it was calculated by assuming two finishrolling temperatures. The influence of deformation conditions on austenite grain-size evolution is illustrated in figure 44. This calculation refers to the microstructural evolution in the foot of the rail during the five last passes. In this case, the temperature is lower and the strain and strain rates are higher than those in the rail's head.

The microstructural evolution model predicts that static recrystallization restores the austenite microstructure after deformation. No dynamic recrystallization occurred because the low deformation temperatures and small strains did not exceed the critical value for its initiation. The pauses between consecutive passes were sufficient, however, for complete static recrystallization to occur early after each pass, even though recrystallization in the rail's foot is more sluggish than in the rail's head. Thus, austenite grain growth is the main process shaping the final austenite microstructure. Computer calculation shows that the austenite grain size after cooling to the pearlite transformation temperature should be approximately 80 to $100 \mu \mathrm{m}$ in the head and 30 to $40 \mu \mathrm{m}$ in the foot of the rail. This result was confirmed by measurement of the austenite grain size of the quenched rail approximately $60 \mathrm{~s}$ after the last pass. The results of the measurement are included in figure 45 , which shows the austenite microstructure in the quenched rail.

Some of the complicated cooling history of the rail after rolling was shown in the laboratory experiment (fig. 46). Depending on the region of the rail, the pearlite transformation shifted in time, an effect associated with the diverse heat-transfer conditions prevailing in the rail's cross section. The characterization of the cooling history of different elements of the rail by FEM modeling is shown in figure 47. For the calculation shown in this figure, the pearlite transformation model was incorporated into the FEM code, which characterized the contribution of the transformation heat to the evolution of the temperature field in the rail during cooling. The calculation shows that the effect of transformation heat should yield equalization of temperatures in the head, web, and foot centers approximately $600 \mathrm{~s}$ after the start of cooling (fig. 48). This effect was observed in the laboratory experiment (fig. 46). 
(a)

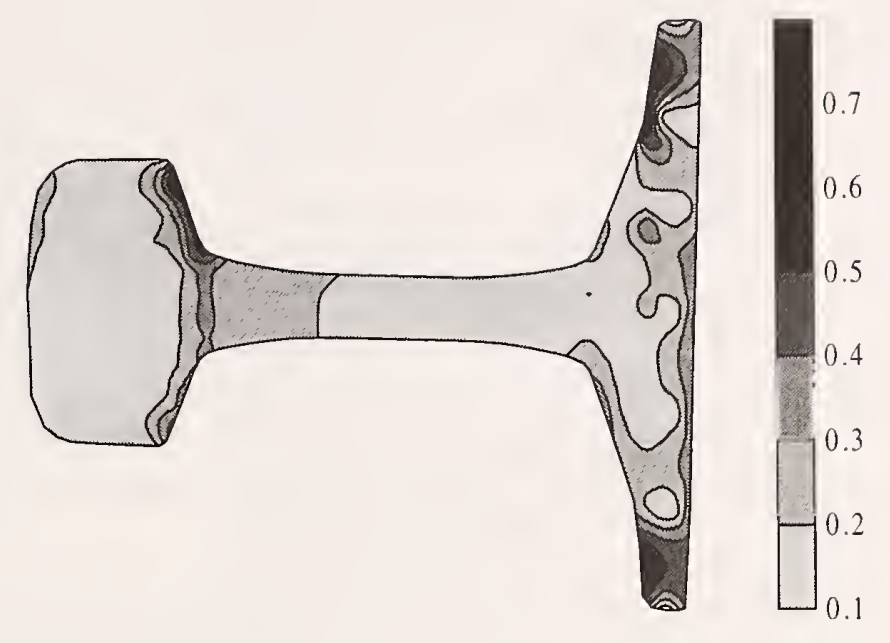

(b)

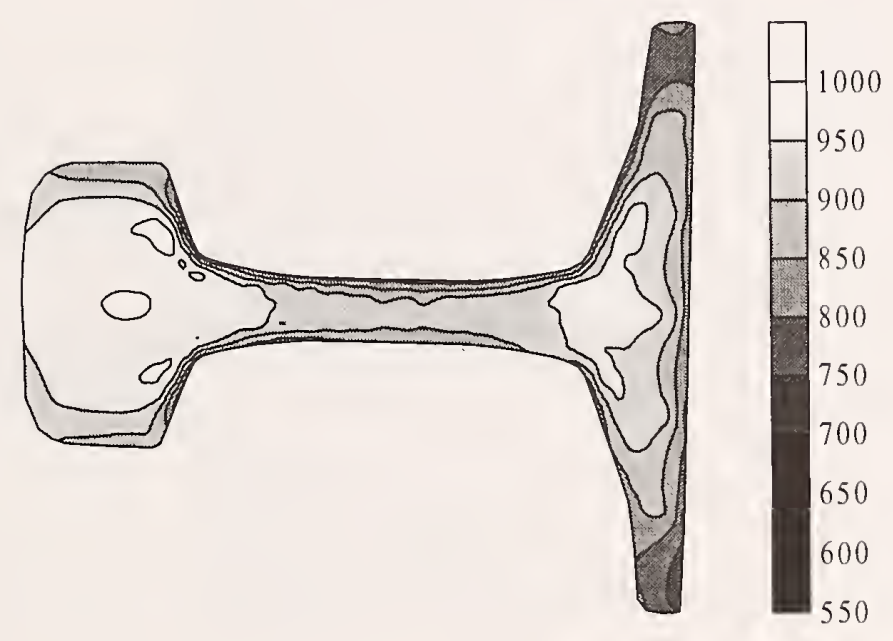

Figure 42. Distribution of (a) strain and (b) temperature (in degrees Celsius) in the UIC- 60 rail's cross section after the last pass. 


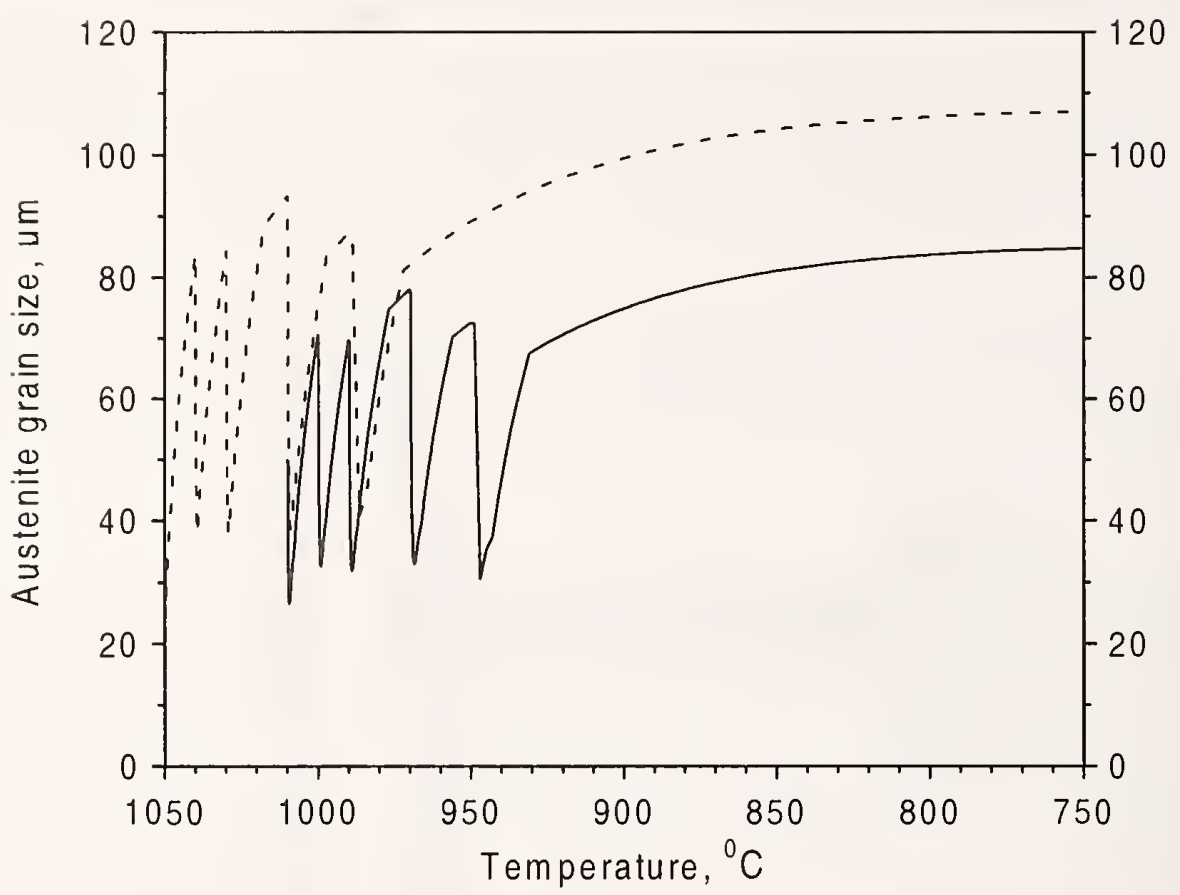

Figure 43. Simulated austenite grain-size changes in the head of the UIC-60 rail during the last five passes of the rolling process for two finish-rolling temperatures: $970^{\circ} \mathrm{C}$ (dashed line) and $930^{\circ} \mathrm{C}$ (solid line). $D_{0}=50 \mu \mathrm{m}$.

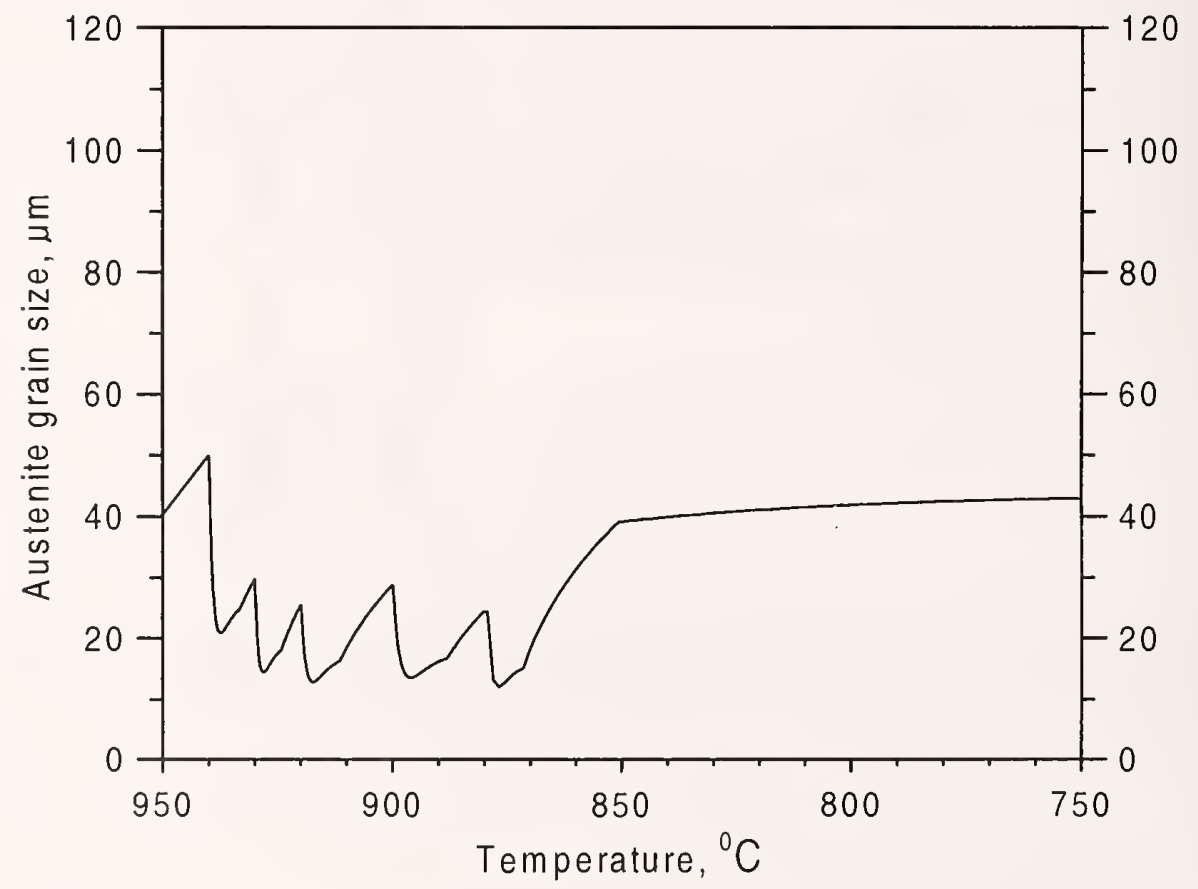

Figure 44. Simulated austenite grain-size changes in the foot of the UIC-60 rail during the last five passes of the rolling process. 
(a)

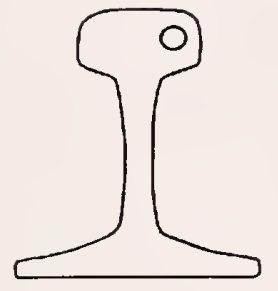

(b)

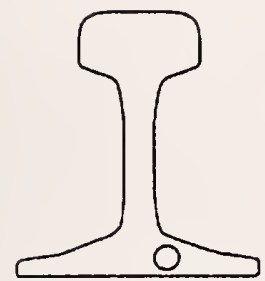

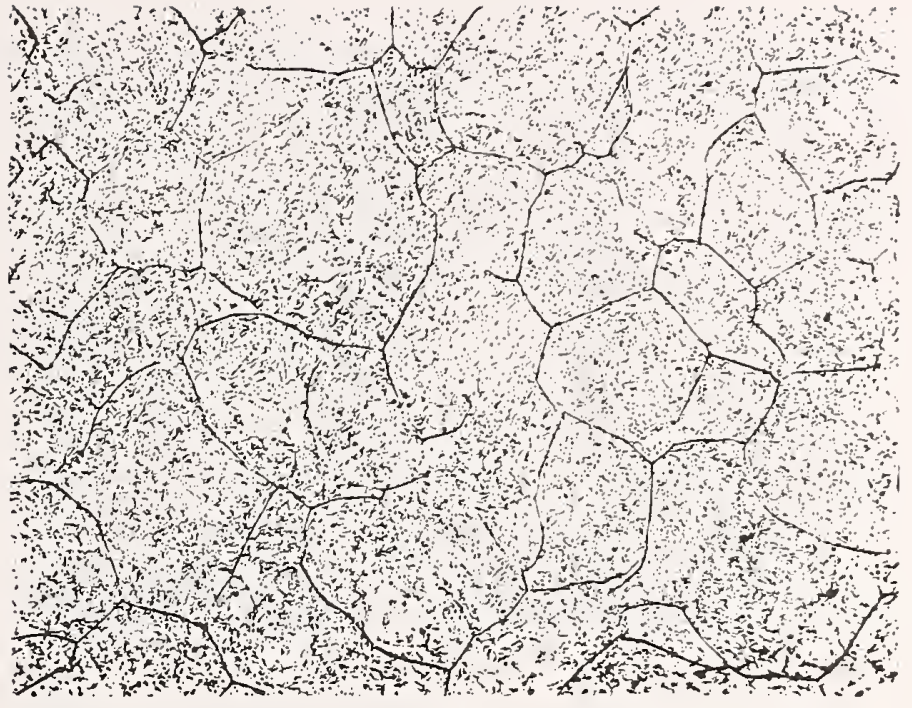

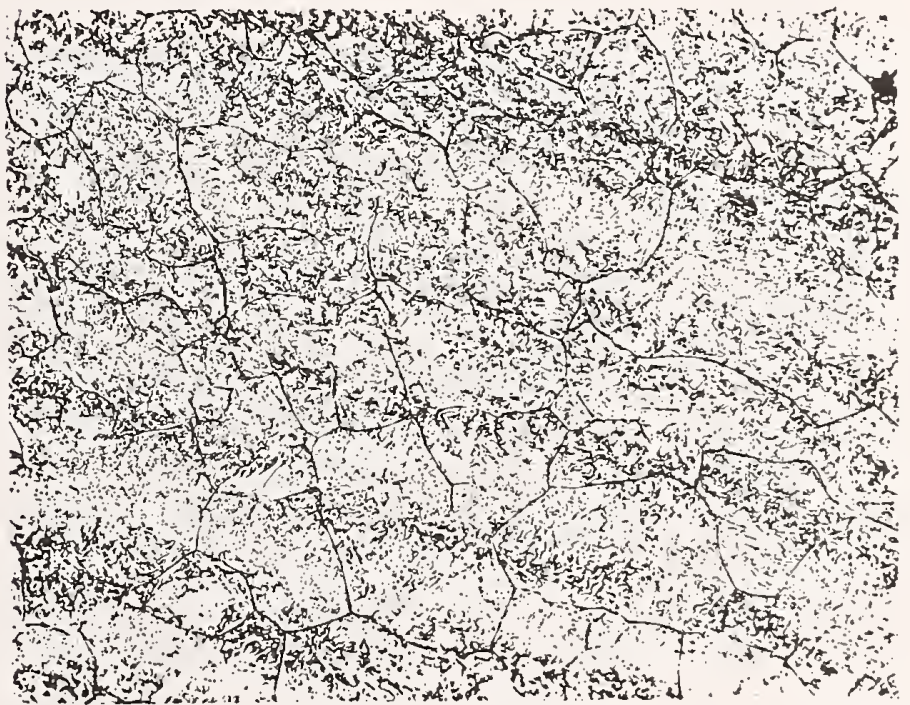

Figure 45. Austenite microstructures $(200 \times)$ at different locations in the UIC-60 rail quenched $60 \mathrm{~s}$ after the last pass. Austenite grain size: (a) $96 \mu \mathrm{m}$; (b) $33 \mu \mathrm{m}$. 


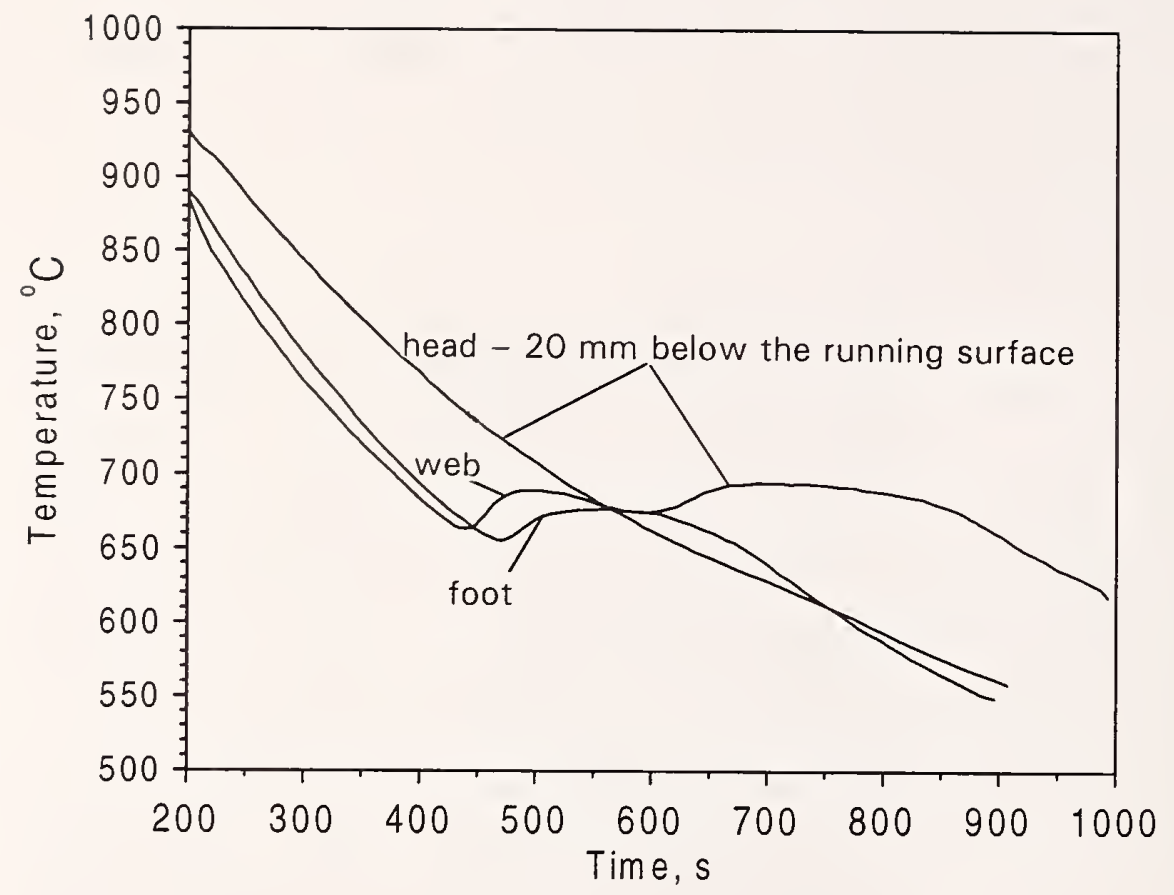

Figure 46. Cooling curves of the foot, web, and head of the UIC-60 rail measured during a laboratory experiment. Thermocouples were installed at the symmetrical centers of the web and foot.

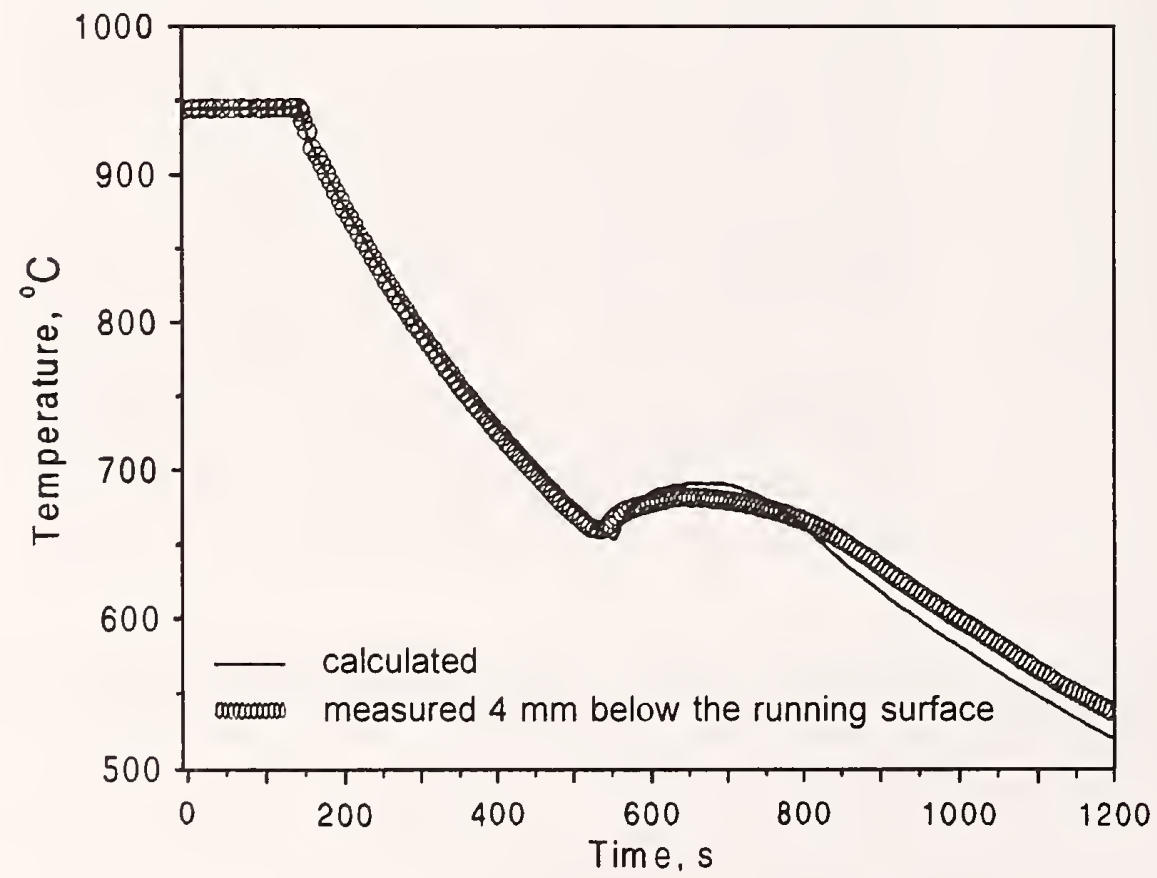

Figure 47. Temperature changes in the head of the UIC-60 rail during a cooling experiment in the laboratory $\left(T_{\gamma}=940^{\circ} \mathrm{C}\right.$ for $\left.20 \mathrm{~min}\right)$. 


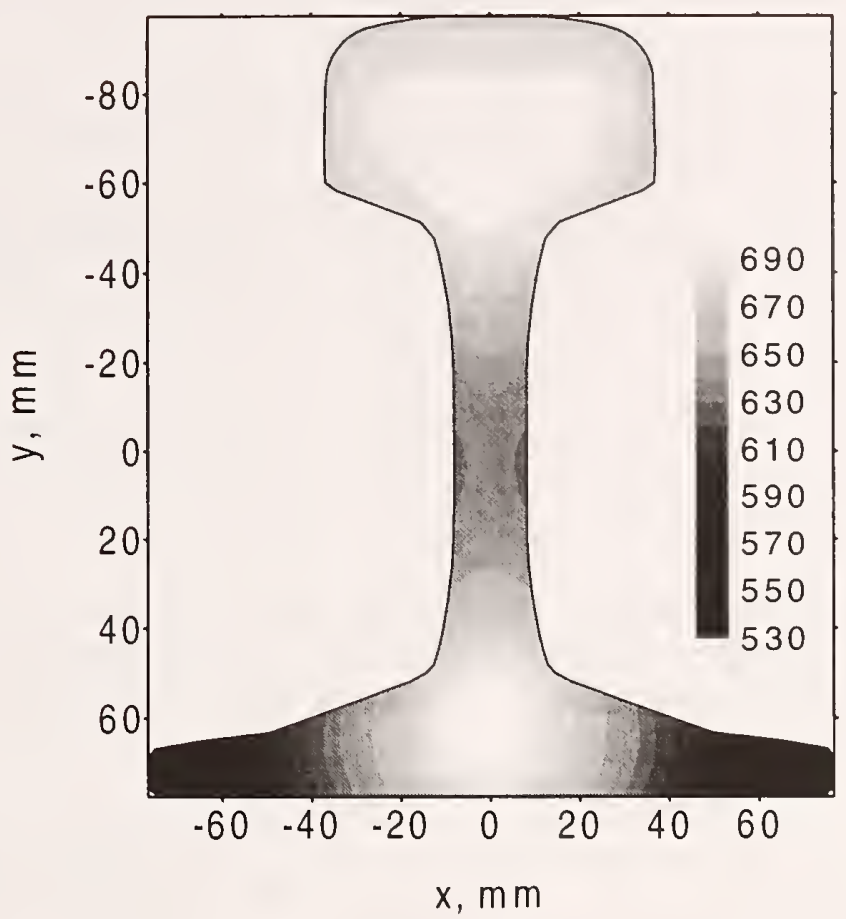

Figure 48. Calculated temperature distribution (in degrees Celsius) in the UIC-60 rail $600 \mathrm{~s}$ after the start of the cooling under laboratory conditions.

The rail-rolling experiments also confirmed the model predictions of the mechanical properties of the rails. For the chemical compositions of the rails shown in table 39 , the microstructural parameters and mechanical properties of the rails are given in table 40 . Taking into account the results obtained from the model, we infer that the variations in the microstructural parameters observed in the rails were caused mainly by the variations in cooling rates after the rolling. The microstructural parameters and mechanical properties of the pearlite were calculated on the basis of the calculated average cooling history in the rail. The results of the calculation (given in table 41) compare fairly well with the measurements.

Table 39. Examples of the chemical composition (mass percent) of the UIC-60 rails rolled from 900A steel continuously cast ingots.

\begin{tabular}{ccccccc}
\hline No. & $\mathrm{C}$ & $\mathrm{Mn}$ & $\mathrm{Si}$ & $\mathrm{P}$ & $\mathrm{S}$ & $\mathrm{Al}_{\text {tot }}$ \\
\hline 1 & 0.74 & 1.10 & 0.28 & 0.016 & 0.018 & 0.001 \\
2 & 0.71 & 1.10 & 0.25 & 0.017 & 0.020 & 0.002 \\
3 & 0.72 & 1.00 & 0.21 & 0.021 & 0.018 & 0.004 \\
\hline
\end{tabular}


Table 40. Measured microstructural parameters and strength properties of the UIC-60 rails rolled from $900 \mathrm{~A}$ steel continuously cast ingots having the chemical compositions specified in table 39.

\begin{tabular}{cccccc}
\hline & \multicolumn{3}{c}{ Microstructural parameters } & \multicolumn{2}{c}{ Strength properties } \\
No. & $N_{d}, \mu \mathrm{m}$ & $D_{c}, \mu \mathrm{m}$ & $S_{0}, \mu \mathrm{m}$ & $\sigma_{y}, \mathrm{MPa}$ & $\sigma_{u}, \mathrm{MPa}$ \\
\hline 1 & 28 & 14 & 0.168 & 540 & 967 \\
2 & 36 & 19 & 0.220 & 480 & 915 \\
3 & 35 & 11 & 0.199 & 500 & 935 \\
\hline
\end{tabular}

Table 41. Calculated average values of the microstructural parameters and the strength properties in the UIC-60 rails (table 39 ) based upon the cooling curve measured in the laboratory experiment, which gave a cooling rate of $0.3^{\circ} \mathrm{C} / \mathrm{s}$ at the location corresponding to the place in the rail's head extracted for the mechanical-properties measurement.

\begin{tabular}{ccccc}
\hline \multicolumn{3}{c}{ Microstructural parameters } & \multicolumn{2}{c}{ Strength properties } \\
$N_{d}, \mu \mathrm{m}$ & $D_{c}, \mu \mathrm{m}$ & $S_{0}, \mu \mathrm{m}$ & $\sigma_{y}, \mathrm{MPa}$ & $\sigma_{u}, \mathrm{MPa}$ \\
\hline 37 & 13 & 0.194 & 510 & 945 \\
\hline
\end{tabular}

\section{Summary}

\subsection{Mathematical Modeling}

Conventional models were developed to calculate the microstructural evolution during thermomechanical processing of experimental $\mathrm{C}-\mathrm{Mn}, \mathrm{VT}$, and $900 \mathrm{~A}$ eutectoid steels. These models quantitatively relate strain, strain rate, and temperature to the parameters describing the state of the austenite microstructure. The parameters include the volume fractions of the dynamically, metadynamically, and statically recrystallized material; recrystallized austenite grain size; and austenite grain size after grain growth. To characterize microstructural evolution occurring in the C-Mn and VT steels, we used the general form of the relationships developed by Sellars [2] and Roberts et al. [7], which well-represented the experimental results. However, to improve the quantitative characterization of deformation parameters and austenite grain size during static recrystallization in the eutectoid steel, we used the model of Choquet et al. [10] for static recrystallization. The models of microstructural evolution during thermomechanical processing were validated by laboratory experiments and incorporated into the FEM codes for the industrial plate, rod, and shape (rail) rolling processes.

Phase transformations in the C-Mn and VT steels were treated in a purely empirical way: ferrite grain size and volume fraction, as well as the mean interlamellar spacing in pearlitic cementite, were quantitatively linked to the austenite grain size, cooling rate over the transformation temperature range, and chemical composition of the steels. This approach was substantiated by the experimental results. 
Finally, microstructure-mechanical properties relationships were developed for the experimental steels. For the ferrite-pearlite steels, we took an approach similar to that of Gladman et al. [1], except that we used the linear law of mixtures to characterize the contribution of the ferrite and pearlite phases to the yield strength. The effect of the mean true interlamellar spacing on the ultimate tensile strength was described by a term that expresses its significant contribution when the ferrite phase loses continuity in the microstructure. For the eutectoid steel, the yield and ultimate tensile strengths were correlated with the mean free path for slip in the ferrite. The best correlation was achieved when this parameter was raised to the -1 power instead of the -0.5 power used in the Hall-Petch relationship.

\subsection{Industrial Experiments}

\subsubsection{Plate Rolling}

1. The assumption of constant deformation parameters and temperature through the thickness direction during plate rolling leads to significant errors in the prediction of microstructural evolution because, during the last few passes, the temperatures of the surface and interior regions of the workpiece differ significantly.

2. A temperature gradient between the surface of the workpiece and its center develops during plate rolling owing to contact with the rolls.

3. The most important austenite-microstructure-restoration process during plate rolling is static recrystallization. Since at high rolling temperatures this process proceeds very rapidly, grain growth contributes substantially to the overall microstructural development.

4. The most effective methods of refining austenite grains during the rolling process are substantial lowering of the finish-rolling temperature or introducing microalloys to hinder austenite grain growth. Increasing deformations in subsequent passes at elevated temperatures does not influence the grain size after processing, since the more refined recrystallized grains have a greater propensity for growth.

5. The final austenite microstructure is shaped in the last four to six passes of multipass rolling; therefore, the starting grain size after reheating and before rolling has little effect on the final grain size.

\subsubsection{Rod Rolling}

1. An effect of strain accumulation leading to dynamic recrystallization initiation during the last few finish passes of the rod-rolling process was predicted by mathematical models.

2. Grain growth caused a significant increase in grain size despite substantial grain refinement that occurred during the last few finish passes. The effect was more pronounced in the eutectoid steel than in the C-Mn and VT steels.

3. A thermomechanical FEM calculation predicted a substantial increase in the rod's temperature during the last few finish passes. The effect was confirmed by measurements, and it can be associated with the plastic work.

4. An FEM calculation predicted that more extensive plastic flow would occur in the nearsurface area than in the central region of the rod during the last few passes. 


\subsubsection{Rail Rolling}

1. An FEM calculation revealed a marked difference in the deformation conditions prevailing in the cross section of the rail during the last few passes.

2. Static recrystallization restores the austenite microstructure during the last few passes of the rail-rolling process.

3. Grain growth of the recrystallized grains, which is very extensive in the eutectoid steel, determines the final size of the austenite grain in the rail. As a result, large grain sizes $(\sim 90 \mu \mathrm{m})$ are achieved in the rail's head prior to pearlite transformation.

4. Pronounced variations in thickness in the cross section of the rail produce very complicated temperature patterns on cooling. The patterns may change substantially during the pearlite transformation, which is connected to the effect of transformation heat.

5. The nonuniformity of deformation and temperature in the workpiece during rolling and subsequent cooling results in marked differences in microstructural refinement in the cross section of a rail.

\section{Acknowledgments}

The authors thank Teddy Bold (Institute of Ferrous Metallurgy, Gliwice, Poland) and Harry I. McHenry (National Institute of Standards and Technology, Boulder, Colorado) for their support and encouragement of this project and Janusz Majta (Academy of Mining and Metallurgy, Cracow, Poland) for his help in interpreting the results of the press-compression experiments for low-carbon steel. The research was supported by the United States-Poland Maria Sklodowska-Curie Joint Fund II.

\section{References}

[1] Gladman, T.; Mclvor, I.D.; Pickering, F.B. Some aspects of the structure-property relationships in high-carbon ferrite-pearlite steels. J. Iron Steel Inst. Dec.: 916-930; 1972.

[2] Sellars, C.M. The physical metallurgy of hot working. Sellars, C.M.; Davies, G.J., eds. Hot working and forming processes; 1979 July 17-20; University of Sheffield, U.K. The Metals Society, London; 1979. 3.

[3] Kwon, O.; Lee, K.J.; Lee, J.K.; Kang, K. B. Modeling of austenite evolution and transformation for MA strips. Korchynsky, M., ed. Proc. int. conf. Microalloying '95. 1995 June 11-14; Warrendale, PA. Pittsburgh, PA: Iron and Steel Society; 1995. 251-261.

[4] Pietrzyk, M. Comp-axi computer program for upsetting simulation of axisymmetrical specimens. Hutnik (Steelmaker) 60: 190-196; 1993.

[5] Laasraoui, A.; Jonas, J.J. Recrystallization of austenite after deformation at high temperature and strain rates-analysis and modeling. Metall. Trans. A 22A: 151-160; 1991.

[6] Beynon, J.H.; Sellars, C.M. Modelling microstructure and its effect during multipass hot rolling. ISIJ Int. 32: 359-367; 1992.

[7] Roberts, W.; Sandberg, A.; Siwecki, T.; Werlefors, T. Prediction of microstructure development during recrystallization hot rolling of Ti-V steels. Korchynsky, M., ed. Technology and applications of HSLA steels. Proc. ASM conf.; 1983; Philadelphia. Metals Park, OH: American Society for Metals; 1983. 67-84. 
[8] Medina, S.F.; Lopez, V. Static recrystallization in austenite and its influence on microstructural changes in C-Mn steel and vanadium microalloyed steel at the hot strip mill. ISIJ Int. 33: 605-614; 1993.

[9] Kuziak, R. Modeling of the microstructural evolution during reheating, thermomechanical processing and cooling after processing of eutectoid steels. IFM Internal Report No. PW-00018/BM/6. Gliwice, Poland: Institute for Ferrous Metallurgy; 1996. 72 pp.

[10] Choquet, P.; Le Bon, A.; Perdrix, C. Mathematical model for prediction of austenite and ferrite microstructures in hot rolling processes. McQueen, H.J. et al., eds. Proc. 7th int. conf. on strength of metals and alloys (ICSMA 7), vol. 2.; 12-16 August 1985; Montreal, Canada. New York: Pergamon; 1985. 1025-1030.

[11] Kuziak, R.; Cheng, Y-W. Microstructural evolution in microalloyed medium-carbon forging steels during thermomechanical processing. DeArdo, A.J., ed. Proc. int. conf. on processing, microstructure and properties of microalloyed and other modern high strength low alloy steels, 1991 June 3-6. Pittsburgh, PA. Warrendale, PA: Iron and Steel Society; 1992. 51-64.

[12] Hodgson. P.D. Mathematical modelling of recrystallization process during the hot rolling of steel. Ph.D. thesis, University of Queensland, Brisbane, Australia; 1993. 192 pp.

[13] Sakai, T. Dynamic recrystallization microstructures under hot working conditions. J. Mater. Proc. Technol. 53: 340-361; 1995.

[14] Pietrzyk, M.; Kuziak, R. Application of the internal variable approach to the simulation of microstructural phenomena in hot forming of eutectoid steel. European conf. on advanced materials and processes 1995, Symposium F. Proc. 4th European conf. on advanced materials and processes (EUROMAT '95); 1995 September 25-28; Padua, Italy; Associazione Italiana di Metallugia; 1995. 239-244.

[15] Bodnar, R.L.; Hansen, S.S. Effects of austenite grain size and cooling rate on Widmanstätten ferrite formation in low-alloy steels. Metall. Mater. Trans. A, 25A: 665-675; 1994.

[16] Sawada, Y.; Foley, R.P.; Thompson, S.W.; Krauss, G. Microstructure-property relationships in plain-carbon and $\mathrm{V}$ and $\mathrm{V}+\mathrm{Nb}$ microalloyed medium carbon steels. Proc. 35th mechanical working and steel processing conf., vol. XXXI; 1993; Hamilton, Ontario, Canada. Warrendale, PA: Iron and Steel Society; 1994. 263-286.

[17] Burnet, M.E. Correlation of forging parameters to microstructure and mechanical properties in vanadium modified 0.4 percent carbon steels. Krauss, G.; Banerji, S.K., eds. Proc. int. symp. on fundamentals of microalloying forging steels. 1986 July 8-10; Golden, CO. Warrendale, PA: The Metallurgical Society; 1986. 601-625.

[18] Campbell, P.C.; Hawbolt, E.B.; Brimacombe, J.K. Microstructural engineering applied to the controlled cooling of steel wire rods: Part III. Mathematical model formulation and predictions, Metall. Trans. A, 22A: 2791-2805; 1991,

[19] Umemoto, M.; Komatsubara, N.; Tamura, I. Prediction of hardenability effects from isothermal transformation kinetics. J. Heat Treat. 1:57-64; 1980.

[20] Pham, T.T.; Hawbolt, E.B.; Brimacombe, J.K. Predicting the onset of transformation under noncontinuous cooling conditions: Part I. Theory. Metall. Mater. Trans. A 26A: 1987-1992; 1995.

[21] Hodgson, P.D.; Gibbs, R.K. Mathematical model to predict the final properties of hot rolled C-Mn and microallyed steels. Yue, S., ed. Proc. int. symp. on mathematical modelling of hot rolling steel; 1990 August 26-29; Hamilton, Ontario, Canada. Available from Iron and Steel Society, Warrendale, PA; 1990. 76-85.

[22] Dollar, M.; Bernstein, I.M.; Thompson, A.W. Influence of deformation substructure on flow and fracture of fully pearlitic steel. Acta Metall. 36: 311-320; 1988. 
[23] Glowacki, M.; Kuziak, R.; Malinowski, Z.; Pietrzyk, M. Modelling of heat transfer, plastic flow and microstructural evolution during shape rolling. J. Mater. Proc. Technol. 53:159-166; 1995.

[24] Kusiak, J.; Kawalla, R.; Pietrzyk, M.; Pircher, H. Inverse analysis applied to the evaluation of material parameters in the history dependent flow stress equation in hot forming metals. J. Mater. Proc. Technol. 60: 455-461; 1996.

[25] Pietrzyk, M.; Lenard, J.G. Thermal-mechanical modelling of the flat rolling process. Heidelberg, Germany: Springer-Verlag; 1991.

[26] Pandi, R.; Yue, S. Dynamic transformation of austenite to ferrite in low carbon steel. ISIJ Int. 34: 270-279; 1994.

[27] Majta, J.; Lenard, J.G.; Pietrzyk, M. On modeling the development of the microstructure and mechanical properties of microalloyed steels. Metall. Foundry Eng. 21: 9-38. 1995.

[28] Majta, J.; Kuziak, R.; Pietrzyk, M.; Krzton, H. Use of computer simulation to predict mechanical properties of C-Mn steel after thermomechanical processing. J. Mater. Proc. Technol. 60: 581-588; 1996.

[29] Majta, J.; Pietrzyk, M.; Lenard, J.G.; Janzen, J. Prediction of mechanical properties of steel strips after hot rolling. Proc. 37th mechanical working and steel processing conf.; 1995; Hamilton, Ontario, Canada. Pittsburgh, PA: Iron and Steel Society; 1996. 89-100.

[30] Yue, S.; Roucoules, C.; Maccango, T.M.; Jonas, J.J. Dynamic recrystallization in rod rolling. Korchynsky, M., ed. Proc. int. conf. on microalloying '95. 1995 June 11-14; Pittsburgh, PA, USA. Warrendale, PA: Iron and Steel Society; 1995. 335-364.

[31] Petkovic, R.A.; Luton, M.J.; Jonas, J.J. Recovery and recrystallization of carbon steel between intervals of hot working. Can. Metall. Q. 14(2): 137-145; 1975.

[32] Kuziak, R.; Glowacki, M.; Pietrzyk, M. Modelling of plastic flow, heat transfer and microstructural evolution during rolling of eutectoid steel rods. J. Mater. Proc. Technol. 60: 589-596; 1996. 


\section{Periodical}

Journal of Research of the National Institute of Standards and Technology-Reports NIST research and development in those disciplines of the physical and engineering sciences in which the Institute is active. These include physics, chemistry, engineering, mathematics, and computer sciences. Papers cover a broad range of subjects, with major emphasis on measurement methodology and the basic technology underlying standardization. Also included from time to time are survey articles on topics closely related to the Institute's technical and scientific programs. Issued six times a year.

\section{Nonperiodicals}

Monographs-Major contributions to the technical literature on various subjects related to the Institute's scientific and technical activities.

Handbooks-Recommended codes of engineering and industrial practice (including safety codes) developed in cooperation with interested industries, professional organizations, and regulatory bodies.

Special Publications-Include proceedings of conferences sponsored by NIST, NIST annual reports, and other special publications appropriate to this grouping such as wall charts, pocket cards, and bibliographies.

Applied Mathematics Series-Mathematical tables, manuals, and studies of special interest to physicists, engineers, chemists, biologists, mathematicians, computer programmers, and others engaged in scientific and technical work.

National Standard Reference Data Series-Provides quantitative data on the physical and chemical properties of materials, compiled from the world's literature and critically evaluated. Developed under a worldwide program coordinated by NIST under the authority of the National Standard Data Act (Public Law 90-396). NOTE: The Journal of Physical and Chemical Reference Data (JPCRD) is published bimonthly for NIST by the American Chemical Society (ACS) and the American Institute of Physics (AIP). Subscriptions, reprints, and supplements are available from ACS, 1155 Sixteenth St., NW, Washington, DC 20056.

Building Science Series-Disseminates technical information developed at the Institute on building materials, components, systems, and whole structures. The series presents research results, test methods, and performance criteria related to the structural and environmental functions and the durability and safety characteristics of building elements and systems.

Technical Notes-Studies or reports which are complete in themselves but restrictive in their treatment of a subject. Analogous to monographs but not so comprehensive in scope or definitive in treatment of the subject area. Often serve as a vehicle for final reports of work performed at NIST under the sponsorship of other government agencies.

Voluntary Product Standards-Developed under procedures published by the Department of Commerce in Part 10, Title 15, of the Code of Federal Regulations. The standards establish nationally recognized requirements for products, and provide all concerned interests with a basis for common understanding of the characteristics of the products. NIST administers this program in support of the efforts of privatesector standardizing organizations.

Consumer Information Series-Practical information, based on NIST research and experience, covering areas of interest to the consumer. Easily understandable language and illustrations provide useful background knowledge for shopping in today's technological marketplace.

Order the above NIST publications from: Superintendent of Documents, Government Printing Office, Washington, DC 20402.

Order the following NIST publications-FIPS and NISTIRs-from the National Technical Information Service, Springfield, VA 22161.

Federal Information Processing Standards Publications (FIPS PUB)-Publications in this series collectively constitute the Federal Information Processing Standards Register. The Register serves as the official source of information in the Federal Government regarding standards issued by NIST pursuant to the Federal Property and Administrative Services Act of 1949 as amended, Public Law 89-306 (79 Stat. 1127), and as implemented by Executive Order 11717 (38 FR 12315, dated May 11, 1973) and Part 6 of Title 15 CFR (Code of Federal Regulations).

NIST Interagency Reports (NISTIR)-A special series of interim or final reports on work performed by NIST for outside sponsors (both government and non-government). In general, initial distribution is handled by the sponsor; public distribution is by the National Technical Information Service, Springfield, VA 22161, in paper copy or microfiche form. 
U.S. Department of Commerce

National Institute of Standards and Technology

325 Broadway

Boulder, Colorado 80303-3328

Official Business

Penalty for Private Use, $\$ 300$ 